\title{
A Novel Apprehension of the Primary Lung Meridian, Sinew Channel, Divergent Channel, Luo-Connecting Channel Acting as a Single Unit System to Serve Respiration Function Based on Modern Neurophysiology and Kinesiology
}

\author{
Peter Chin Wan Fung1*, Regina Kit Chee Kong2 \\ ${ }^{1}$ Division of Medical Physics, Department of Medicine, University of Hong Kong, Hong Kong, China \\ ${ }^{2}$ School of Chinese Medicine, Southern Medical University, Guangzhou, China \\ Email: *peterallegro333@gmail.com
}

How to cite this paper: Fung, P.C.W. and Kong, R.K.C. (2020) A Novel Apprehension of the Primary Lung Meridian, Sinew Channel, Divergent Channel, Luo-Connecting Channel Acting as a Single Unit System to Serve Respiration Function Based on Modern Neurophysiology and Kinesiology. Chinese Medicine, 11, 31-95.

https://doi.org/10.4236/cm.2020.112004

Received: April 24, 2020

Accepted: June 5, 2020

Published: June 8, 2020

Copyright $\odot 2020$ by author(s) and Scientific Research Publishing Inc. This work is licensed under the Creative Commons Attribution-NonCommercial International License (CC BY-NC 4.0). http://creativecommons.org/licenses/by-nc/4.0/

\begin{abstract}
The TCM philosophy of a meridian and associated channels pertains to the specific function of one or more organs. We define the Lung Primary Meridian (LUM) together with the Lung Sinew (LUSC), Divergent (LUDC), Luo-connecting (LULCC) Channels as a system of routes plus some parts of the body (such as muscles) to fulfil respiration, as a main function under different situations. There is very limited information about the Lung associated channels in classical literature of TCM. With a clear focus on the function of respiration, we have carried out a detailed analysis of the biomedical consequence of stimulating the LUM, analysed the roles played by LUSC, LUDC, and LULCC. The updated LUM and LUDC include acupoints of other meridians, serving the same purpose of performing satisfactory respiration starting from checking the quality of the inflow through the nose. The LUSC includes the respiratory muscles (plus the associated connective tissues) extending to various parts of the body. The muscles of the limb (as part of the LUSC) embrace the nerves that provide routes for somatosensory reflexes and play the role of locomotion, providing voluntary respiration via the pectoralis muscles. The muscles of LUSC are bounded by stiff connective tissue layers, forming compartments, and are part of the pulley system for various body locomotions. Within a compartment, the interstitial fluid, blood, lymph flows must be potent to protect the associated nerves related to LUM; the healthy state of the LUSC also provides freedom of various types of locomotion. The LULCC exists because the vagus nerve has a part of it passing through the spinal cords all the way down to the sacrum domain, with exiting nerve in-
\end{abstract}


nervating two-third of the large intestine. The crucial steps of our deductions are supported by experimental evidence based on modern neurophysiology and kinesiology. We discover that all the four channels stated above work as a unit system to allow respiration to be possible under various postures/conditions. The complexity of structures and processes is eased off by providing 29 figures and 13 tables for the relevant muscles and nerves. In addition to respiration, the Lung system in TCM context includes interaction of this system with the sweat gland and neuroendocrine system; such aspects will be left to another study.

\section{Keywords}

Lung Meridian, Sinew, Divergent, Luo-Connecting Channels, Mechanical Advantage of Muscles, Sympathetic Nerves, Parasympathetic Nerves, Muscles of the Tongue, Pharynx, Larynx, Intercostal Muscles, Inspiration and Expiration Muscles, Swallowing, Somatosensory and Segmental Reflexes, Acupoints of the Lung, Urinary Bladder, Kidney, Governing (DU), Conception (REN) Meridians, Pulmonary Diseases, Lung $\rightarrow$ Large-Intestine Connection, Acupuncture, Bian Stone Therapy

\section{Introduction}

\subsection{Mechanotransduction through the Largest Organ of the Body as the First Bridge to Join Non-Herbal TCM and Western Medicine}

One of the most important issues in bridging western and the non-herbal part of TCM is the realization of the importance of mechanotransduction in almost all physiological processes-mechanical/electrical force is the key initiator of numerous biochemical reactions taking place in physiological process of living organisms [1]. A general communication network of the body must have been developed to cater for the specification of anatomical parts of the body since the start of development. Connective tissues, which are non-cellular structures, are built from the mesoderm. In TCM terminology, we can say that the living organism starts to build such a network with some pathways which are the best ways for the transportation of energy signals - the main pathways can be called Meridians. However, there must be cells to synthesize the connective tissues for homeostasis and repair. The most abundant cells are the fibroblasts. Mast cells are known to upkeep fibroblasts. These two types of cells become the two main residence cells in the communication network [2]. Instead of waiting for stem cells to migrate from the bone marrow when wound repair and growth are needed, an efficient way in nature is to have stem cells around the body. The connective tissues form a complicated network with different mechanical tensions in different parts of the body. The connective tissues contain proteins such as fibronectin which can be activated by fibroblasts to stretch out, increasing the density of the tissues for cell migration. When a fibroblast migrates to connec- 
tive tissues with greater tension, the phenotyping is changed accordingly. The cell becomes a chondrocyte when it migrates near the knee; it has the phenotyping of osteoblasts and then osteocytes (bone cell) when it migrates to the periosteum [3]. Many nutrients, biochemicals are water soluble, and some are lipids which must be enclosed by spherical lipid structures (called chylomicrons) to be transported. Water is therefore a natural medium for transportation in the stated communication network. Even during embryonic development, the shear fluidic force directs growth and the order of development [4]. Due to different requirement of internal organs, and the need to discard debris of metabolism, the water-nature medium is separated into five circulating and connected system (blood, interstitial fluid or IF, lymphatic fluid in the extra-cranial part, glymphatic fluid inside the brain, and the primo fluid which exist in tiny vessels still under research) in a rather intriguing manner, as described in details in reference [5]. In passing, we note that, it was the discovery that some fluid, considered to be IF, was found by radioactive labelling to follow some Meridians some decades ago [6] [7] [8] [9]. It was found experimentally that the calcium content near Meridians, and even more so near acupoints are particularly high compared to non-Meridian domains [10]. The nervous system supports and helps the development of blood vessels that carry the necessary nutrients, oxygen, proteins, reaching all organs via the interstitial fluid and the processes are governed by laws such as diffusion, fluid pressure gradient. The immunity cells migrate from the blood vessels, through the interstitial fluid to the tissue sites in need to carry their duties. It has become a rather known experiment that when acupuncture is applied to the acupoint (Hegu LI-4), thermography examination shows a clear relatively high temperature pathway along the Large Intestine Meridian [11], highly suggestive of vessel dilation as a result of simple rotation of the needle or application of electro-acupuncture at that acupoint. Using the rat model, there is clear evidence of aggregation of sympathetic neurotransmitters near the nerve endings, forming lines/tracts, indicating that paths pertaining to more efficient transmission of the sympathetic message on the skin do exist [12] [13].

Through a series of analyses [2] [3] [5], it is not difficult to understand that the Meridians are pathways that cannot be found in surgery, but are tracts for efficient communication of energy signals and the migration of cells to carry out physiological functions and to help wound repair if necessary. With the presence of residence cells and some immunity cells in transit, this network forms an active organ-the largest organ of the body, the fascia [14]. This concept certainly helps in building a bridge between non-herbal TCM and Western Medicine.

\subsection{Studying the Consequences of Stimulating the Lung and Other Meridians via Neurophysiological Responses}

Based on the experience in over 1600 years, the sensation of soreness, numbness, swelling, ache must be felt in order to acquire efficacy when acupuncture is applied to an acupoint for treating practically any disorder, and the fact that the meridian routes are found to be located near nerves [15], we started to look into 
the sphere of neurophysiology, for explaining the mechanism and hence the efficacy of stimulating meridians via TCM modalities.

Recent advancement in scientific technology allows microscopic examination of the environments of acupoints. We start with the findings that acupoints are near nerves fibers, blood vessels (with lymphatic vessels automatically), always amidst one kind of connective tissues or another, and between muscle stripes [3]. We emphasize on the participation of the nervous system during acupuncture, moxibustion, Bian stone therapy treatments. It is established in neurophysiology that stimulating the peripheral nerves would affect the function of internal organs. For example, scratching the ventral domains of the rat model has been shown to weaken motility of the gastric movement, whereas stimulating even slightly sites of the dorsal part would enhance such motility [16].

The action of acupuncture is therefore similar but more specific, due to the special arrangement of the anatomical structure and settings of the routes of the meridians (see sections (2.1)-(2.17) of [15] for details).

In the previous work of [17], we have provided the necessary background materials of neurophysiology, plus somatosensory reflex in the brain cortex, and have explained the mechanism via which stimulation of acupoints of the Lung Meridian would lead to activating a branch of T1 nerve having axons projecting to the root of the lungs; we have also explained how the reflex efferent from the cortex would mobilize thoracic nerves, leading to the activation of the intercostal muscles in general [17]. In the same paper, we have also outlined how the lung and large intestine are connected through the branch of vagus nerve that passes through the spinal cord from the brain stem to the sacrum [17]. The parasympathetic vagus nerve exits from S2-S4 of the sacrum region, innervating two/third of the colon. Such a lung $\rightarrow$ large-intestine connection can be understood intuitively: when we need to take a fight/flight action, we must increase our breathing rate, but at the same time, the body must have a system to call for a stop of the digestive and secretion system.

We have just published a paper [18] that explains the following details: (i) The mechanisms involved in spinal (segmental) reflex and again on cortical reflex based on electroencephalography (EEG) as well as magnetic resonance imaging examination on subjects; the main idea was to pin-point the location of the topographic representation of the hand and arm domain at the cortex. (ii) Review of the existence of the phrenic nucleus, which is a group of interneurons forming a tube-like structure through the spinal cords whose nerve roots form the phrenic nerve. (iii) Introduction of the recent discovery of the scalene nucleus [19] (another group of interneurons forming a tube-like structure in the medial ventral horns of $\mathrm{C} 3-\mathrm{C} 7$ in the rat); this nucleus regulates the activity of the scalene muscles in the developing rat. (iv) Review of the important phenomenon that neurons of the phrenic and scalene nuclei demonstrated coherent electrical firing activity, implying that the scalene muscles are intrinsic muscles in action during breathing at rest. (v) Review on the existence of the locomotion-respiration coupling system, with the lower limbs playing a crucial role. (vi) 
The effect of sensory input from the phrenic nerve to the C3-C5 dorsal horns in humans, as one indirect supportive evidence that stimulating the Lung Meridian (via TCM modalities) conveys regulating inputs to the dorsal horns of C3-C5. (vii) The neurophysiological reasons for the founded efficacies in applying 11 sets of acupoints of different Meridians to treat chronic obstructive pulmonary disease (COPD) patients under strict statistical arrangement and randomized control with hidden identities of patients, examination centers, and curator. (viii) We also emphasized the overlapping of two sets of efferent tracts-one from somatosensory reflex, and the other from the intrinsic "pace-maker" of the respiration centers at the brain stem, giving an indirect supportive reason for acupuncture applied at the arm acupoints could enhance the intrinsic inspiration in a similar way.

\subsection{Partial Explanation of the Functions of the Lung Sinew Channel in Our Previous Work}

Based on the analysis of the recent efficacy of surgical methods used in Western Medicine to treat exertion compartment syndrome, we have proposed that the twelve (hand and foot) Meridians are surrounded by groups of muscles separated by harder connective tissue layers. The muscle units are joined to the associated bones by tendons, and the bones are connected by ligaments, so that the bone-tendon-ligament-muscle system can form a pulley system [15]. Since such a pulley system is enclosed by stiff connective tissue layers, the interstitial fluid is required by nature to be flowing at the right speed at different regions of the body, so that metabolic debris can be drained by the lymphatic vessels (for details see [5]). If the muscle cells are over-strained, leading to edema, or that the collecting ducts of the lymphatic vessels are unable to drain the metabolic and other types of debris (such as that resulting from cell damage during inflammation) in time, the muscles in the pulley system, or the Sinew Channel is in a poisonous state in TCM language. In Western Medicine, the "T2 signals" of MRI examination will reflect such a state and immediate surgical operation to release the fluid is needed for survival. There is a clear objective connection between non-herbal TCM and modern Western Medicine, on the pathology as explained in [5] [15]. The Sinew Channel in general has been known in TCM to embrace the Meridian of the same name; whereas the Meridian cannot be found in surgery operation, the Siew Channel is well defined in anatomy. We have explained partly the function of the Sinew Channel in general locomotion only, without specification to the associated Meridian in the analysis of [15].

We proposed that groups of such pulley systems form various Sinew Channels. Note that a Sinew Channel "encloses", in surface topological representation, the Meridian bearing the same.

\subsection{The Necessity of Paying a Revisit to the Functions of the Lung Meridian (LUM), Lung Sinew Channel (LUSC), Lung Divergent Channel (LUDC) and Lung Luo-Connecting Channel (LULCC)}

The philosophy of TCM is based on the functions of the body. For example, the 
Kidney Meridian is related not only to the function of kidneys, it is also related to the genital function. There are acupoints related to genital function in the Kidney Meridian. Taking the LUM as the second example, after a series of studies, we understand that stimulating the acupoints of the hand-arm region could lead to enforcement of respiration. However, the entry of air starts from the nose. The first safeguard of respiration is to detect any harmful entities during the nasal entry. There are no acupoints of LUM in the nasal region, and the LUM starts at a site not even reaching the neck, that carries many important nerves (part of the brachial plexus) and muscles (such as the scalene muscles, the sternocleidomastoid muscle) for respiration processes under different conditions. In the application of acupuncture/acupressure or moxibustion, acupoints such as Feishu (BL-13), Geshu (BL-17), Shenzhu (DU-12), Yingxiang (LI-20), and other acupoints rather than that of the LUM are used with efficacy in the past centuries.

The Sinew Channel in classical TCM, covers roughly down to the diaphragm. For forced expiration, which is important for survival (such as coughing out the harmful materials from the lungs), many muscles at the back and muscles anchored to the pelvic are in action. Also, the LULCC is vaguely noted to connect the large intestine. Around 2000 years ago, the discovery of the Meridians, Sinew Channel, the Divergent Channels, the Luo-connecting Channel was a tremendous achievement based on the scarcity of scientific technique available at that time. Medicine is a living science, and we must let TCM develop, incorporating new experimental results and concepts based on modern knowledge. There is a necessity to revisit the acupoints and muscles that are directly related to the main function (respiration) of the Lung system in this paper. We will analyse, based on modern neurophysiology and kinesiology, the nerves and muscles that are involved in rest respiration and forced respiration, and list the updated crucial members of the Lung Sinew Channel in the 13 tables in the Appendix, with brief particulars on the origin, insertion, nerve innervation and respiratory function, for convenience of the readers. To reduce the technicality in anatomical structure and neurophysiological processes, we provide 29 schematic figures to explain the functions and locations of the crucial members of LUSC, together with our written analysis. Every crucial step of deduction is provided with evidenced-based laboratory experiments (at least animal models) and clinical studies of COPD or other respiratory disorders of patients. We come up with a novel extension of our ancestors' wisdom, with an updated LUM, LUSC, LUDC and LULCC, focussing on the function of breathing and its disorders. In our presentation, we follow up analysis of the respiratory system from the nasal region down under different sections. After a detailed analysis, we show for the first time, that the LUM, LUSC, LUDC and LULCC form a single unit system to regulate the respiration function, with intrinsic governing centers at the brain stem. After this detailed investigation, we can understand the reasons for choosing many acupoints of various Meridians by acupuncturists to treat respiratory 
disorders. Since there are numerous sources of references for the many respiratory muscles, and such information can be found in physiology texts, we will not take the extensive space to cite the references for the muscles in the 13 tables of the Appendix. If there is any special property to be emphasized, we will cite the reference in the main text.

\section{Respiration in the Wake State Is an Integration of Voluntary and Involuntary Action, Rhythmic and Non-Rhythmic Drives, Respiratory and Non-Respiratory Inputs}

The respiratory centers at the brain stem generate cyclic signals leading to ventilation to excrete carbon dioxide and absorb oxygen for metabolic needs. The imbalance of the concentrations of these two gases leads to pathological states. Hypercapnia is defined as an increase in $\mathrm{CO}_{2}$ in the arterial blood, partial carbon dioxide pressure $\mathrm{PaCO}_{2}$, compared to the value under the physiological condition. Thus, exercise, acidosis, fever automatically increase ventilation, i.e., the respiration rate. In contrast, hypocapnia $\left(\right.$ low $\mathrm{PaCO}_{2}$ ) depresses the activity of pre-Bötzinger and Bötzinger neurons in the breathing centers (see Figure 14 of [17] and more recent development of cardiac-respiratory connection system in [20]) leading to apnea-because there is no need to respire if there is no $\mathrm{CO}_{2}$ to expel. During sleep, a decrease of $\mathrm{PaCO}_{2}$ by only a few $\mathrm{mmHg}$ would already induce apneas and the usage of a mechanical ventilator is now known to effectively reduce the number of apneas during sleep (for some details see [21] for most patients). During the wake state, humans have strong resistance to hypocapnia, even though from metabolism consideration. Such an ability is important for humans, since speech, a daily life activity, induces hypocapnia [22] and humans must have a mechanism to overcome naturally such hypocapnia during the wake state. There are non-rhythmic drives during speech, singing and swallowing. Medical scientists have searched for this mechanism from the higher brain (particularly the cortex) [22] [23] for a couple of decades till recent days, noting first breathing commands can be triggered in the primary motor cortex (which has been established decades ago, and can be found in text books), premotor cortex [24], and the supplementary cortex [25].

In [26], 10 subjects participated in the study. Ventilatory flow was recorded by a mouthpiece with occlusion of the nose by a pneumotachograph. The expired gas was collected at the mouth and the expired fraction of $\mathrm{CO}_{2}$ was determined. The electroencephalographic (EEG) signal was recorded during flow measurement in real time. Correlation of the EEG pattern and the $\mathrm{CO}_{2}$ pressure pattern was then obtained. Based on such analysis, it was suggested that human hypocapnia breathing is driven in part, at least, by cortical mechanisms similar to that involved in voluntary breathing, against weakened inspiratory muscles (diaphragm, scalene muscles etc) or mechanical constraints (such as obstruction of the airway entrance due to obesity/aging). We consider that the cortical areas corre- 
lated to breathing activity were around the motor, premotor cortex (based on their data), but the degree of accuracy cannot be ascertained because of the small number of electrodes (near the vertex) being employed in the EEG measurement, and the signals having to pass through different thickness (of bony, and collagen structures) and arrival of signals from different directions (because there could be more than one source of generation) between the cortex and the scalp. For the same reason, we could not accurately pin down the topographical mapping of the body representing these electrode sites. However, this result [26] is relevant because humans were the participants. In another study with subjects [27], magnetic stimulation was used. The authors presented data from analysis of the process of hypocapnia in real time, indicating that the corticospinal pathway to the diaphragm can be modulated in both directions by conditioning the supplementary motor cortex. In other words, the "two-direction" result indicates that signals from the diaphragm are sent to the supplementary cortex, which in turn sends back efferent signals to modify the diaphragm function. This aspect has just been mentioned in [18], giving hints that TCM modalities might also play the role of the sensory input from the diaphragm (in the wake state), if stimulating an acupoint can send signal to the somatosensory cortex; via a reflex action the function of the diaphragm can be regulated.

Non respiratory inputs refer to influence from emotion, an experience felt almost practically by anyone [28].

From the viewpoint of Traditional Chinese Medicine, based on the discussion in Sections (12) and (13) of [18], we are looking for a similar cortical support of breathing in the sleep state, in order to treat COPD. What signals would trigger off the cortical commands to breath at the premotor and supplementary motor regions during the sleep state remains one main aim of future studies, such as application of acupressure/acupuncture during the sleep state while brain activity is monitored by electroencephalography (EEG) using dipole source analysis to locate the source of activity [29].

\section{Acupoints and Nerves Innervating the Nasal Region}

\subsection{Begin the Inhalation Process-Three Nerves Affect the Inflow Rate Based on Three Different Physiological Processes-Propose the Extraordinary Acupoint Bitong (M-HN-14) plus Yingxiang (LI-20) Could Be Included as the Appoints of the Lung Meridian in the Nasal Region Based on Neurophysiological Analysis-Bian Stone Maneuver on These Sites Can Improve the Fluency of Inflow Air}

As shown in Figure 1, three cranial nerves innervate the nasal region. CN 1 originates from the entorhinal cortex, passing through amygdala, temporal lobe and other regions to form the olfactory bud which is next to the ethmoid bone. The olfactory nerves and the bud form a comb-like structure; the nerves pass through numerous foramina of the ethmoid bone and enter the superior part of the nasal cavity, and their endings are encapsulated with receptors capable of 


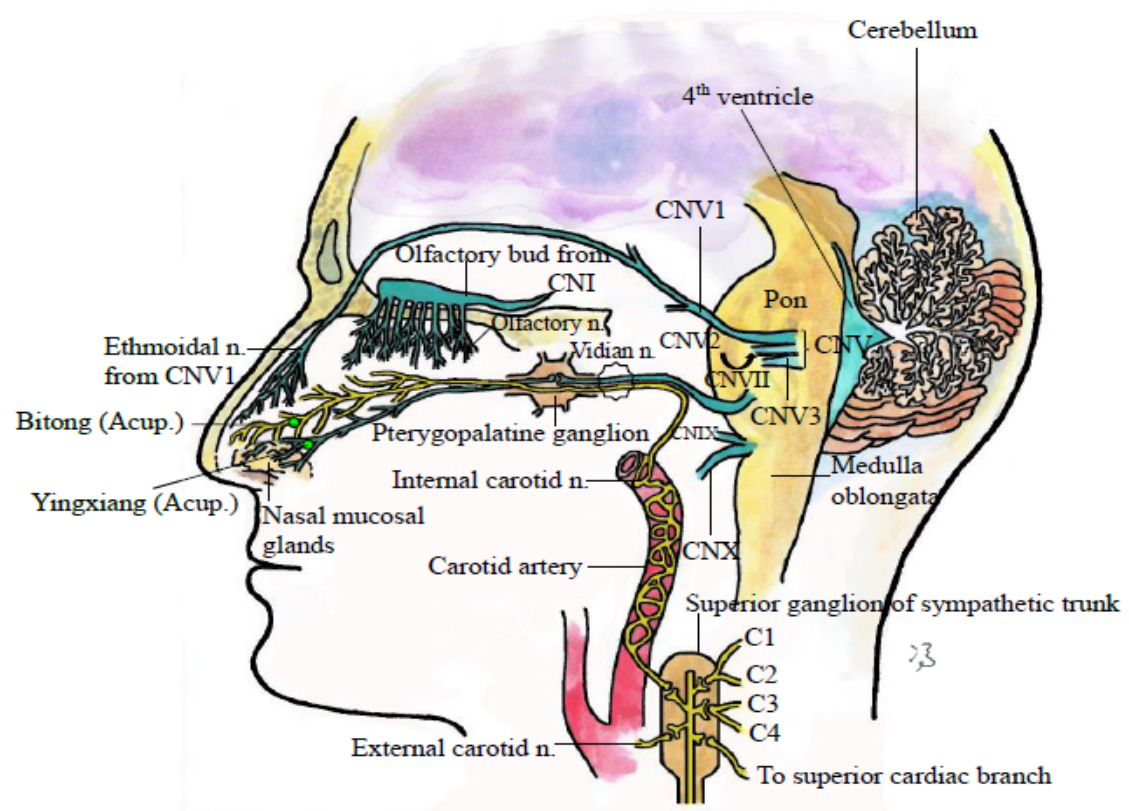

Figure 1. Two parasympathetic cranial nerves ( $\mathrm{CN}$ V/trigeminal nerve and CN VII/facial nerve) participate in homeostasis of the mucosal secretion of the nose cavity and toning the blood vessels dilation of the nose. The CN V nerve system has three branches; CN V1, after passing through the ethmoid foramina, becomes the anterior ethmoidal nerve to enter the upper part of the nose cavity. CN VII emerges from the inferior part of the pons. Neuron from the superior salivary nucleus synapses the second neuron in the geniculate ganglion; this neuron becomes the vidian nerve and synapses the third order neuron in the pterygopalatine ganglion. This third order neuron innervates the mucosal glands in the nose. The axons of neurons of the sympathetic truck synapse four spinal nerves (C1-4, yellow) plus the superior cardiac branch (yellow). The axon of a "relay neuron" exits from the superior cervical ganglion enters the internal domain of the internal carotid artery as the internal carotid nerve; this nerve is the main sympathetic nasal nerve to tone nasal glands. The sites of acupoints Bitong and Yingxiang are marked by small green circles. Yingxiang is at the wing of the nose and is also in the midst of the two nerves just mentioned. This figure was hand-painted by author PCWF.

detecting smell. These receptors are the first line "guards" in respiration, warning the brain if irritant molecules in the inhaled air are being detected. The warning signals are fed back to the dorsal respiratory group of the respiratory centers in the brain stem (see Section 5.6 and Fig.14 of [17]). The cranial nerve V (trigeminal nerve) is originated from the middle part of the pons (Figure 1). The $\mathrm{CN} V$ system innervates the facial region with three branches- $\mathrm{CN} V 1, \mathrm{CN} V 2$, CN V3 [30]. The branch CN V1 is a sensory nerve, passing through the ethmoid bone from the brain as the ethmoidal nerve which innervates the mid-part of the nasal cavity. This nerve feeds back the sense detected to the respiratory centers (Figure 14 of [17]), to modulate the amount of air inhaled. The CN V2 branch (maxillary branch) is a motor nerve; it passes through the bony infra-orbital canal and enters the facial region as the infraorbital nerve, several centimeters below the eye-ball (not shown in Figure 1). A part of the infraorbital nerve also innervates the nasal wings, for controlling part of the nasal muscles in motion. 
The first order neuron of CN VII (facial nerve, blue) emerges from the inferior part of the pons. It synapses another CN VII neuron in the pterygopalatine ganglion (light orange), and the second order parasympathetic neuron innervates the nasal mucosal glands to cause secretion [30]. The above nerves are all parasympathetic. On the other hand, an internal organ is in general innervated also by the sympathetic nerves. Sensory neurons of the brachial plexus enter the dorsal horns of the spinal cords as shown in Figure 9 of [17]. Each sensory nerve synapses an interneuron in the "butterfly" shaped grey matter; the interneuron synapses a (sympathetic motor) neuron at the tip boundary of the ventral horn; this sympathetic nerve exits to join the sympathetic trunk at a specific ganglion. There are only three sympathetic ganglia (superior, middle, inferior/stellate) corresponding to the 8 cervical spinal nerves $(\mathrm{C} 1-\mathrm{C} 8)$ and one thoracic nerve (T1) - relevant to the 6 Hand Meridians. The axons of the C1-C4 nerves (yellow) all terminate at the superior ganglion (orange) and synapse the cell bodies/dendrites inside the sympathetic trunk, which has many branches of axons, as schematically shown in Figure 1. One such axon exits from the superior ganglion and enters the internal wall of the carotid artery, as the internal carotid nerve. The internal carotid nerve forms a network-like structure in the internal connective tissue layer of the carotid artery. This nerve is the main sympathetic nasal nerve to tone nasal glands. The internal carotid nerve joins the CN VII nerve stated as a "mixed" nerve fiber called the vidian nerve fiber, which enters the pterygopalatine ganglion. The sympathetic nerve, without synapsing, innervates also the nasal mucosal glands, as a regulation of mucosal secretion. About half of the obstruction of air flow occurs in the nose, and it is thus important, to know the condition under which more air would pass through the nose [31]. In short, the sympathetic nerves constrict blood vessels, and when the blood vessels in the nasal cavity are constricted, the nasal passage for air flow becomes wider. Decades ago, that simulation of the contralateral cervical sympathetic nerves which would affect the size of the nose cavity in the cat model was established [32]. From the neurophysiological point of view, we can understand that stimulating the Lung Meridian would send signals to a range of the spinal nerves, and some signals would activate the internal carotid nerve and hence widen the nasal air passage, reducing inhale resistance. Of course, a certain amount of mucosal secretion at the nasal glands is needed to moist the internal epithelial wall of the nasal cavity [31]. The "extraordinary" acupoint Bitong (M-HN-14) and acupoint of the Large Intestine Yingxiang (LI-20) (as painted in green, Figure 1) have long been used in TCM to increase fluent air flow. We would remark that acupuncture applied at LI-20 has been reported to be effective in treating allergy rhinitis [33] [34] [35] and bronchial inflammation [36]. Bitong is an "extra-ordinary point" and has not been used often in academic studies-normally the traditional acupoints have been chosen in research papers. However, it is the personal experience for some years of the authors that applying acupressure on Bitong with warm Bian stone $\left(39.5^{\circ} \mathrm{C}\right)$ relieves nasal congestion. The sites of 
these acupoints are at the proximity of the ethmoidal nerve and close to the destination of the vidian nerve. We consider that these two points may be labelled as LUSP-1 and LUSP-2 (meaning lung special acupoint 1 and 2) respectively of the Lung Meridian.

The muscles of the Sinew Channel in this region are Nasalis, Levator labii superioris alaeque nasi, Procerus, Orbicularis oris, Depressor septi nasi, and depressor anguli oris; they are listed with information of their origin, insertion, innervating nerve, and basic function with respect to respiration only in Table A1 of the Appendix.

\subsection{Bian Stone Maneuver to Treat Nasal Congestion}

Based on the analysis of the last section, and our experience in treating over 100 subjects in the past few years, we briefly describe the Bian stone pressure modality in this section, with reference to the muscles (or the updated Lung Sinew Channel members).

We propose that the extraordinary acupoints Bitong and Yingxiang should be included as the acupoints of the Lung Meridian based on neurophysiological analysis-Bian stone maneuver on these sites of Bitong (LUSP-1 = M-HN-14) and Yingxiang (LUSP-2 = LI-20) can improve the fluency of inflow air.

Normally, we do not exercise the nasal muscles much. There are many muscles in the face around the nose, as shown in Figure 2. One tends to change the gesture of the face to improve air inflow sub-consciously. The maneuvers using warm Bian stone as shown in Figure 3 are suggested to redistribute the mechanical

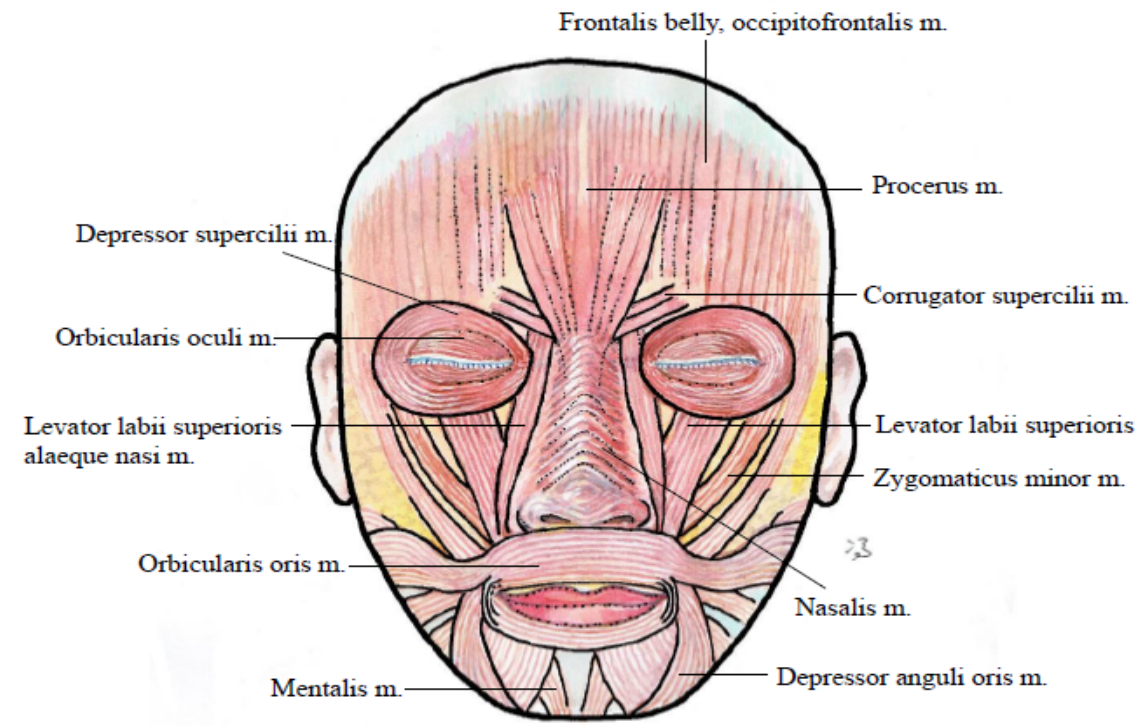

Figure 2. Muscles on the face as labelled. Some of these muscles affect the amount of inflow through the nose [40]. In fact, it is a common experience that one moves the "gesture" of the face to improve inspiration. The depressor septi nasi (triangular shape pointing towards the point between the two nostrils), which can widen the nose, is behind the orbicularis oris $\mathrm{m}$. and is not shown here. The symbol $\mathrm{m}$. stands for muscles in the figure. See also Table A1. This figure was hand-painted by author PCWF. 


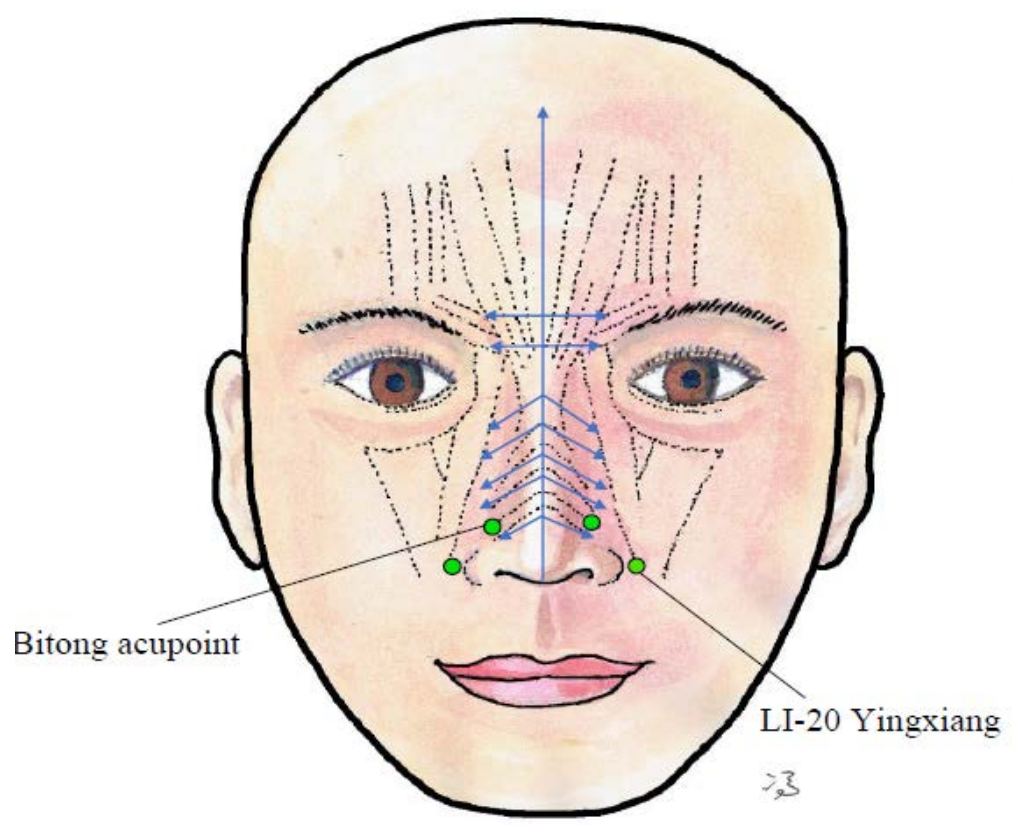

Figure 3. The proposed maneuvers using warm Bian stone along the blue arrows for relaxing the connective tissues associated with the procerus muscle (plus the muscle itself), the corrugator supercilia muscles, the nasalis muscles, the levator labii superioris alaeque nasali muscles (refer to Table A1 also). Acupressure is applied to acupoints Bitong and Yingxiang. This figure is hand-painted by author PCWF.

tensions of the collagen fibers around the striated muscles and blood vessels, nerves. Briefly, the procedure can be summarized as:

1) Use two Bian stone knives to scrape and pull from Yintang (M-HN-3) towards both brows.

2) Use a Bian stone knife to scratch straight from the tip of the nose to the middle of the eyebrows (Procerus muscles).

3) Scratch outwards on the lateral and wing on both sides of the nasal muscles with a Bian stone knife.

4) Use the tip of the Bian stone knife to stimulate the Bitong (M-HN-14) and Yingxiang (LI-20) acupoints and on both sides of the nose.

5) Repeat the above procedures two or three times till the nasal muscle appears pink in colour. Technically, one can follow the strokes indicated by the blue arrows in Figure 3.

These maneuvers amount to the reorganization of mechanical tension so that the nasal system is in the lowest mechanical energy state. Technically, referring to Figure 3, these strokes relax the connective tissues associated with the procerus muscle (plus the muscle itself), the corrugator supercilia muscles, the nasalis muscles, the levator labii superioris alaeque nasi muscles. The authors have tried these noninvasive strokes with warm Bian stones (at $\mathrm{T}=39.5^{\circ} \mathrm{C}$ ) well over a hundred times to improve inspiration efficiency, though no quantification with statistical test has been performed. The procedure above is not only good for activating the olfactory nerve, but can also induce the flow of debris from the in- 
tracranial region to the facial region (i.e. a simple way to treat neuro-degenerative disease) which is equipped with peripheral lymphatic collecting vessels, in the manner described in [5].

In passing, it is important to note that the sympathetic nerves innervate arterial and venous vessels, as well as arteriovenous anastomoses, but there are less sympathetic nerves found around glands. Sympathetic nerves contain norepinephrine, or norepinephrine and neuropeptide Y (NPY) as neurotransmitters [37]. Both norepinephrine and NPY (acting for long duration) are vasoconstrictors [38]. Exercise causes a drop of total nasal airway resistance within 30 seconds, maximizing at 5 minutes, and could persist for up to 30 minutes in response to aerobic performance. In fact, in Western Medicine, it has been established over five decades ago that sympathetic vasoconstriction of nasal vessels has the general sympathetic effect to maintain the supply of oxygenated blood to the muscles [39] [40]. In other words, acupuncture of the Lung Meridian, leading to activation of the spinal nerve $\mathrm{C} 5, \mathrm{C} 4, \mathrm{C} 3, \mathrm{C} 2$ or exercise increases airflow rate via the nasal cavity during respiration.

\section{The Intrinsic and Extrinsic Muscles of the Tongue}

\subsection{The Intrinsic Muscles of the Tongue Are Involved in Respiration}

The Intrinsic and extrinsic muscles of the tongue are innervated by a system of nerves mixed by the hypoglossal (CN XII) and sympathetic rami branches of the cervical nerves C1-C3 [41] [42]. The superior longitudinal, inferior longitudinal, vertical and transverse muscles constitute the intrinsic muscles. Since the muscles are more entangled in presentation and their anatomy structures provide one function in respiration-changing the shape of the tongue, we simply painted the "upper tongue" to represent these four intrinsic muscles in Figure 4, with some particulars listed in Table A2. The intrinsic muscles of the tongue are used during chewing, swallowing, speaking, singing, vomiting, and coughing. All these actions involve intermittent stopping and resumption of respiration. They are therefore muscles involved in breathing. We also remark that lateral movement of the tongue is accomplished by the intrinsic muscles. These muscles change shape and volume during speech and swallowing.

\subsection{The Extrinsic Muscles of the Tongue}

The styloglossus, genioglossus, geniohyoid and the hyoglossus muscles build up the extrinsic muscles. The four extrinsic muscles of the tongue are shown, together with the innervating nerves schematically in Figure 4 [43].

One crucial cause of developing obstructive sleep apnea (OSA) was suggested to be the failing of the genioglossus muscle (as a dilator muscle) in the upper airway during sleep. A clear demonstration using the rat model has been presented in [44]. In human, this problem has been analysed in [45].

In the awake state, the same patient may not demonstrate such weakness [45] 


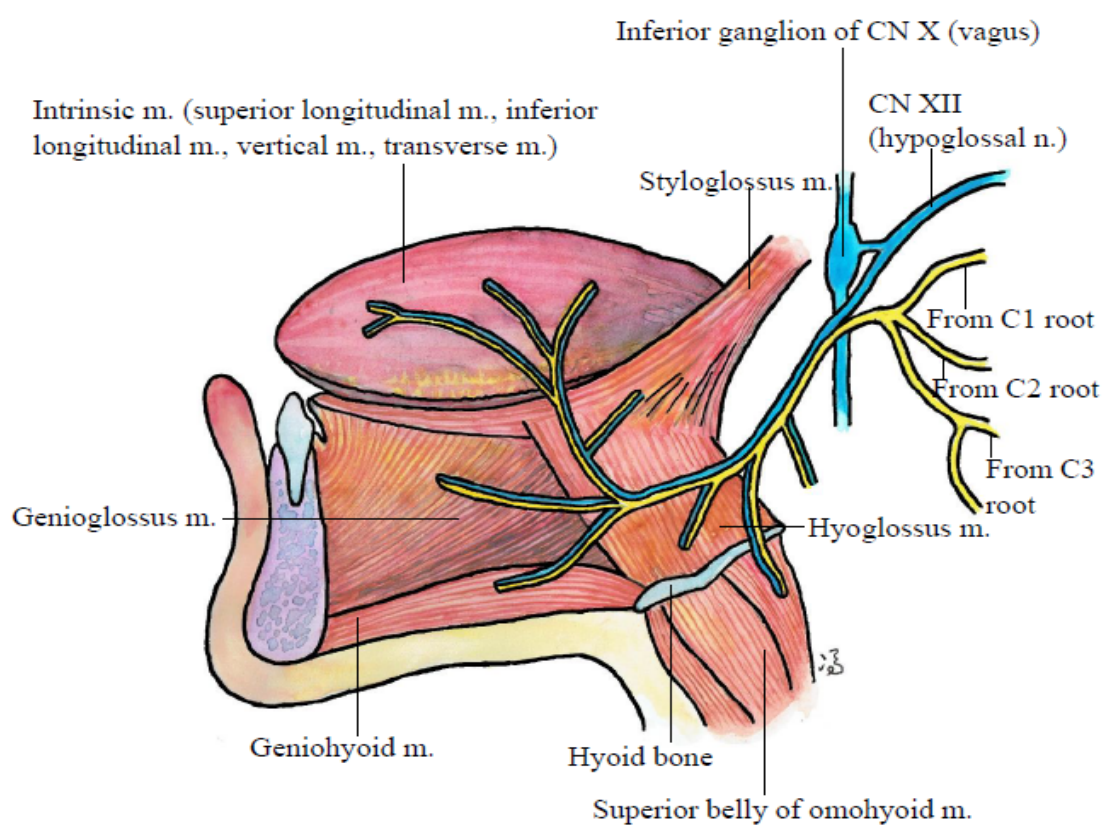

Figure 4. Muscles of the tongue. The styloglossus, genioglossus, geniohyoid and the hyoglossus muscles build up the extrinsic muscles. The superior longitudinal, inferior longitudinal, vertical and transverse muscles constitute the intrinsic muscles. Since the transverse and vertical muscles are perpendicular in their geometrical directions, we have not shown separately the four intrinsic muscles in this figure [43]. See Table A2 and Table A3 and text for more details. This figure was hand-painted by author PCWF.

[46] [47]. The weakness was shown to be compensated by increasing pharyngeal dilator muscle activity (genioglossus); this activity was due to a neuromuscular reflex to retain patency of the airway size [48]. Moreover, it will be explained in a later section that the electrical activity of the muscle starts synergistically with the contraction of the diaphragm and the scalene muscles, indicating that it is intrinsically related to the breathing process. Note that genioglossus is involved in disorder of breathing during non-rapid eye-movement sleep and the other three muscles are involved in the act of swallowing (to be described in a later section). These four muscles can be classified as members of the Lung Sinew Channel. Some particulars of the extrinsic muscles, which are muscles of the Sinew Channel in TCM language, are listed in Table A3.

\section{The Four Intrinsic and Eight Extrinsic Muscles of the Larynx}

\subsection{The Intrinsic Muscles of the Larynx}

Speech is an important daily activity of humans, and the four intrinsic muscles of the larynx carry the main function of opening and closing of the vocal cord during speech, swallowing, vomiting, and cough. The vagus nerve enters the superior sympathetic ganglion, which is a "station" of spinal roots 1 - 4 . The internal laryngeal nerve exits from this ganglion, and it is a mixed sympathetic and parasympathetic nerve. The external recurrent laryngeal nerve is a branch of the vagus nerve only. 
The aryepiglottis muscle adducts the arytenoid cartilages, acting as a sphincter on laryngeal inlet.

The transverse arytenoid muscle and is an adductor of the vocal folds and is thus playing an important role in phonation.

The oblique arytenoid adducts the arytenoid cartilages towards each other, leading to closure of the inlet to the larynx, with the result of inhibiting respiration. The posterior cricoarytenoid abducts and rotates the arytenoid cartilage, pulling the vocal ligaments from the midline, thus opening the glottis. This muscle is therefore essential for the resumption of respiration during speech and swallowing. We refer to Figure 5 and Table A4 for their anatomy structure and other particulars in brief [48] [49].

\subsection{The Extrinsic Muscles of the Larynx-The Four Infrahyoid Muscles and the Four Suprahyoid Muscles}

Note that the size and shape of the upper airways can be altered by movements of the hyoid bone and the study of the muscles in such movement is important in breathing. The tip of the hyoid bone moves cranially during inspiration and moves caudally during respiration [50]. Suprahyoid muscles are four muscles above the hyoid bone: the (i) digastric, (ii) stylohyoid, (iii) geniohyoid, and (iv) mylohyoid muscles. Muscles (i), (ii) and (iv) are shown in Figure 6 and side

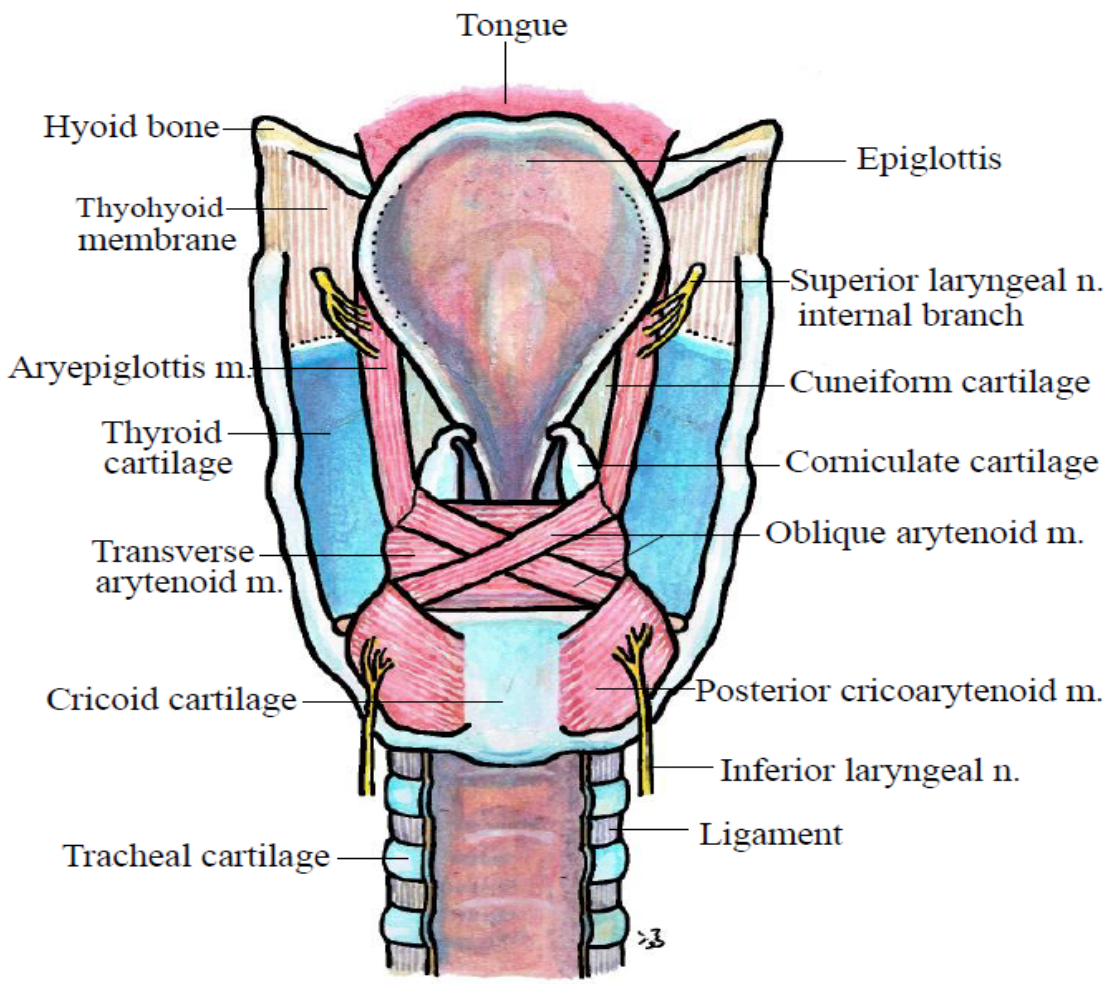

Figure 5. The aryepiglottis, oblique arytenoid, transverse arytenoid muscles, and the posterior cricoarytenoid are the main muscles that control the epiglottis to open and close the vocal cords intermittently during speech, singing and swallowing. This figure was hand-painted by author PCWF. 


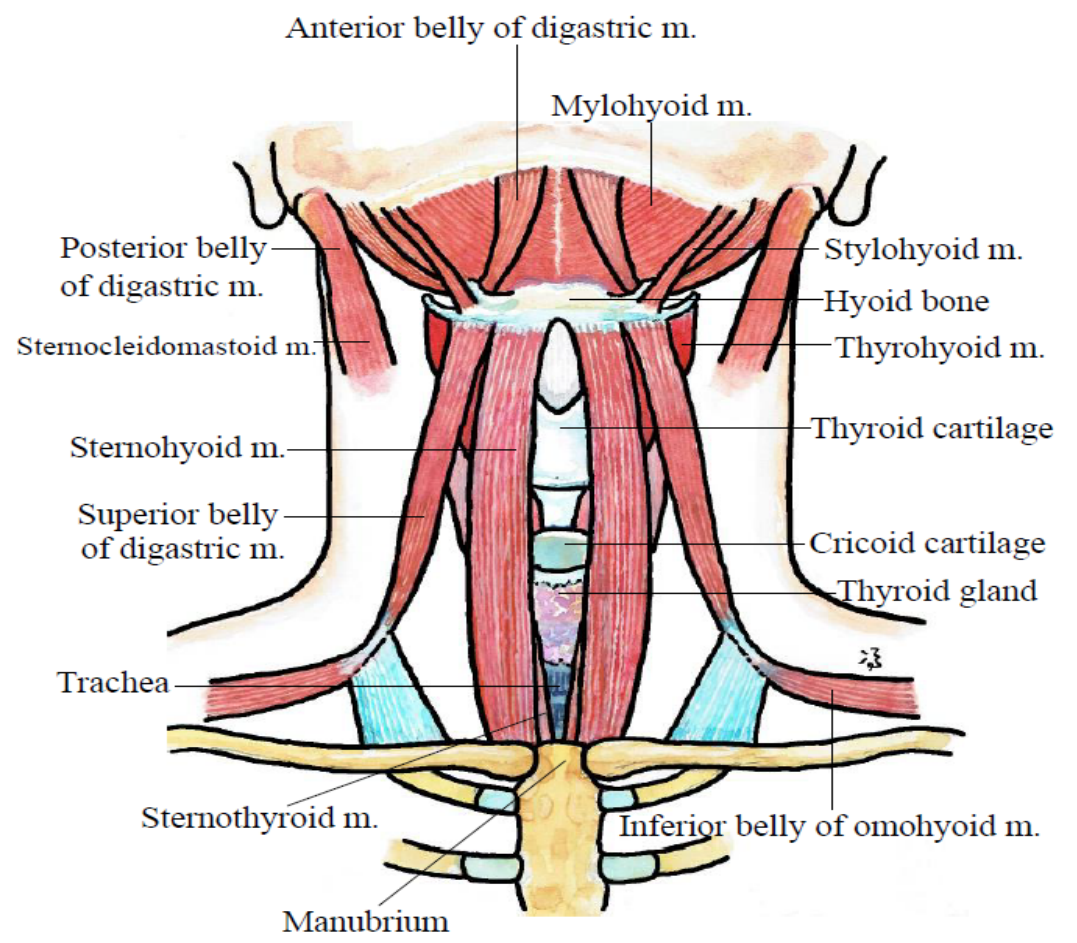

Figure 6. The 8 extrinsic muscles of the larynx. The suprahyoid muscles have four components: (i) the digastric, (ii) stylohyoid, (iii) geniohyoid, and (iv) mylohyoid muscles. These muscles participate in mouth breathing and inhibition of breathing during swallowing, a necessary step for survival. The four members of the infrahyoid muscles are: (v) the omohyoid muscle, (vi) sternohyoid muscle, (vii) thyrohyoid muscle, (viii) sternothyroid muscle. Muscle (v) also has two members-the superior and inferior bellies. The total set of 8 muscles (i)-(viii) ae called extrinsic muscles of the larynx. These muslces are innervated by sympathetic nerves of $\mathrm{C} 1-\mathrm{C} 3$ and three parasympathetic nerves. In short, the main function of the 8 muscles is to raise or depress the position of the hyoid bone during speech and swallowing. For other details, see text and Table A5 and Table A6. This figure was hand-painted by author PCWF.

view of muscle (iii) is hidden behind the stated muscles in this figure. Some particulars of these four muscles are listed in Table A5. There are two sub-members of (i). The superior belly of digastric muscle originates from the inner side of the lower border of the mandible and connects the superior part of the hyoid bone by a tendon (in loop form). The posterior belly arises from the inferior surface of the skull (called the mastoid notch). The two bellies join at the stated tendon loop, as shown in Figure 6. Since the superior belly is innervated by the CN V3 (mandible branch, via mylohyoid nerve), as well as sympathetic nerve derived from spinal nerves $\mathrm{C} 1-\mathrm{C} 3$, whereas the posterior belly is innervated by the $\mathrm{CN}$ VII (digastric branch), plus spinal nerves C1-C3, each belly can contract separately. When the hyoid bone is fixed in position by the infrahyoid muscles (to be discussed in the following section), the digastric muscles are involved in mouth breathing. The stylohyoid muscle arises from the styloid process of the temporal bone and inserts the lateral aspect of the hyoid bone. Since the hyoid bone has a bow-shape structure as viewed from above, the stylohyoid muscle, together with 
tongue muscles, is considered to be the initiator of the swallow action by pulling the hyoid bone in a posterior and superior direction. When the hyoid bone (which is connected to the epiglottis) is in the posterior position, the muscles attached to the epiglottis can bend the epiglottis down by contraction, closing the airway, as discussed further in the next section. The mylohyoid muscle is originated from the mylohyoid line of mandible. In short, the suprahyoid muscles participate in mouth breathing and inhibition of breathing during swallowing, a necessary step for survival.

The four members of the infrahyoid muscles, below the hyoid bone, are: (v) omohyoid muscle, (vi) sternohyoid muscle, (vii) thyrohyoid muscle, (viii) sternothyroid muscle (Table A6). Muscle (v) also has two members-the superior and inferior bellies. The superior belly inserts the hyoid bone and is connected to the inferior belly, which originates from the superior border of the scapula bone. The "intermediate tendon" attaches the joint of the two bellies to the clavicle bone. Contraction of muscle (v) set depresses the hyoid bone. The sternohyoid muscle is a thin muscle originating from the manubrium and posterior aspect of the sternoclavicular joint. It inserts into the body of the hyoid bone. When this muscle cotracts, the hyoid bone is depressed. The thyrohyoid muscle connects the horn of the hyoid and the thyroid cartilage. Relaxation of muscle (vii) lowers the thyroid cartilage to its normal position after swallowing action. When the thyroid cartilage is raised, the sternothyroid muscle is extended from its normal state. Relaxation of the sternothyroid muscle brings the thyrod cartilage down after the swallow action, and breathing resumes. The main function of the infrahyoid muscles is to depress the hyoid bone and larynx during swallowing and speech. Muslces (v)-(viii) are all inervated by the ansa cervicalis nerve which contains both the sympathetic nerves (C1-C3) and the prasympathetic nerve $\mathrm{CM}$ XII [51]. The total set of 8 muscles (i)-(viii) are called extrinsic muscles of the larynx.

\section{Swallowing Stops Respiratory Action for a Short Period-More Muscles Must Be Added to the List of Members in the Lung Sinew Channel}

Muscles of the tongue, larynx and trachea must be coordinated in such a way as to avoid laryngeal penetration or tracheal aspiration (the action of producing a sound with an exhalation of breath), and respiration must be interrupted during swallowing and resumed in the expiratory phase. Using whole-body plethysmography and video recordings of (i) normal rat models, (ii) rats suffering from pulmonary emphysema, the authors discovered that there was significant difference in the stated coordination in group (ii). They inferred that respiratory diseases are associated with changes in swallowing-ventilation coordination [52]. Symptoms of similar dis-coordination might be an indication of aspiration/lung diseases. We describe very briefly the process of swallowing below to show an example of the complicated coordination.

As shown in Figure 7, air breathed in normally through the nasal entry and 


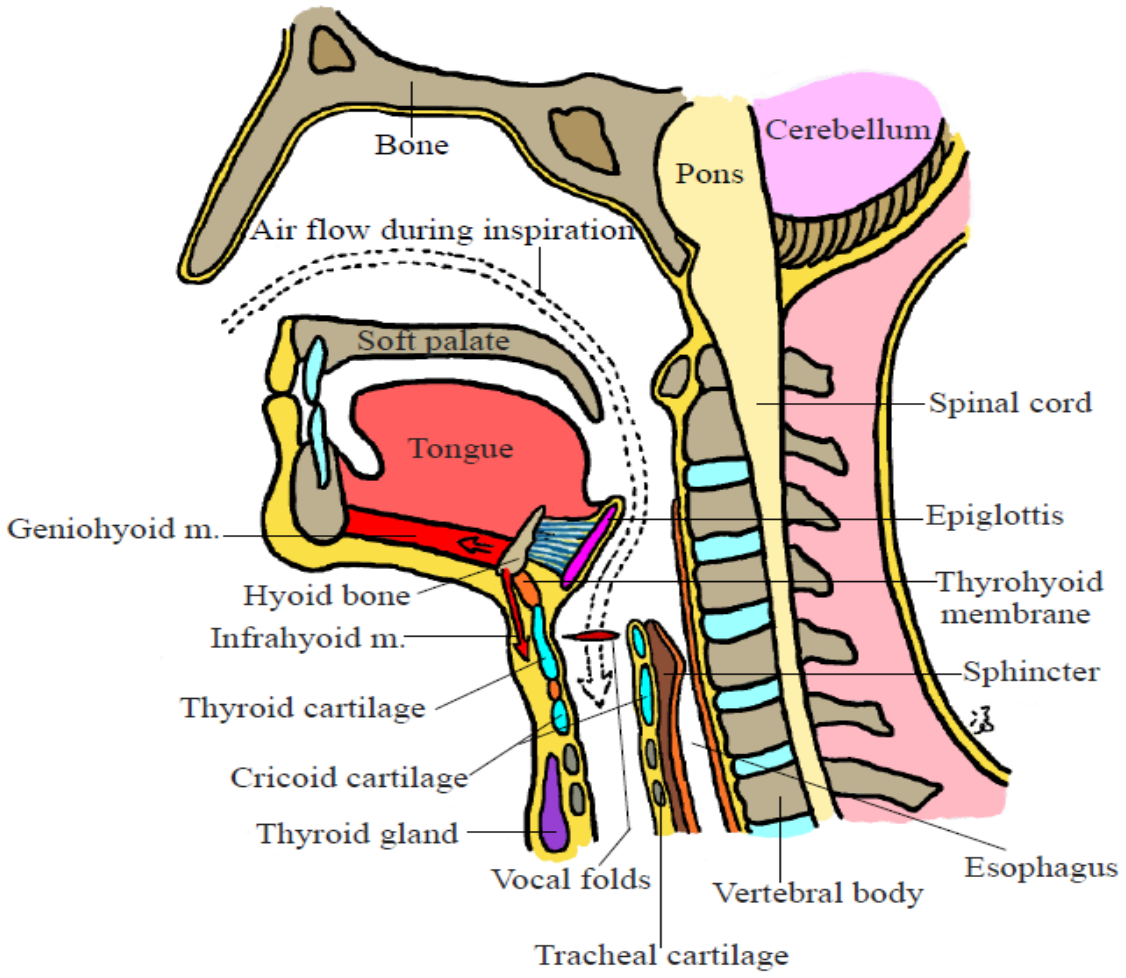

Figure 7. Showing the moment before swallowing. Respiration is possible only when the epiglottis is not in the close position and the vocal cords are open. For details, see text. This figure was hand-painted by author PCWF.

follow the dotted arrow, passing the vocal cords which must be open during respiration. Since the esophagus is just behind the trachea, food can easily get into the lung if the opening of the trachea is not closed completely during the acion of swallowing. First, the "cover" of the airway is the epiglottis, which is connected to the hyoid bone that is, in turn, attached to 8 muslces (4 suprahoid muscles and 4 infrahyoid muscles) as discussed in the last section. The hyoid bone (orchid color) is attached to the epiglottis (bright purple) by the hyo-epiglottis ligament (deep blue with white lines). The thyroid cartilage (blue) is attached to the hyoid bone by the thyrohyoid muscle (red brown) in the superior direction, and is connected to the cricoid cartilage by a layer of membrane (not show in Figure 7) in the inferior direction. The cricoid cartilage is also connected to a series of trachea cartilages (greyish brown) via connective tissues. The tongue, which is composed of a number of muscles as described in Section (4), is also connected to the hyoid bone and epiglottis. The dotted arrow indicates the air flow direction during inspiration. The base of the tongue has a muscle (bright red) called the geniohyoid muscle, which is also inserted to the hyoid bone and the arrow within this musle region indicates that the hyoid bone can be pulled towards the chin when the geniohyoid muscle contracts. The red arrow pointing downwards indicates that the infrahyoid muscles (sternohyoid muscle etc., see Figure 6) can pull the hyoid bone caudally when these muscles contract. The other muscles of the tongue function to move the tongue and are helping with the swallowing ac- 
tion. The deep brown layer with a bulging structure (marked sphincter) is the entrance of the esophagus. The two light brown layers on both sides represent the cross-section of the esophagus built basically of elastic smooth muscles. When one breathes, the esophagus is in the collapsed situation, with the sphincter closed. Some other key anatomy parts are marked in Figure 7.

In Figure 8, we show the situation when one tries to swallow some food, represented by a large green bulos. The stylohyoid muscle is considered to be the initiator of swallowing by pulling the hyoid bone in the posterior direction (see also for other detailed action [53]). The force on the hyoid bone at this stage is represented by the little arrow on the right side of the hyoid bone in Figure 8 . Since all the muscles of the tongue are connected in a complicated way to allow for tongue movement in speech, swallowing and breathing, other tongue muscles also help indirectly to push the food towards the posterior direction. While the food is under the soft plate region, breathing still proceeds, as the epiglottis is closing gradually, by its "intrinsic muscles" (as descibed in Section (5) with Figure 5). Before the food is forced through the sphincter muscle, the airway must be covered by the epiglottis, and the vocal cords/folds are closed, so that the food will not enter the trachea and hence the lung region. To cater for such closing action, the thyroid cartilage has to be pushed up by the system of muscles mentioned. At the position shown in Figure 9, there is a short time interval in which respiration is impossible. Note that the thyroid cartilage is now raised because it is connected by the thyrohyoid muscle which is attached to the hyoid bone. The little solid arrow on the right side of the hyoid bone is still working to ensure the

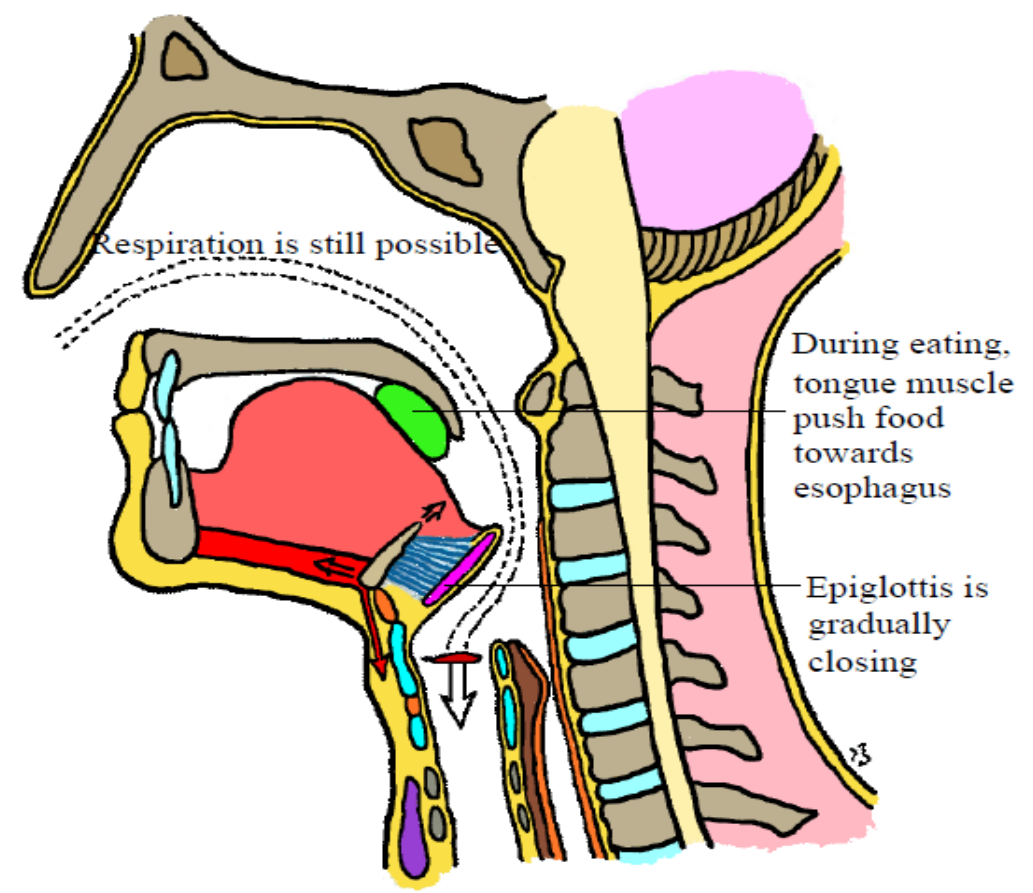

Figure 8. When the food is still under the soft plate and the epiglottis has not yet been closed, respiration can proceed. This figure was hand-painted by author PCWF. 


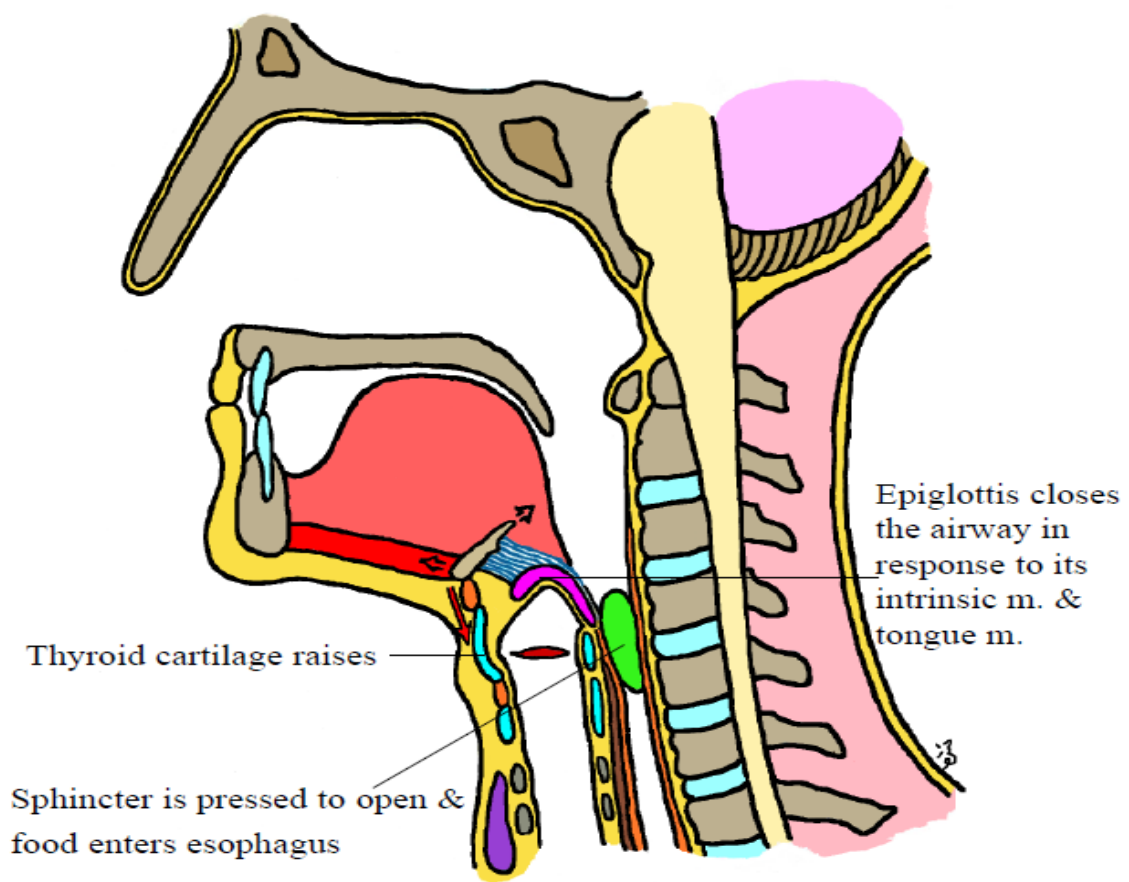

Figure 9. The epiglottis must close the airway before the food enters the esophagus, avoiding the food goes to the wrong way, and respiration stops for a period. This figure was hand-painted by author PCWF.

swallow action is complete. After food is swallowed down by the action of the smooth muscles of the esophagus, the sphincter resumes its normal closing condition (Figure 10). The epiglottis resumes its original "breathing position" as the tongue muscles relax, while the thyroid cartilage is lowered to its original postion too. At this time, respiration resumes. When the food is forced through another sphincter of the stomach, the swallowing action is complete. If the food is blocked at the situation in Figure 9 for too long, the person can be suffocated to death, which happens unfortunately at times.

\section{Four Important Muscles of Inspiration-The Scalene Muscles in Quiet Breathing; The Forced Driving Sternocleidomastoid Muscle and Superior Trapezius Muscle as Two Strong Forced Inspiratory Muscles; the Acupoint Futu (LI-18) Is Related to the Activation of the Superior Fibers of the Sternocleidomastoid Muscle}

The three scalene muscles are used non-stop, like the diaphragm even during quiet breathing, though the workload is far less. Note that the brachial plexus and subclavian artery pass between the anterior and middle scalene muscles, whereas the subclavian vein and phrenic nerve pass anteriorly to the anterior scalene [54]. Any edema and disorders in scalene muscles is serious. Figure 11 shows their positions. The overall function of the anterior, middle and posterior scalene muscles, is to raise the rib cage, resulting inspiration, when the neck turns. There is also direct evidence that the scalene muscles participate in 


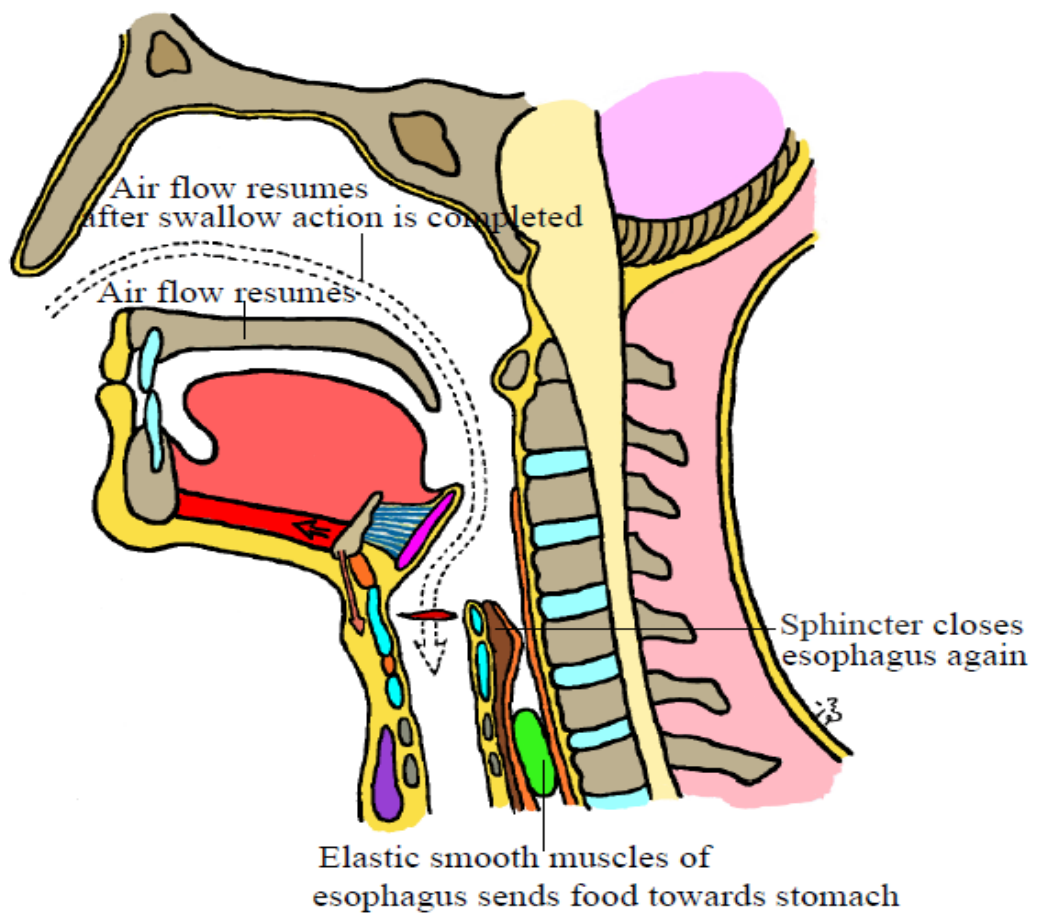

Figure 10. When the food is swallowed down the esophagus, the sphincter of the esophagus closes again, while the epiglottis resumes its original position, and breathing resumes again. This figure was hand-painted by author PCWF.

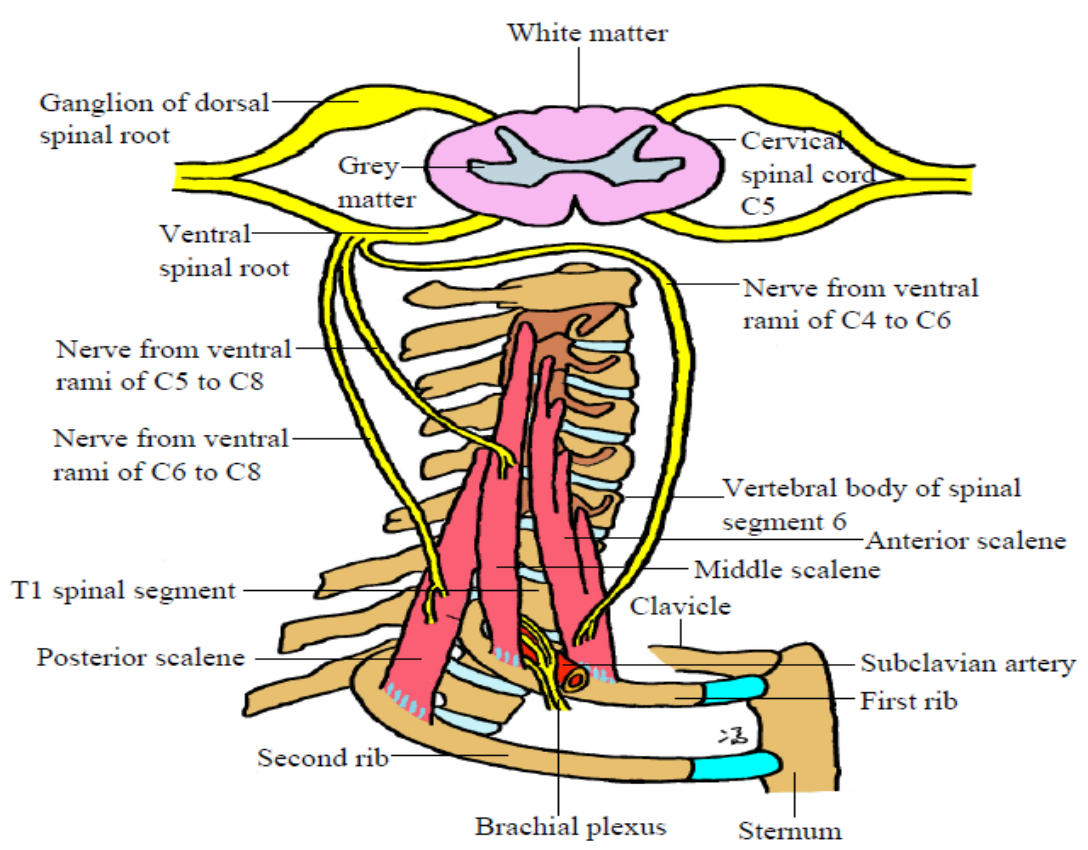

Figure.11. Positions of the three inspiratory scalene muscles and associated anatomy entities. This figure was hand-painted by author PCWF.

rest respiration, followed up in a later section. The sternocleidomastoid muscles have two parts - the round-shape sternal head which joins the anterior aspect of the manubrium of the sternum, as shown in Figure 12. The other part has a 


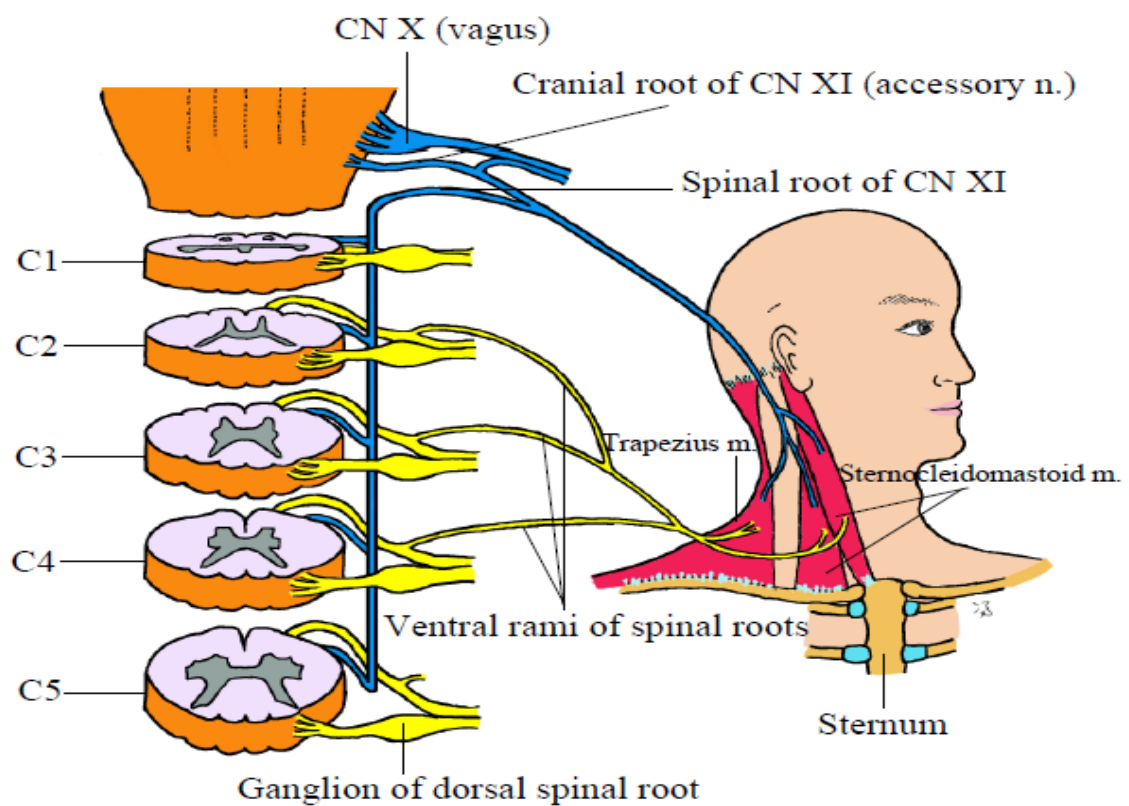

Figure 12. The accessory nerve (blue) has two parts: the cranial part joins the vagus nerve (also blue), and the spinal part with five branches (each is a motor nerve) exit from the ventral horns of spinal cords $\mathrm{C} 1-\mathrm{C} 5$; these 5 nerve fibers combine to innervate the sternocleidomastoid and trapezius muscles. Note that $\mathrm{CN} \mathrm{XI}$ is also connected to $\mathrm{CN}$ X. The sympathetic branches from $\mathrm{C} 2-\mathrm{C} 4$ innervate both the sternocleidomastoid and trapezius muscles [61]. The superior trapzius muscle is an inspiration muscle [62]. This figure was hand-painted by author PCWF.

flat shape and is attached to the superior aspect of the middle third of the clavicle. The two branches of the muscle system are attached to the outer surface of the mastoid process and the outer superior nuchal line of the occipital bone, behind the ear. During breathing at rest, the sternocleidomastoid muscles rarely contract. But when other muscles (such as the scalene muscles) fail during a disease state, or during heavy exercise when stronger/deep inspiration is needed, the sternocleidomastoid muscles are at work in inspiration [55] [56].

COPD patients also use these muscles when the diaphragm, intercostal muscles, scalene muscles are weakened, or that there is obstrution in the airway. Since the deep site of the acupoint Futu (LI-18) is in the neighborhood of C2-C4 nerves, we consider that stimulation applied to LI-18 would activate the sternocleitomastoid muscles. Acupoint LI-18 has been used, together with other acupoints which have specific application in three clinical studies to treat COPD patients [57] [58] [59]; the consequence of acupuncturing the other acupoints have been explained in section (12.2) of our very recent study [18]. When the superior muscle fibers of the trapzius contract, they help to raise the rib cage, and the superior part is an inspiratory muscle. The inferior part, however, is expiratory, as will be mentioned later. In Figure 12, the accessory nerve (blue) has two parts: (i) The cranial part that joins the vagus nerve (also blue). (ii) The spinal part with five branches (each is a motor nerve) that exit from the ventral horns of spinal cords $\mathrm{C} 1-\mathrm{C} 5$; these nerve fibers combine to innervate the sternocleido- 
mastoid and trapezius muscles [60]. We particularly note that the main work of the accessory nerve CN XI seems to be that of acting on the sternocleidomastoid and trapezius, and pass on some messages to the brain and vagus nerve. These two muscles are also innervated by sympathetic branches of roots $\mathrm{C} 2-\mathrm{C} 4$ [61] [62]. When we go to the other skeletal muscles, known so far, the sympathetic nerves control their activities. Some features of the scalenes, sternocleidomastoid are listed in Table A7.

\section{The Sympathetic and Parasympathetic Neurons Play Important Roles in Regulating the Contraction and Relaxation of the Smooth Muscles of the Trachea and Branches Inside the Lungs-Hint Gathered for Choice of Acupoints from Several Meridians to treat Respiratory Disorders by Stimulating the Thoracic Sympathetic Nerves}

Two separate types (painted in brownish-red and orange) of parasympathetic postganglionic neurons have been discovered to contract and relax the muscles of the airway and the lung in the guinea [63]. We postulate that such development exists also in humans. Together with the sensory neuron (green in the top part of Figure 13) of the vagus nerve, there are thus at least three types of neurons in the vagus that innervating the trachea and lungs in humans. It is well established that the internal laryngeal nerve is a branch of the vagus nerve and this nerve innervates parts of the larynx; the external laryngeal nerve, however, is projected from an outlet of the superior cervical ganglion (see Figure 8, section 4.6 of [17]). Since the vagus nerve joins the superior cervical ganglion, the sympathetic nerve could also participate in the internal laryngeal innervation. The main branch of the vagus nerve also runs down and projects into the root of the lungs together with the outlets from the sympathetic thoracic ganglia (specie dependent), forming the pulmonary plexus [64]. Let us see some results on animal model studies. By retrograde labelling from the lung, it was found in the rat that sensory neurons from the trachea $\mathrm{C} 2-\mathrm{C} 6$ roots innervate the trachea (with relatively lesser activity compared to that of the vagus sensory neurons effectively), and sensory neurons from T1-T6 roots innervate the lung, contributing to the major sensory detection (as compared to that of the vagus) [64]. Later, using double-labelling immunofluorescence, it has been reported in the guinea-pig model, that the trachea is innervated by sensory neurons of C1-T1, and the lung by T2-T4; in fact, a thorough topographic mapping of innervation was obtained in [65]. Further, another analysis shows that the sympathetic innervation of the trachea and lungs should not be neglected [66]. In humans, it is now known that sympathetic nerves from the superior cervical ganglion, which is the "station" for $\mathrm{C} 1-\mathrm{C} 4$ roots, send postganglionic neurons to innervate the upper airway (larynx and trachea), whereas postganglionic neurons from the thoracic T1-T5 innervate the airways in the lungs [67]. Ten years ago, it was discovered [63] that 


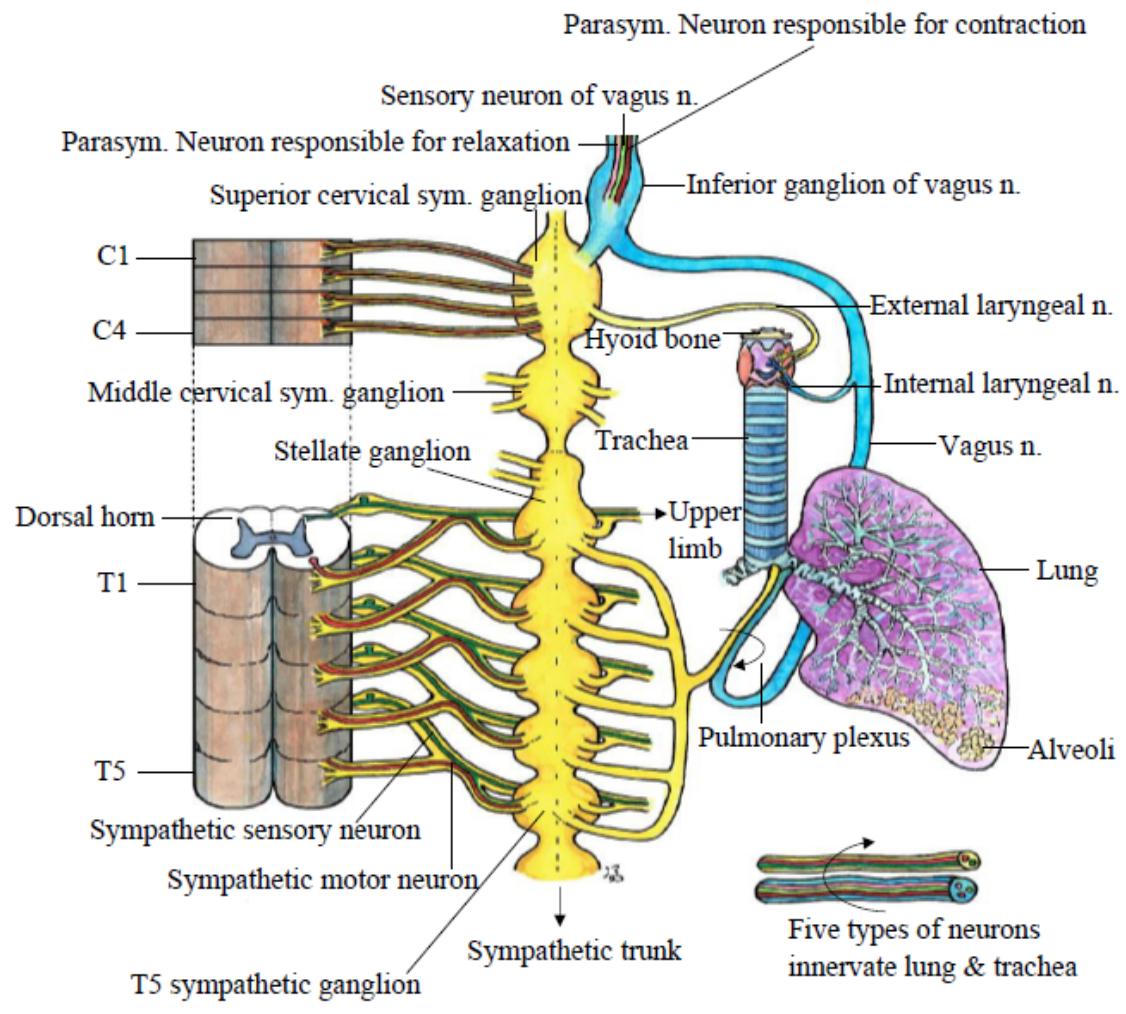

Anterior view

Figure 13. The trachea and lungs are innervated by five types of neurons. Two distinctive types (painted in brownish-red and orange) of parasympathetic postganglionic neurons have been discovered to contract and relax the muscles of the airway and lung in the guinea [63]. The parasympathetic nerve here also contains sensory neurons (light green). Sympathetic nerves from roots T1-T5 have their post ganglionic neurons innervating the lungs and trachea-they mix with the vagus nerve to form the pulmonary plexus in humans [67]. Since the sympathetic nerve embeds an afferent sensory and an efferent motor nerve, the trachea-lung system is innervated by at least five types of neurons. Only part of the Alveoli is shown. For other details see text. This figure was hand-painted by author PCWF.

the anatomically distinct parasympathetic postganglionic neurons mediate airway contractions and relaxations separately in guinea pigs; such a result implies that these neurons are in turn innervated by distinct preganglionic neurons. It is established that the vagus nerve embeds a sensory nerve (mainly for chemical-sensitive signals). Thus we postulate that in humans such two types of parasympathetic neurons also exist, and represent in Figure 13 the vagus nerve exiting the nodose ganglion as composing of three types of neurons well-defined in functions: (i) motor neuron (axon in brownish red) to contract airway; (ii) motor neuron (axon in orange) to relax the airway; (iii) the usual sensory vagal neuron (axon in green) to bring sensory signals from the airway-lung system up to the brain stem where the respiration centers are (see brief review in Sections (5.6) with Figure 14 of [17]). The overall vagus nerve is painted in bright blue. In Figure 13, the dorsal horns of $\mathrm{C} 1-\mathrm{C} 4$ are hidden. The motor neurons from the ventral horns mix with the vagus neurons to innervate the larynx via the internal 
and external laryngeal nerves. The motor neurons from the ventral horns of the spinal cords T1-T5 enter the sympathetic ganglia of T1-T5, from which postganglionic neurons extend to the root of the lungs [67]. The combined mixed-nerve group forms the pulmonary plexus (yellow and blue). Since the sympathetic nerve contains both the sensory and motor neurons (see Figure 3 of [18] for the peripheral nerve), the nerve innervating the trachea and lungs are composed of at least five types of neurons known so far; schematic structure of these five types of nerve fibers is represented by the small diagram in the lower right part of Figure 13. The lungs and trachea send signals by the (deep green) sensory neurons, via relays in the sympathetic ganglia T1-T5 to the appropriate dorsal horns; we show only some portions of these sensory axons "to join" the peripheral sensory nerve for simplicity. The peripheral T1 nerve is relevant to the stimulation by TCM modalities, in order to treat both the heart and lung disorders. Since the brachial plexus is built from roots $\mathrm{T} 1 \mathrm{up}$ to $\mathrm{C} 1$ in a complicated way (see Figure 4(a) in Section (4.2) of [17]), when acupuncture or other TCM modalities is applied at the arm acupoint of the Lung Meridian, some part of the signal is also shared to T1 (to the heart). It is intuitively true that when we want the lungs to work harder for some reason, we must automatically speed up the heart rate. We can now see that stimulating a number of thoracic sympathetic nerves would help the lungs' function. This brings out a key question: why did the classic Lung Meridian miss to include acupoints that are related to the upper thoracic sympathetic nerves? This issue will be followed up in the last part of this paper.

We would also remark that very little attention has been paid to the study on the role played by the sensory neurons in the sympathetic nerves of the trachea and the lungs in humans and other vertebras because it was thought that sensory communication was mainly done by the sensory neurons of the vagus. However, in the study of [66], using retrograde labelling from the lungs of rat models, it was shown that there was clear indication that sensory signals were sent from the lungs to the thoracic dorsal horns. These sensory neurons send signals to the dorsal horns of the spinal cords on the characteristics of the sensory stimuli received. On reception of these signals, the interneurons in T1-T5 would feed back the information to the ventral horns where the motor neurons innervate the lungs (and trachea) after a relay process at the sympathetic ganglia. This is a general spinal segmental reflex phenomenon observed in many parts of the body. We put forth this argument with respect to the role played by the sensory nerve of the diaphragm in [20]. We propose that using TCM modalities, by stimulating the T1-T5 nerves, the signals would also affect the function of the interneurons at the dorsal horns, leading to regulation of the lungs' function.

\section{The Diaphragm and Intercostal Muscles Initiate to Expand the Lungs, with the Sensory Neurons of the Sympathetic Nerve Regulating the Driving Force}

When the diaphragm contracts, approaching a flat sheet like structure, the chest 
cavity is enlarged and so is the lung, creating an internal air pressure that is smaller than the external atmospheric pressure. Air begins to flow in through the nose (or mouth) as the initial move to inspire. The diaphragm muscle has two "muscle legs" ending as the left medial crus as well as the right medial and lateral crus (tendons), which are inserted into the $2^{\text {nd }}$ and $3^{\text {rd }}$ lumbar vertebral bones respectively [49]. The left, right pleura and costal diaphragm with some anatomical information, is shown in Figure 14 and Table A8. Apart from the diaphragm, other muscles (first the external intercostal muscles) also need to work in a synergistic manner in order to complete the inspiration action.

We have explained briefly in [17] and in details too in [18] that stimulating the acupoints in the hand region would trigger a somatosensory reflex (providing supportive evidence also), mobilizing an efferent nerve descending along the anterior corticospinal tract. This tract projects all the way down to the thoracic spinal cords. In the last section, we have noted that sympathetic spinal roots from C1-C4 plus the vagus nerve, play a role in controlling the larynx. Those sympathetic nerves from T1-T5, mixing with the vagus nerve too, innervate the trachea and the lungs. Basically, branches of the T1-T5 roots, apart from innervating the lungs and trachea, also participate in an important work in respiration in a very intriguing manner. This aspect is followed up below.

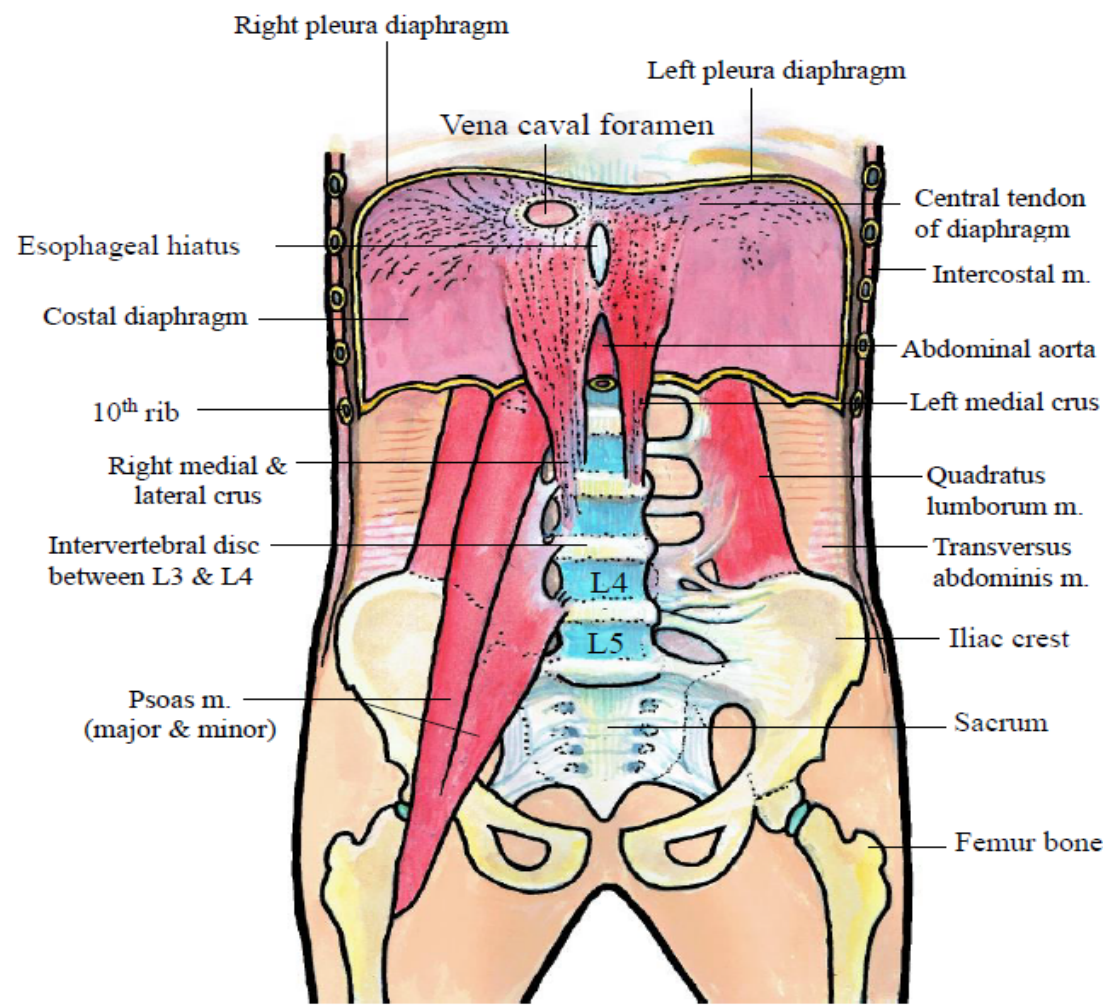

Figure 14. The basic structure of the diaphragm (painted in pink) and associated anatomical units as marked. Notice that the left medial crus and the right medial lateral crus (tendons) are inserted respectively to the second and third lumbar segments [49]. It is a common experience that force is extended to the lumbar domain during a severe cough. This figure was hand-painted by author PCWF. 
First note that the structure of the intercostal muscles with the ribcage in a ventral view is shown schematically in Figure 15. The outside layer is the external intercostal muscle (EIM, brown) with the orientation of the muscle striation as shown in the figure. The muscle in each inter-rib space extends from the spinal segment to the end of the bony structure of each rib, which is attached to a cartilaginous portion (light blue), the other side of which is inserted into the sternum. There is internal intercostal muscle (IIM, light brown) in every inter-rib space behind the external one (with a thin collagen connective in between). There is also an innermost internal intercostal layer (not shown in this figure), with similar structure as the internal intercostal one. The intercostal nerve and blood vessels run between these two internal layers, with branches piercing through the external intercostal layer to regions outside the rib, to supply nutrients to the muscles and bone (more detailed information will be presented in a later figure).

The parasternal intercostal muscle (green) is just a portion of the internal intercostal muscle, and is attached only to the cartilaginous portion and upper and lower parts of a pair of consecutive ribs. The muscle orientation is the same as the internal intercostal muscle. It was found long ago that the parasternal intercostal muscles (PIM) have a rather strong inspiratory effect (for details, see [68]). Some anatomical particulars of these intercostal layers are summarized in Table A8.

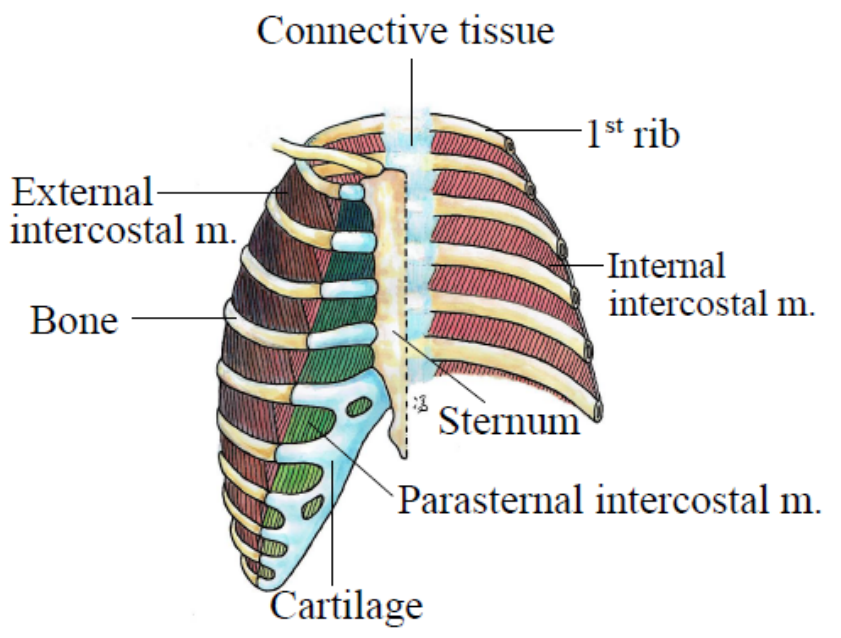

Figure 15. Ventral schematic view of the ribcage including the external, parasternal, and internal intercostal muscles $(\mathrm{m})$ with gradings of colors representing the mechanical advantage (MA, defined in the text). The MA of the parasternal intercostal muscle decreases as the interspace number increases (from first to ninth). The MA of the external intercostal muscle also has this property along the surface of the rib downwards. The external intercostal muscle (EIM) is the outmost layer with orientation of the muscular striations shown in the brownish muscle in each inter-rib space. Within one inter-rib space, the MA of EIM increases from dorsal to ventral. The darker brown colour represents the portion having the greater MA. The variation in MA in different interspaces has important relevance to choosing the acupoints (of different Meridians) to treat disorders related to breathing in general. This figure was hand-painted by author PCWF. 
Now the turning effect when a force is applied to an object is called torque. The basic principle of generating torques by the external and internal intercostal muscles is schematically presented in Figure 16. Since there is a cartilaginous portion in the ventral part of each rib, the volume of the rib cage can be changed within certain limits. During the initial stage of inspiration, the external intercostal muscles in inter-rib spaces generally contribute to lifting of the cage, as illustrated schematically in the left part of Figure 16. The cartilaginous portions of the system allow the chest cavity to expand during inspiration. On the other hand, the internal intercostal muscles, with a different orientation of the muscle striations, would produce the opposite effect when they contract-lowering of the cage, as indicated on the right side of the figure. The mechanism was learned decades ago via analysis of mechanics of the rib-muscle system [68] [69]. The deep blue arrow heads indicate the directions of movement of the rib cage. The chest volume decreases during expiration, because the torque has a turning effect of bringing the ribcage down. Note that the sternum is "anchored" by the collar bone. Unless one moves the shoulders, when the EIM contracts at the dorsal part (which is "anchored" by the spine), contraction of the PIM helps to lift the ribcage up also. Before we proceed, we need to introduce the concept of mechanical advantage of the external intercostal muscles, in order to bridge the results of TCM and modern biomedical science.

\section{The Concept of Mechanical Advantage of the External Intercostal Muscles; Such Property Is Relevant to the Choice of Acupoints to Treat Pulmonary Disorders to Be Discussed in a Later Section}

Before we proceed, we need to introduce the term "mechanical advantage".

The effects of passive inflation on the changes in length of the muscles throughout the ribcage were assessed using 8 dog models in [69]. Several quantities are

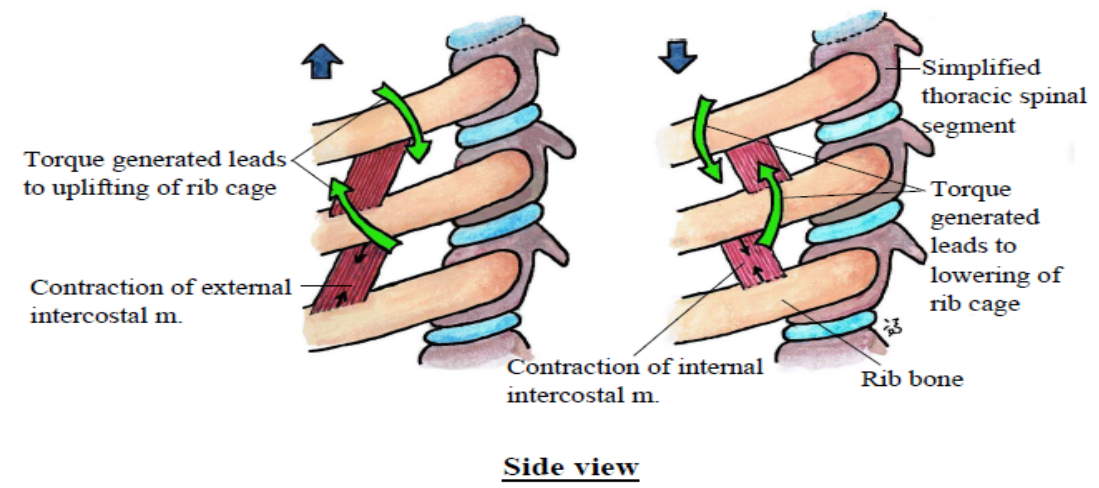

Figure 16. Torques generated by contraction of external and internal intercostal muscles lead respectively to uplifting and lowering of the ribcage based on mechanical analysis [68] [69]. The deep blue arrow heads indicate the movement direction of the rib cage. During inspiration, the rib cage is also enlarged, as the ventral parts of the rib are cartilages. The chest volume decreases during expiration. This figure was hand-painted by author PCWF. 
involved in the calculation of the mechanical advantage of a muscle according to the Maxwell reciprocity theorem: (i) The potential change in airway pressure $\Delta \mathrm{P}_{\mathrm{ao}}$, produced by the muscle contracting alone against a closed airway; here the subscript ao specifies the airway close situation. (ii) The mass $m$ of the muscle. (iii) The maximal active tension per unit cross-sectional area $\sigma$, being 3.0 $\mathrm{kg} \cdot \mathrm{cm}^{-2}$ by measurement. (iv) The fractional change in muscle length $(\Delta L / L)$ per unit volume increase of (v) the relaxed chest wall $\left(\Delta V_{L}\right)_{\mathrm{Rel}}$. These quantities are related by

$$
\Delta P_{\text {ao }}=m \sigma\left\{\Delta L /\left[L\left(\Delta V_{L}\right)_{\text {Rel }}\right]\right\}
$$

The mechanical advantage (MA) is defined as the ratio of the force delivered at the load to the force applied at the handle for a machine. By analogy, the MA of a respiratory system is defined as

$$
\mathrm{MA}=\Delta P_{\text {aо }} /(m \sigma)=\left\{(\Delta L / L) /\left(\Delta V_{L}\right)_{\text {Rel }}\right\}
$$

To determine the relevant quantities and hence the mechanical advantage, it was noted in [69] that repeated measures, and multiple comparison testing of the mean values was performed, when appropriate, using Student-Newman-Keuls tests. The criterion for statistical significance was taken as $P<0.05$.

The intramuscular signals of the intercostal muscles of 6 subjects (breathing at rest) were measured with electromyography (EMG) in [70]. Considering the orientations and masses of strips of the external intercostal muscles (EIM) in consecutive interspaces, it was found, after a series of detailed numerical fitting using the measured data, that the dorsal half of the external intercostal muscle has a significantly higher mechanical advantage in lifting the ribcage [70]. At the dorsal interspaces, it was found that the muscle in the third interspace was the strongest (see Figure 7 of [70]) and the second interspace also contained a strong inspiration muscle in another study [71]. The stronger inspiratory muscles often start contracting in the earlier phase of inspiration [69]. Moreover, it was found that the mechanical advantage of EIM decreases ventrally within one inter-rib space. In Figure 15, we use color grading to represent the magnitude of mechanical advantage of an intercostal muscle for a specific inter-rib space, the second one, say, the brownish color is darker at the left edge of the ribcage (to a reader) than that near the sternum (which is at the central position) to show schematically the above idea. The mechanical advantage of EIM across different inter-rib spaces was found to decrease caudally [70], as reflected by the grading of color across inter-rib spaces (vertically down) in Figure 15. The EIM extends only to the bony part of the ribs, not reaching the sternum. Behind the EIM is the internal intercostal muscle (IIM), which has different orientation arrangement, making an angle $\sim 30$ degrees to that of the EIM. The parasternal intercostal muscles (PIM) has a deeper green in the first inter-rib space, slightly lighter green in the $2^{\text {nd }}$ inter-rib space etc, to convey the idea that the mechanical advantage is decreasing towards the caudal direction, as in the case of EIM. To link 
up the discussion on the choice of acupoints in treating COPD, we present the cross-section of the layers of EIM, IIM, PIM of an inter-rib space in Figure 17. The front little diagram represents the simplified basic structure of the intercostal muscle. There are basically five layers. The outermost is the EIM, which is separated from the IIM by a thin connective tissue layer (not painted in this little diagram but painted in the main diagram). The innermost layer is behind IIM, and the intercostal nerve, together with blood vessels running between the IIM and the innermost layer. These (yellow) nerve fibers (and vessels, not shown) pierce through the several muscle layers and connective tissues to control the action and nourish the rib bones, the spinal segment plus muscles outside the rib cage. In the main diagram, we clearly see the cross-section of five layers. The thickness of the two arc-shape green scales measures the mechanical advantage (MA) of the EIM only. At the dorsal side near the spinal segment, the thickness

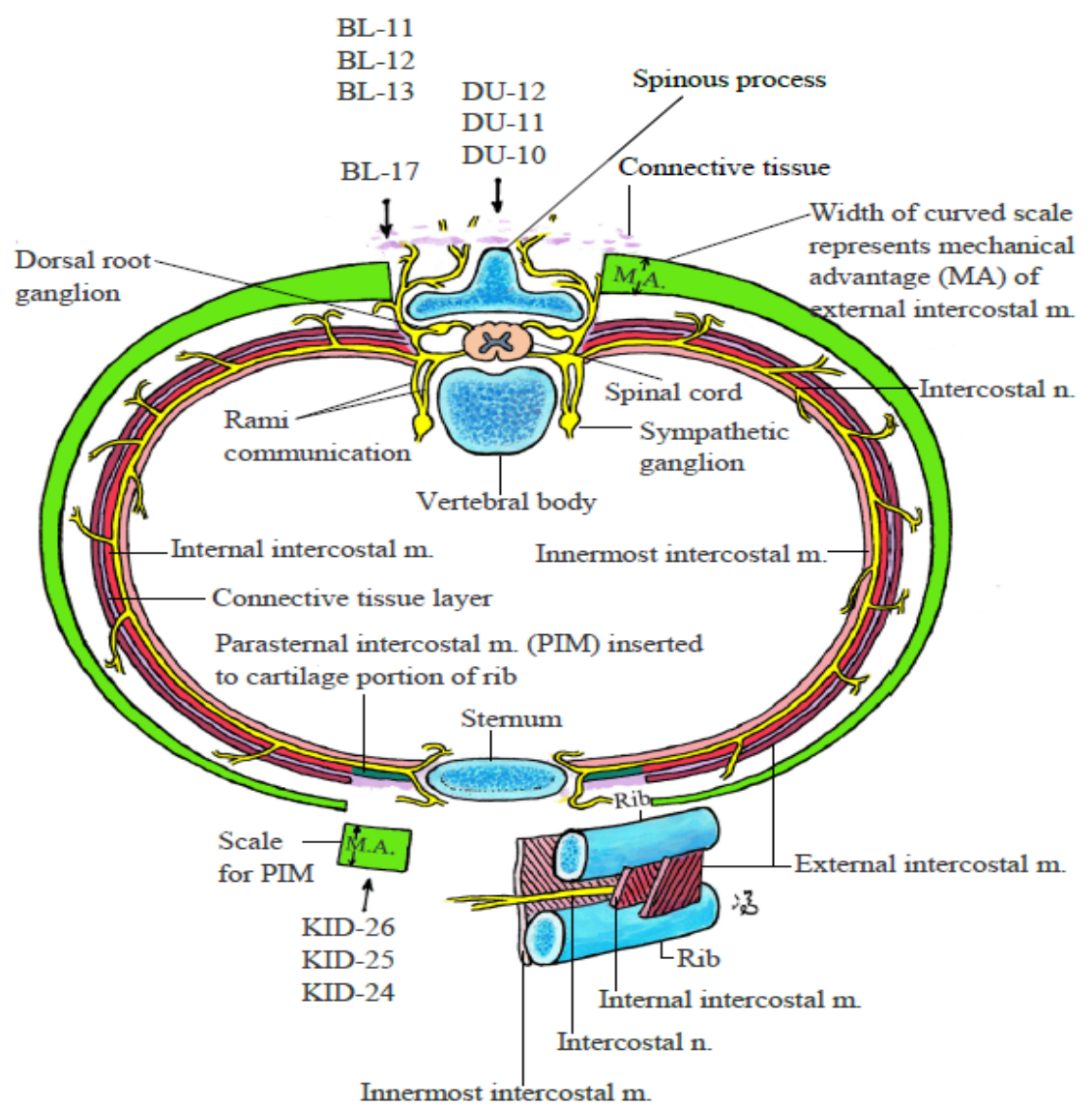

Figure 17. Top view of the intercostal muscles along an inter-rib space (between two successive ribs). The front little diagram represents the basic simplified structure of the intercostal muscles. The acupoints of the DU Meridian are on the central line at the dorsal side. Some of the acupoints of the BL Meridian are 1.5 cun from this central line. Viewing above, they are at the same site. Note that acupoints KID $24-26$ are 2.0 cun from the other central line of the sternum in front. Viewing from above, they also occupy the same site. See text for the explanations of choosing all those acupoints to treat disorders of respiration with evidence briefly stated in this section and details in a later section. This figure was hand-painted by author PCWF. 
is highest (largest), indicating that the EIM muscle there has the strongest effect in lifting the rib cage. Such strength decreases to almost zero near the PIM (deep green) at the ventral domain. This diagram holds true for most of the inter-rib spaces. Another light green scale bar is painted to be associated with the PIM in front, indicating a rather uniform mechanical advantage of the PIM in each inter-rib space. The spinal segment, spinal cord, dorsal root ganglion, sympathetic ganglia are marked in the figure.

Let us now mark the positions of the relevant acupoints for the convenience of discussion on the issue of the choice of specific acupoints to treat pulmonary diseases and the biomedical consequences. Acupoints Zhiyang (DU-9), Lingtai (DU-10), Shendao (DU-11), Shenzhu (DU-12) and Taodao (DU-13) are close to the central line of the spine as viewed from top, taking the approximation that the spine is straight. Feishu (BL-13), Jueyinshu (BL-14), Geshu (BL-17) are 1.5 cun on both sides of the vertical central line of the "simplified" spine. They appear as one site in the top view. Lingxu (KID-24), Shengcang (KID-25), and Yuzhong (KID-26) are 2.0 cun on both sides from the central vertical line passing through the sternum; they are also at the same site as viewed from top.

\section{Experiment Demonstrating That the Intercostal Muscles, and Scalene Muscles, the Genioglossus Muscle Are Important Muscles Participating in Inspiration, Once the Diaphragm Starts to Contract}

Let us proceed to the results of some other research groups on kinesiology (on the micro-scale) of the intercostal muscles. Units of muscles in living organism show different electrical oscillation signals in general. The discharge frequencies and patterns of firing of these motor units directly reflect the output of the motoneurons (close to the ventral horn of the related spinal cord) that innervate them. The frequency range of these muscle/neurons demonstrates a range from a few $\mathrm{Hz}$ to over $50 \mathrm{~Hz}$, similar to that measured by encephalogram (EEG; [29]). In the studies of [45] [72] [73], and review of [74], the authors reported the time-frequency plots of six inspiratory motoneuron units: (i) Diaphragm; (ii) Scalene muscles (without specifying which of the three in their reports); (iii) $3^{\text {rd }}$ dorsal external intercostal muscle (see Figure 17 for schematic representation of the muscle and innervating nerve); (iv) $5^{\text {th }}$ external intercostal muscle; (v) $2^{\text {nd }}$ parasternal intercostal muscle; (vi) genioglossus muscle of the tongue. Note that the greatest piece of muscle of the tongue, the genioglossus is the major upper airway dilator muscle, which is innervated by the hypoglossal and ansa cervicalis motoneurons via the hypoglossal nerve (Figure 6 and Table A5). This tongue muscle therefore plays an important role during breathing [72].

Each horizontal bar (in Figure 4 of [45] and Figure 3 of [73]) has a certain length representing the relative time of firing (with respect to the total inspiration time, in \%). The bars were painted in different colors, dependent on the frequency of the end part of the discharge. There are several tens of bars in each plot, with the bottom one indicating the initial time of firing; the vertical axis is 
the real time of firing of the motoneurons. Analysing these plots for the case of quiet breathing, the authors of [45] [72] [73] concluded that: (i) There is recruitment of the motor units of the inspiratory muscles mentioned above by a principle of neuromechanical matching [75] in which neural drive is higher in the muscles which lead to the greatest mechanical advantage for inspiration, in order to minimize the metabolic cost of respiration. (ii) When the neural drive magnitude is plotted against the mechanical advantage for the parasternal intercostal muscles (from the first rib space to the $5^{\text {th }}$ one) and the dorsal external intercostal muscles $\left(3^{\text {rd }}, 5^{\text {th }}\right.$ and $7^{\text {th }}$ rib spaces), the two lines are both linear, with positive slopes. Here the neuronal drive is measured by the number of discharges per unit time from a unit muscle. The result of these two linear plots implies that the strength of contract of both the parasternal muscle and the dorsal part of the external intercostal muscles decline towards the caudal direction. The works reviewed here substantiate what was described in the last section, pointing out the fact that the diaphragm, external intercostal muscles, the scalene and genioglossus muscles are intrinsically active during quiet breathing and disorders of any one among them readily leads to COPD. In fact, it is now well established that the "slacking" of the genioglossus muscle in obesity and aging is one major cause of airway obstruction, leading to sleep apnea [21]. Now let us go back to specify other inspiratory muscles.

\section{Four Inspiratory Muscles Attached to the Ribs and Scapula}

The pectoralis major and minor are two strong voluntary inspiratory muscles experienced daily by pulling the arms to the back. The clavicular head of the pectoralis major is innervated by branches of the spinal roots $\mathrm{C} 5-\mathrm{C} 7$, whereas the sternal head of the pectoralis major, plus the pectoralis minor muscles are innervated by $\mathrm{C} 8$ and $\mathrm{T} 1$, as shown in Figure 18. At the back, the levator scapula muscle is innervated by the dorsal scapular nerve which originates from the ventral ramus of the fifth cervical spinal nerve in most people (Figure 19). This nerve may also receive inputs from C-4 (or even thoracic spinal nerves) [76].

The deltoid muscle is an expiratory muscle because it is an antagonist muscle of the pectoralis major and minor muscles which are both inspiratory [77].

The serratus anterior originates on the surface of the $1^{\text {st }}$ to $10^{\text {th }}$ ribs at the side of the chest and inserts along the whole anterior length of the medial border of the scapula. This muscle is innervated by branches of sympathetic roots $\mathrm{C} 5-\mathrm{C} 7$ [78] (see Figure 20). The muscle set lifts the ribs when the shoulder girdle is fixed, and is is a set of inspiratory muscle. Some information on these four muscles in this section is listed in Table A9.

\section{Expiratory Muscles-With the Superior Part of the Largest Muscle at the Back also Playing a Role of Inspiration}

During quiet breathing, contraction of the diaphragm and scalene are 


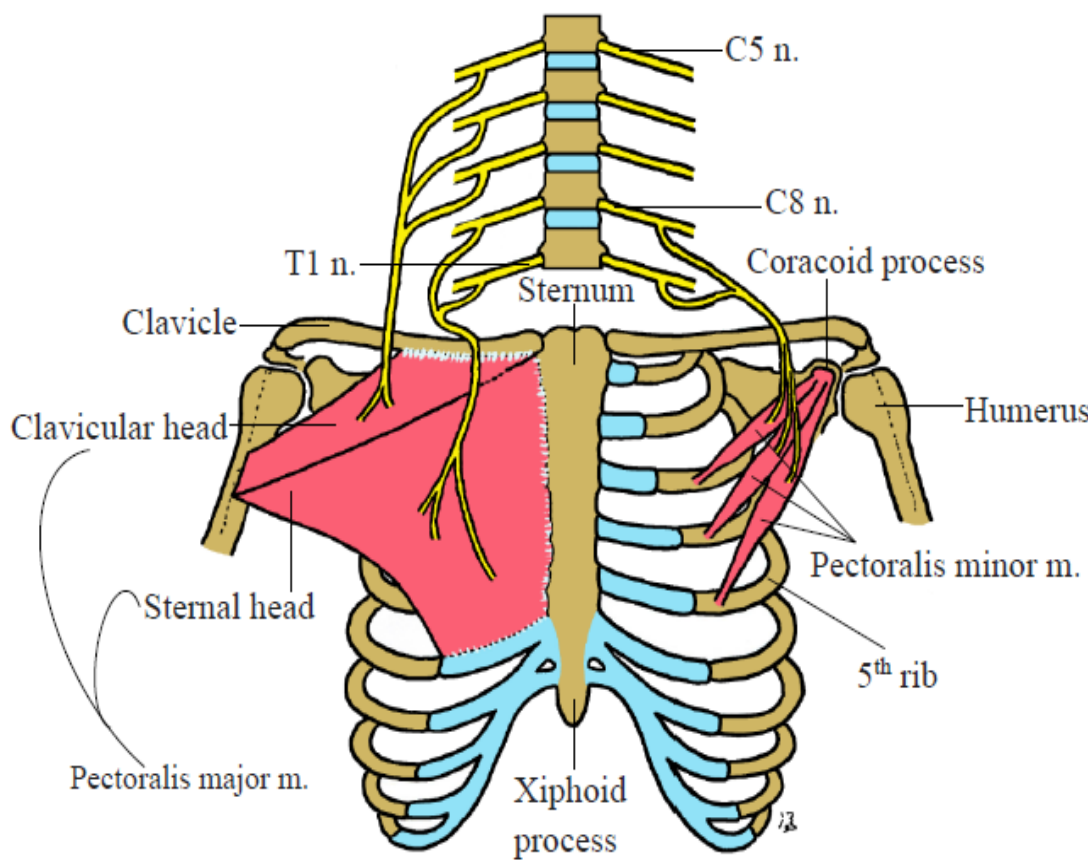

Figure 18. The pectoralis major and minor muscles with other relevant parts are labelled. These muscles are innervated by the spinal roots of the brachial plexus, as shown. Refer also to Table A9. This figure was hand-painted by author PCWF.

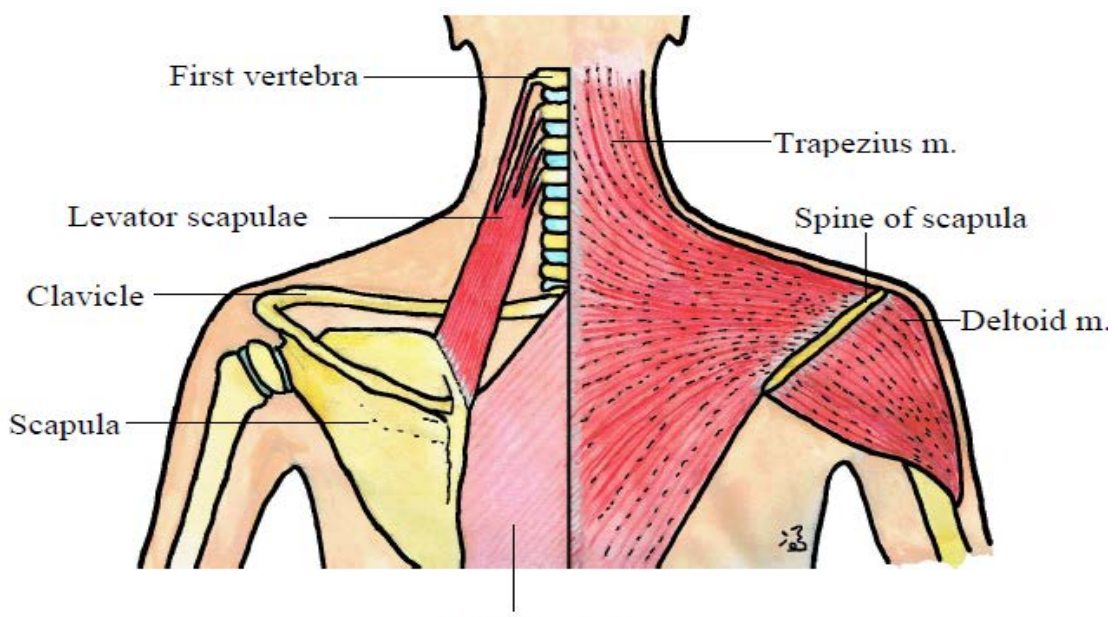

Rhomboid $\mathrm{m}$.

Figure 19. The posterior view showing the levator (inspiration) and deltoid (expiration) muscles [77], together with the trapezius (upper: inspiration; lower: expiration) muscle which covers the neck, shoulders, back, and thorax regions. Nerves innervated are listed in Table A9. This figure was hand-painted by author PCWF.

the main inspiration muscles, as explained before. The elastic recoil of the lungs plays the role of the expiratory muscles. If one suffers from emphysema (loss of elasticity of the lung tissues), voluntary action of the abdominal muscles are needed to push the internal organs into the "cave" of the diaphragm when this tough muscle relaxes, in order to counteract the extraordinary resistance offered by the lungs. The main expiratory muscles considered here (with more information 


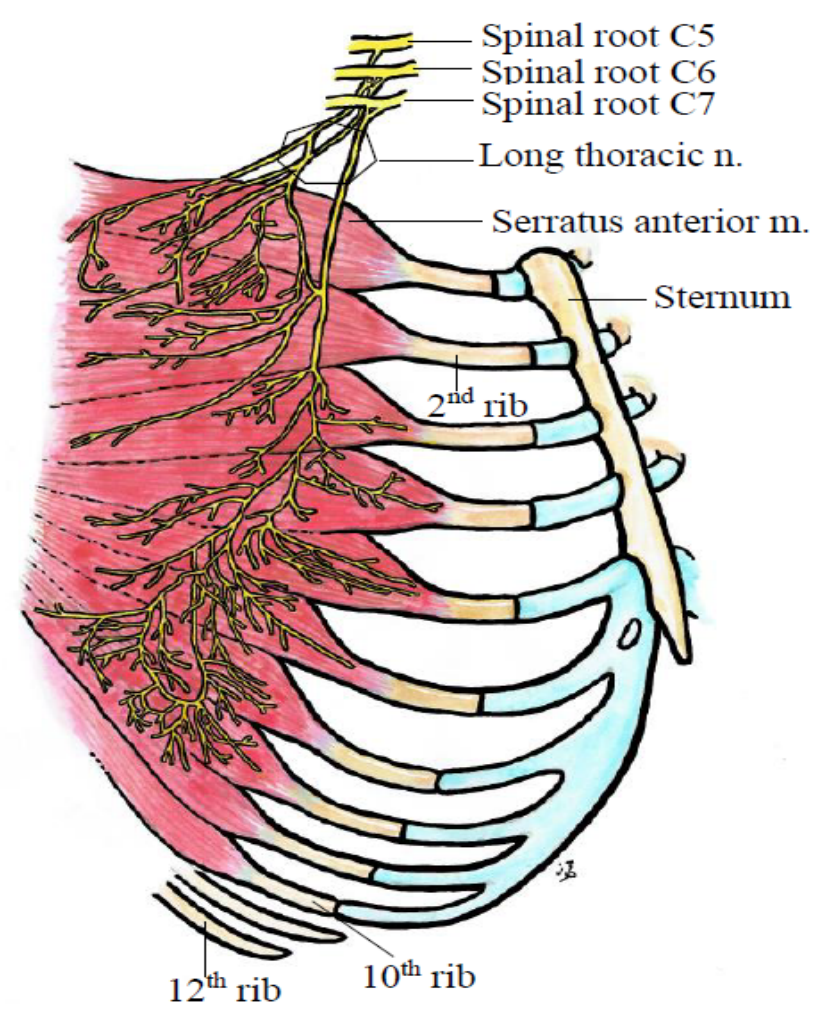

Figure 20. According to the findings of [78], branches of spinal roots C5, C6, C7 innervate the inspiratory serratus anterior muscles in humans. Refer also to Table A9. This figure was hand-painted by author PCWF.

in Table A10 and Table A11) are: (i) The fibers of the internal costal muscles that are aligned obliquely downward and backward in a rib-to-rib manner, and their contraction helps to lower the rib cage, decreasing the chest volume (Figure 15 and Figure 16). (ii) The internal oblique muscles; (iii) The external oblique muscles (shown in Figure 21, with (ii) hidden behind). (iv) Rectus abdominis (Figure 21). (v) Transverse abdominis (hidden behind in Figure 21). (vi) Latissimus muscles (Figure 22, and partly in Figure 22); (vii) Serratus posterior inferior (Figure 22). The muscles (ii)-(v) function in a similar way-pushing the internal organs into the space created by the relaxation of the diaphragm. The latissimus muscle, being the largest piece of muscle at the back, originates lower down in several sites as stated in Table A11, and it inserts high up into the bicipital groove of the humerus bone. As indicated by the three arrows in Figure 22, contractions of this piece of muscles generate three directional forces. One force plays the synergistic role in extension (by the posterior fibers) and lateral flexion (by the anterior fibers) of the lumbar spine; the former action helps in inspiration because the ribcage is enlarged, and the latter two forces help in forced expiration. The latissimus muscle thus works as a muscle of forced expiration (posterior fibers) and an accessory muscle of inspiration (superior fibers) [77] [79]. The serratus posterior inferior was thought to be involved in pulling the ribcage down during forced expiration. 


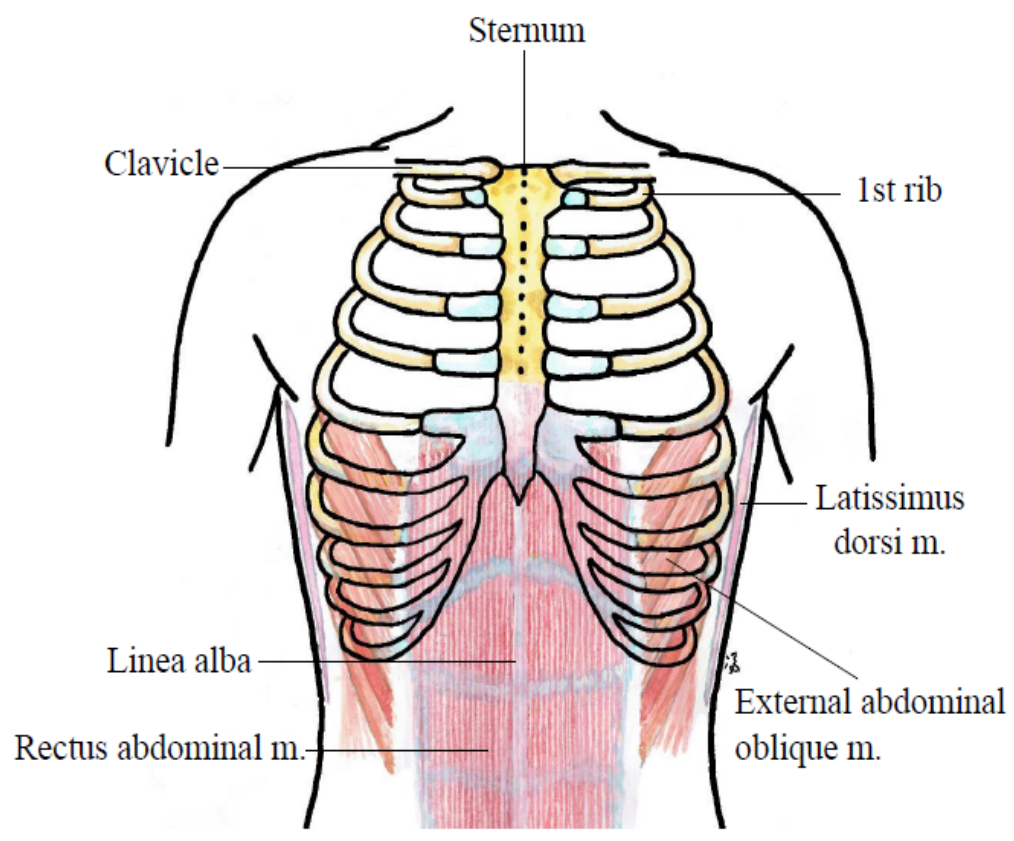

Figure 21. The external abdominal oblique muscle, the rectus abdominal muscle and a part of the latissimus, are expiration muscles. Nerves innervated are listed in Table A10. This figure was hand-painted by author PCWF.

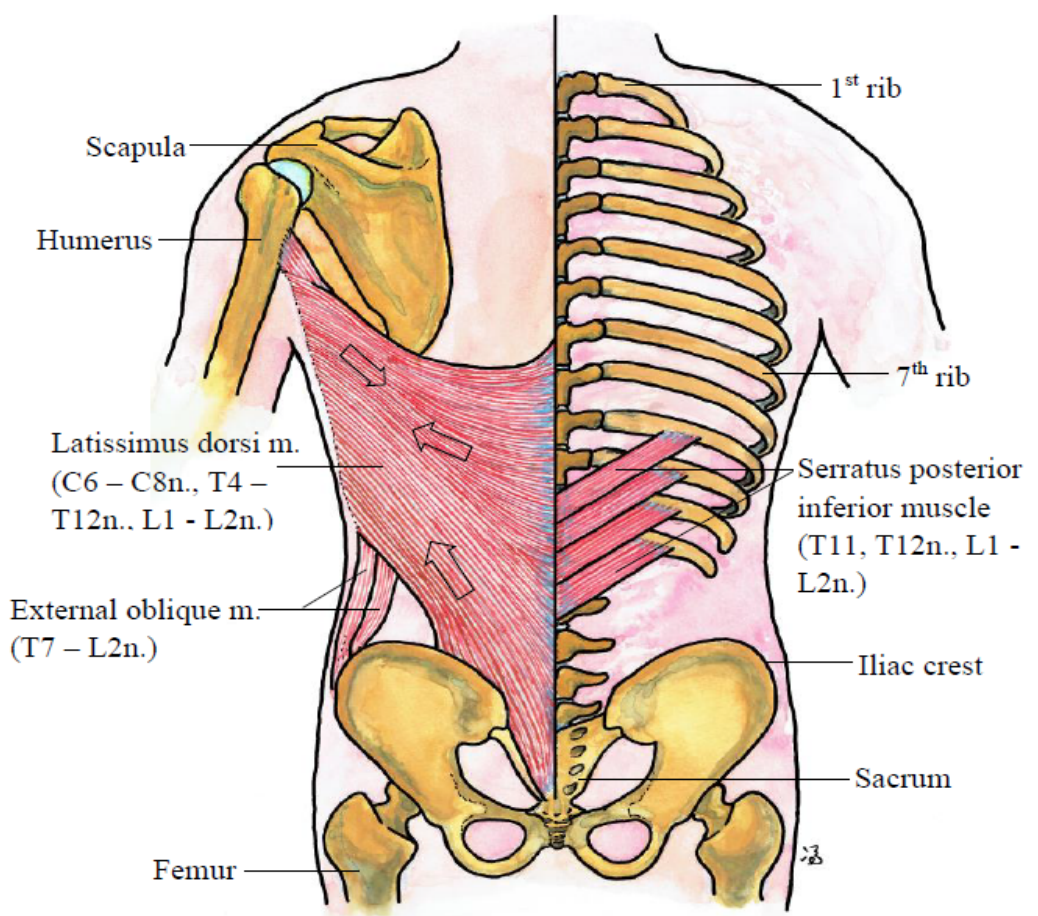

Figure 22. The latissimus dorsi muscle is the largest piece of muscle at the back. The three arrows indicate the directions of contractions. The downward arrow implies that the superior part of this muscle is inspiratory, whereas the two lower arrows imply that the middle part and the caudal part of the muscle play expiration roles [77]. The serratus posterior inferior muscle is also a set of expiratory muscles. The nerves innervating these muscles are labelled. Refer also to Table A10 and Table A11. This figure was hand-painted by author PCWF. 


\section{The Lung Sinew Channel from Upper Arm to the Thumb-Analysis of the Compartments of Muscles in Western Medicine Tells the Same Story}

Recent anatomy analysis with frozen sections (with $2 \mathrm{~mm}$ thickness) of two cadavers provides relatively more detailed structure variation along the limbs and the body trunk [80]. Most of the acupoints were found to be within layers of connective tissues [81] [82]. A meridian was suggested to be along the routes "in between muscles" in TCM classics [83]. As explained in sections (3) and (4) with Figure 3, 4 in [18], a peripheral nerve, using the median nerve as example, contains fascicles (smaller nerve fibers) of both sensory and motor neurons. Different fascicles fibers exit the main nerve fiber at different places and innervate different muscles. The muscles innervated by these fascicles were labelled in the cross-section of the median nerve at the elbow site in Figure 4 of [18]. Referring to Figure 23 below (based on the information of [49] [80] [84]), which shows the cross-section of the forearm where the acupoint LU-5 is situated [15], there are 4 compartments in the muscles whose boundary are relatively stiff connective tissue layers. A main nerve, together with the associated blood vessels, is always protected by a set of stiff layers of connective tissue for obvious reasons. As

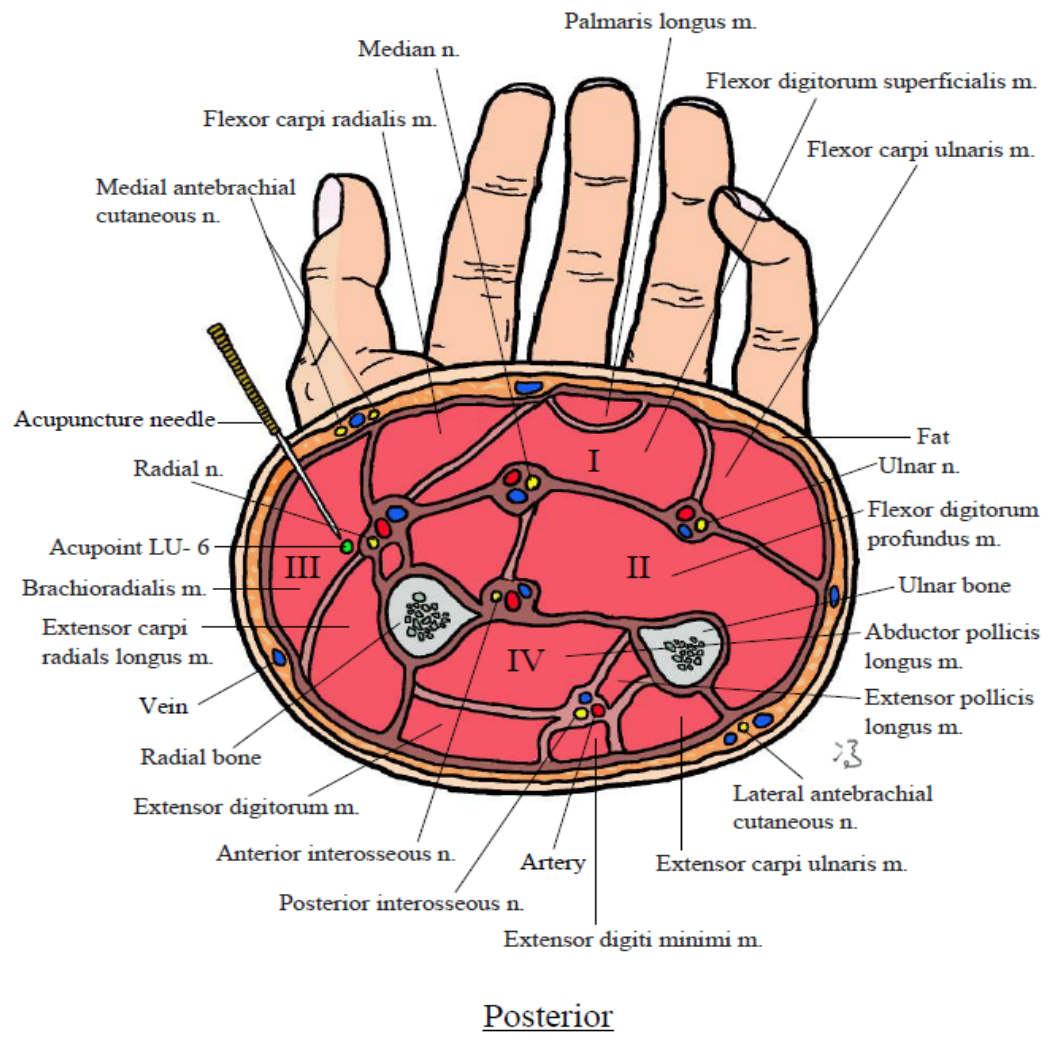

Figure 23. Cross-section of the forearm at the site of acupoint LU-5. There are four compartments bounded by stiff connective tissue layers marked as I, II, III, IV. The nerves and muscles in these compartments are labelled. The Lung Sinew Channel is within compartment III in this part of the forearm. Symbols: $\mathrm{n} .=$ nerve; $\mathrm{m}$. = muscle. This figure was hand-painted by author PCWF. 
the meridians are closely related to main nerves in sites [17] [18], the acupoint of a meridian at a cross-section is therefore more closely associated with one compartment. In view of the analysis of the exertional compartment syndrome in [15], bridging classical TCM conception and modern anatomical structure analysis points to the fact that compartment III (Figure 23) pertains to the Lung and Large Intestine Sinew Channels. The Heart, Small Intestine, and Pericadium Sinew Channels are within compartments II and IV. The Sanjiao Sinew Channel is associated with compartment I. Such divisions are true only in the forearm region, as the muscles have different shapes and lengths in different parts of the limb. Compartments merge, and so do the Sinew Channels, with some muscles serving more than one Sinew Channel at certain places. This is understandable, as the pulley systems are intermingled; one fulcrum may serve more than one pulley system for different types of locomotion. The muscles of the Lung Sinew Channel from the shoulder to the thumb have been mentioned in recent literature, and we only present Figures 24-27 to show their positions, with relevant anatomical particulars briefly listed in Table A12 and Table A13 (see e.g. particular of brachialis muscle [85]). Clearly, from the exertional compression syndrome as a typical example, the muscles in each compartment must be maintained in a healthy state with proper interstitial flow through the connective tissues, soft or tough, to keep nerves, blood vessels healthy and in turn the muscles themselves. Therefore, in TCM language, the members (muscles) in the arm-hand region of the Lung Sinew Channel do not participate directly in enhancing the function of respiration, but they keep the nerves (plus blood vessels)

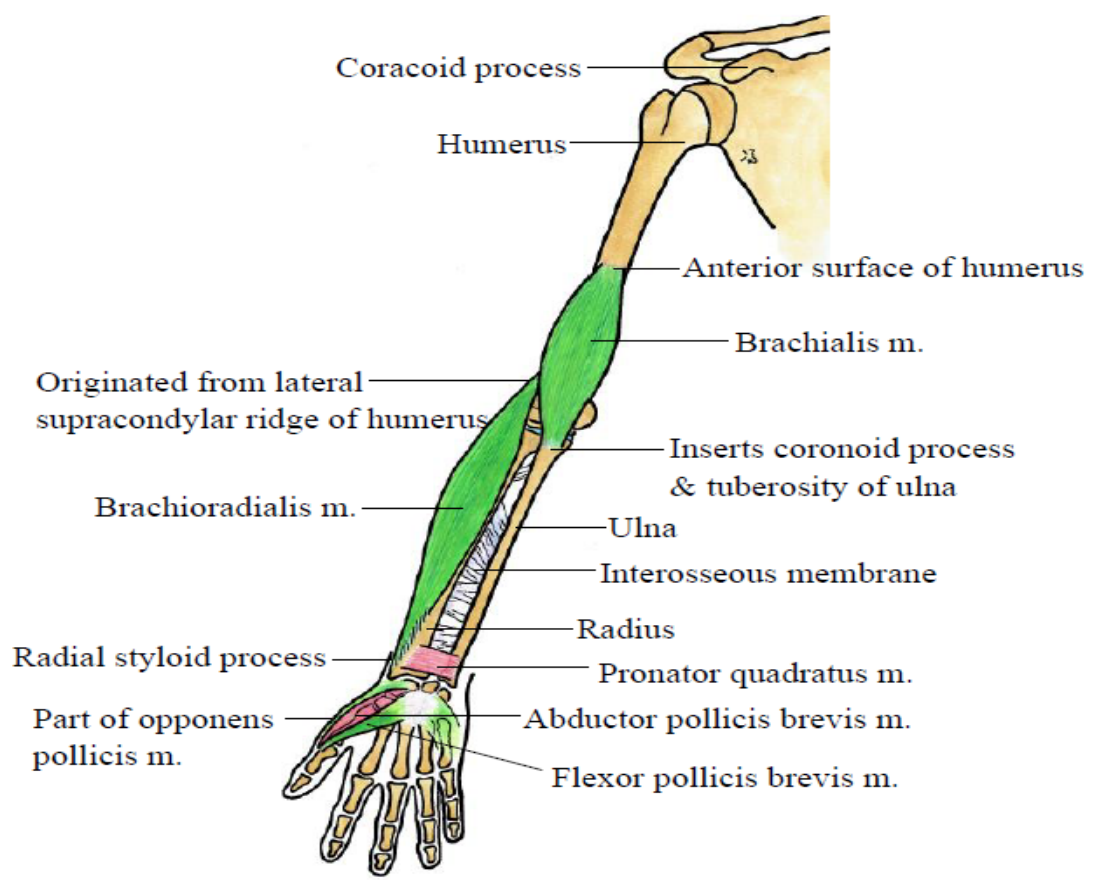

Figure 24. Anterior view of the brachialis [85], brachioadialis, abductor pollicis brevis, flexor pollicis brevis, and opponens pollicis muscles. See also Table A12. This figure was hand-painted by author PCWF. 


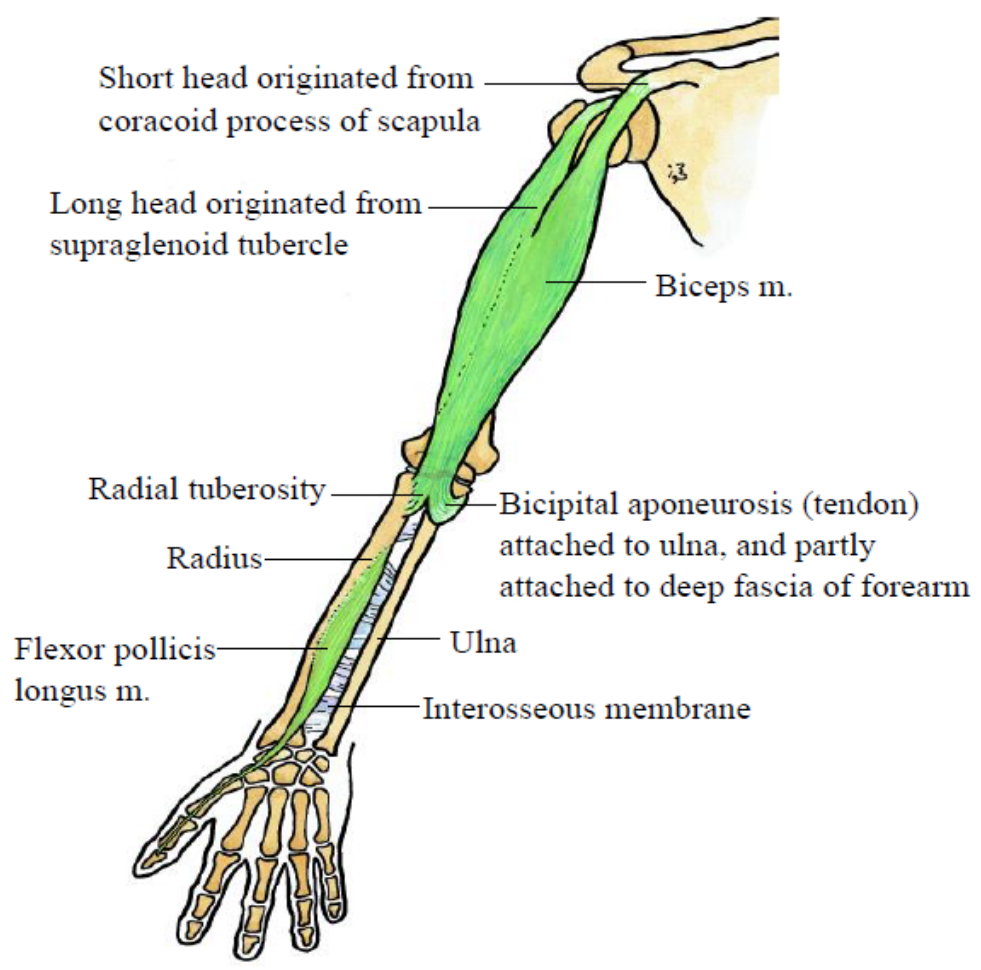

Figure 25. Anterior view of biceps and flexor pollicis longus muscles which affect the contractions and relaxation of the pectoralis major and minor muscles that are respiratory (see Figure 18). See also Table A12. This figure was hand-painted by author PCWF.

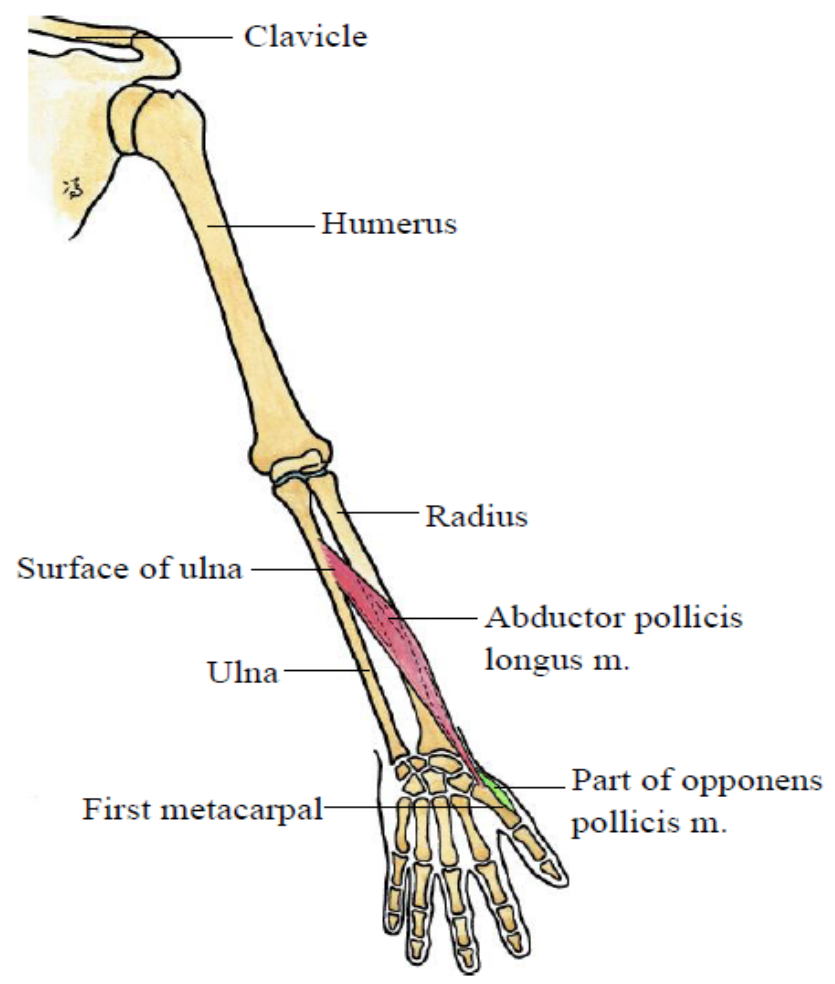

Figure 26. Posterior view of abductor pollicis longus muscle which abducts the thumb. See also Table A13. This figure was hand-painted by author PCWF. 


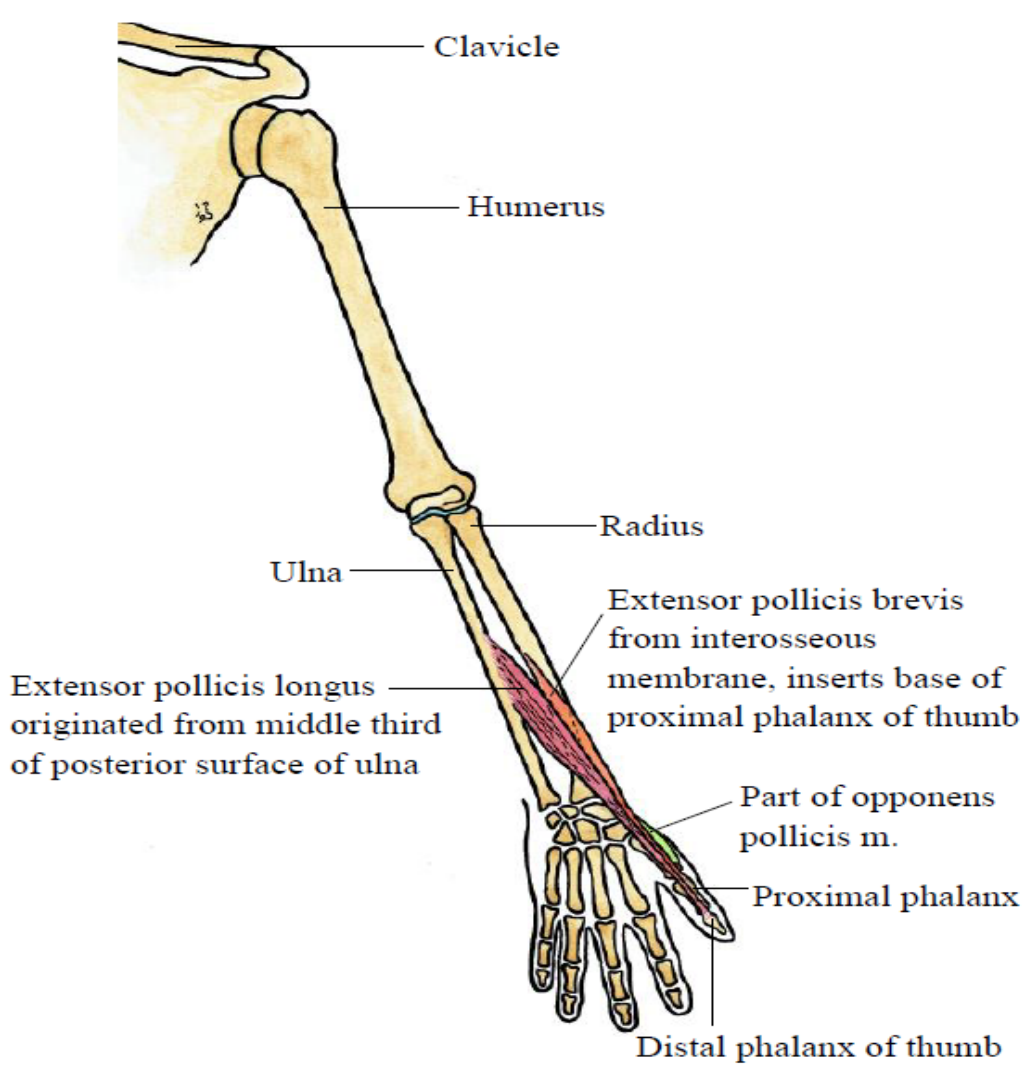

Figure 27. Posterior view of extensor pollicis longus and brevis muscles which extend the thumb. See also Table A13. This figure was hand-painted by author PCWF.

in good state. These nerves rearrange themselves as the brachial plexus enter the dorsal horns of spinal cords C5-T1, playing important physiological roles in response to external stimuli, resulting in somatosensory reflexes that are related to respiration, as explained in [20]. Intentional nociceptive stimulation as therapeutic measures (TCM modalities) send signals to initiate the somatosensory reflexes at the brain cortex and also the spinal cord through these nerves when necessary; the processes of these reflexes will be summarised in a later section. The muscles corresponding to members of the Lung Sinew Channel are already mentioned in more recent TCM literature (see Table 1 in [15]). We therefore leave Figures 24-27, plus Table A12 and Table A13 as a source of discussion in a later section and references for the readers.

\section{Evidence of the "Collateral Neurons" Linking Different Segments of the Spinal Cord, in Both the Grey and White Matters}

It was established decades again that inter-neurons on the cross-section of a spinal cord link up different laminae. In fact the peripheral input to the dorsal horn of the grey matter of the spinal cord can send neuronal signals to the ventral horn and hence motor neurons which innervate muscles and organs; these interneurons also "crossover" to the contralateral part of the cord to join as- 
cending tracts (such as the well-known spinothalamic tract along the white matter) through the white matter of a number of spinal cords to the brain. From the brain, there are also descending tracts which lead to mobilization of motoneurons at the ventral horns of spinal cords-these motoneurons innervate internal organs and skeletal muscles. How do the inter-neurons of one spinal cord contact other inter-neurons of the adjacent (up or down) spinal cords is certainly an important issue to understand the neural network of which the spinal cords play key roles. In particular, do interneurons also project through grey matter of consecutive spinal cords?

Experimentally, using animal models, a popular technique was to inject Dimidino Yellow Dihydrochloride (DY) unilaterally to the grey and white matter of a certain spinal cord (such as T2 in [86] [87]; see also the work using macaques models in [88]) and count the labelled inter-neurons in the spinal cord and parts of the brain and brain stem. True Blue (TB) was also injected unilaterally in domains of the brain including thalamus, dorsal midbrain, dorsal medulla. This double-labelling technique allowed tracing the ascending and descending interneurons that join up adjacent segments of the spinal cord and parts of the brain. The rat, cat and monkey models were employed, leading to the discovery of the established tracts such as the spinothalamic tracts, corticospinal tracts, bulbospinal tracts (see examples of [17] [18]). The number of inter-neurons in a lamina or grey matter was found to decrease gradually (from $\sim 20 \%-30 \%$ to $\sim$ a few $\%$ ) along an ascending or descending tract, as expected. Note that these known tracts are along the white matter. There are also inter-neurons connecting the same lamina in the grey matter between two vertically adjacent spinal segments.

In another early investigation using the cat model [89], recording the electrical activities of cervical inspiratory neurons followed by antidromic mapping, it was reported that 66 out of 70 upper cervical inspiratory neurons projected down to T9, T10, T12, L1, L2, even L3. It means that at least in the cat, axons from propriospinal respiratory neurons in the rostral cervical cords could project to the vicinity of the phrenic nerve and thoracic inspiratory external intercostal motoneurons; some reached the lumbar section. In other words, the result suggested that when the nose/mouth breaths in air (by the action of the diaphragm first), messages would be sent to the relevant respiratory muscles stated. The results of the example studies mentioned in this section also provide (indirect) evidence that when a nociceptive message (sent off by acupuncture, say) reached the dorsal horn of the associated spinal cord, the message could also be sent by the Lissauer tract at the tip of the dorsal horn upwards to other cervical cords. The resulting plausible biomedical consequence is the sensitization of the "filtering process" on the incoming air (Section (3)). Moreover, in case the stated "intrinsic natural" communication from the cervical cords to the thoracic cords is weakened, simulating the sympathetic nerves (via TCM methods) directly to mobilize the supporting inspiratory muscles is a way to enforce respiration, an issue to be pursued in later sections. 


\section{Stimulation of the Classical Lung Meridian Leads to Enhancement of Respiration via Mobilization of the Diaphragm, Intercostal Muscles and Scalene Muscles by Somatosensory Reflexes from the Brain Cortex and the Spinal Cords}

Suppose acupuncture is applied at an acupoint at the right hand or arm domain of the Lung Meridian. The A-delta neuron detects the nociceptive signal at the connective tissue and sends the signal through the light green nerve with an upward arrow at the left side, in Figure 28. The axon enters the dorsal horn and synapses an interneuron (pink) at about lamina V. This neuron follows the spinothalamic tract and projects upward towards the thalamus in the way depicted in Figure 8 of [18]; this tract is not shown here due to shortage of space. This interneuron is the "second order" neuron and synapses the "third order" neuron at the ventral posterior lateral nucleus of the thalamus. The third order neuron synapses a pyramidal neuron at the somatosensory cortex (see Figures 11 and 12 of [17]). After reflex, the downward efferent neuron from the primary motor cortex (or the supplementary or premotor cortex) follows the anterior corticospinal

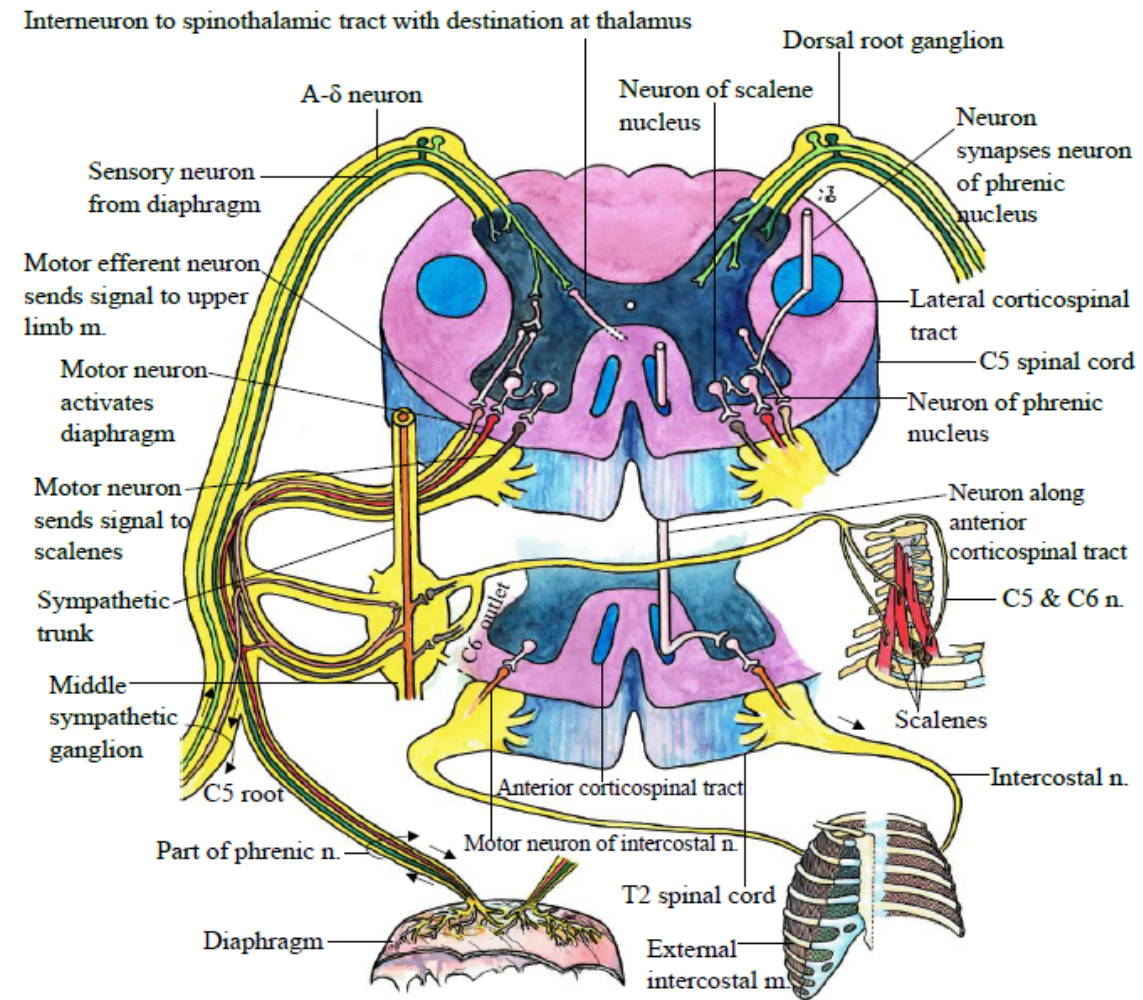

Figure 28. Schematic representation of the neurons participating in somatosensory reflex and spinal segmental reflex at the spinal C5 and T2 levels. These two reflexes lead to the mobilization of the diaphragm, intercostal muscles, and the scale muscles. Notice that the phrenic nerve has sensory afferents which send sensory inputs to the dorsal horns of C3-C5 intrinsically; we consider such inputs play a similar role as simulation by TCM modalities in the regulation of the diaphragm and scalene muscles' functions. For other details, see text. This figure was hand-painted by author PCWF. 
tract (pink). Depending on the site of stimulus, the tract can be within the elliptical domain which is painted in bright blue. The neuron following this tract has an axon projecting an interneuron at the tip of the ventral horn of the T2 spinal cord (the second spinal cord, partly shown in this figure). The pink interneuron synapses the motoneuron (orange) in the intercostal neve (which includes many motoneurons and painted in yellow). The left intercostal nerve (in the figure, it is on the right side because the diagram is viewed at the ventral direction) innervates the external intercostal muscle (see Figure 15) of second inter-rib space. There is a similar arrangement if acupuncture is applied to the left hand. The action activates the EIM which works in synchrony with the contraction of the diaphragm. If an arm acupoint is stimulated, the reflex follows another path called the lateral corticospinal tract (bright blue circle) on the right. Neuron along this tract has an axon projecting to an interneuron at the "phrenic nucleus" (actually it is a group of neurons passing through C3-C5 in humans). So far, we know that the nucleus is an organization center at the "local site" for breathing. The activated interneuron synapses a motoneuron (bright red) which is one of the neurons of the phrenic nerve that innervates the key muscle-diaphragm. The actual tract of the motor neuron can be found on the left side (schematically) - with a relay system in the middle cervical sympathetic ganglion. Since the upper spinal cord in Figure 28 is C5 and the phrenic nerve is also contributed by $\mathrm{C} 3-\mathrm{C} 4$, there are inputs from these other spinal cords too.

Moreover, we put forward the notion that in humans a neuron in the phrenic nucleus also synapses an interneuron in the "scalene nucleus", a group of interneurons passing through $\mathrm{C} 3-\mathrm{C} 7$ in the rat. We hypothesize that such a nucleus also exists in a human, since such a nucleus was experimentally confirmed very recently to exist in the developing rat, and neurons of these two nuclei are in resonance in firing electrical signals during respiration [19]. Assuming such hypothesis to be valid, the bright red motoneuron forms a part of the nerve, after relaying at the middle sympathetic ganglion, to innervate the scalene muscles, as shown on the right side of the diagram. Since roots C5 and C6 enter the middle sympathetic ganglion, there is an outlet from that ganglion to join the nerve projecting to the three scalene muscles. As the scalene muscles have been shown to be intrinsic during the early phase of inspiration (see Section (7)), our hypothesis is strongly supported. The light brown motoneurons at the ventral horns are simply motoneurons that project back to the muscles of the upper limb responding to the nociceptive stimulus.

The spinal segmental reflex is executed by the branch of the bright green sensory neuron (on the right side of the subject for right side stimulation) which synapses an interneurons (hypothesized to have relays), that eventually leads to the mobilization of motoneurons in the phrenic nerve, without passing through the brain cortex. The existence of these two reflex processes has been discussed in detail in [18]. Notice that in Figure 28, a sensory nerve of the diaphragm sends signals to the dorsal horns of $\mathrm{C} 3-\mathrm{C} 5$ to regulate the activity of the phrenic nucleus, a process discussed already in [18]. 
The sympathetic stimulation of the genioglossus muscle of the tongue, which gives a lot of trouble to sleep apnea patients is still under research.

There are many studies reporting on the efficacy of stimulating the Lung acupoints that leads to the relief of respiration disorders. Just in passing, we note that a clinical study with two asthma patients groups was carried out in the report of Han et al. [90]: (i) acupuncture group of 288 patients who received acupuncture at LU-10 (Yuji); (ii) inhaler group of 289 patients who inhaled Salbutamol aerosol, a commonly used inhaler for asthma patients. The asthma symptom was reported to be relieved immediately in group (i) [90].

\section{The Overall Picture of the Lung Meridian, the Divergent Channel, the Sinew Channel and the Luo-Connecting Channel}

\subsection{The Updated Lung Meridian}

We have explained in detail in three papers that the main purpose of stimulating the acupoints of the Lung Meridian is to trigger off somatosensory reflex at the brain cortex (contralateral) and spinal segmental reflex (ipsilateral). The efferent nerves project from the motor cortex downward along the anterior and lateral corticospinal tracts activate the diaphragm, the intercostal muscles, and the scalene muscles. The classical Lung Meridian has well defined purposes along this regard. However, air only comes into the nose (or mouth in pathological states). If the Lung Meridian is to be specific mainly in respiration function, it should include acupoints and regulate the inflow air through the nose. We consider that Bitong (M-HN-14) and Yingxiang (LI-20) should be acupoints of the Lung Meridian based on the description in Section (3) and the evidence of clinical practice that acupuncturing Yingxiang would provide credit to fluent inflow of air and bring in relief of rhinitis [33] [34] [35] in subjects and in rat models including the biochemical interaction induced by the nerve stimulation [91]. In Figure 29 we therefore painted the Lung Meridian route up to the wing of the nose region to include these two points. We might tentatively call them LUSP-1 and LUSP-2 to represent Bitong and Yingxiang respectively. Moreover, the experiment described in Section (11) indicates that the genioglossus muscle is also an intrinsic muscle that participates in the inspiration process only slightly after the diaphragm in time, it is an important respiratory muscle, which is innervated by the ansa cervicalis (from the $\mathrm{C} 1-\mathrm{C} 3 / \mathrm{C} 4$ roots) plus the hypoglossal nerve $(\mathrm{CN}$ XII) (Section (4), Figure 4). The sympathetic neurons have a long (longitudinal) distance of influence and stimulation at the C5 root can send signals high up even to the $\mathrm{C} 1$ root (Section (14)), but what is the percentage of the intensity of signal that can reach $\mathrm{C} 1$ or $\mathrm{C} 2$ is yet under research.

Much of the maintenance of the activity of the genioglossus muscle depends on the "orders" reaching there from the higher brain. So far, we have not found any acupoint to excite the genioglossus muscle by acupuncture. Note that the inert state of the genioglossus muscle during sleep is one main cause of sleep apnea, and the research on finding the modality to activate this muscle by non-invasive 


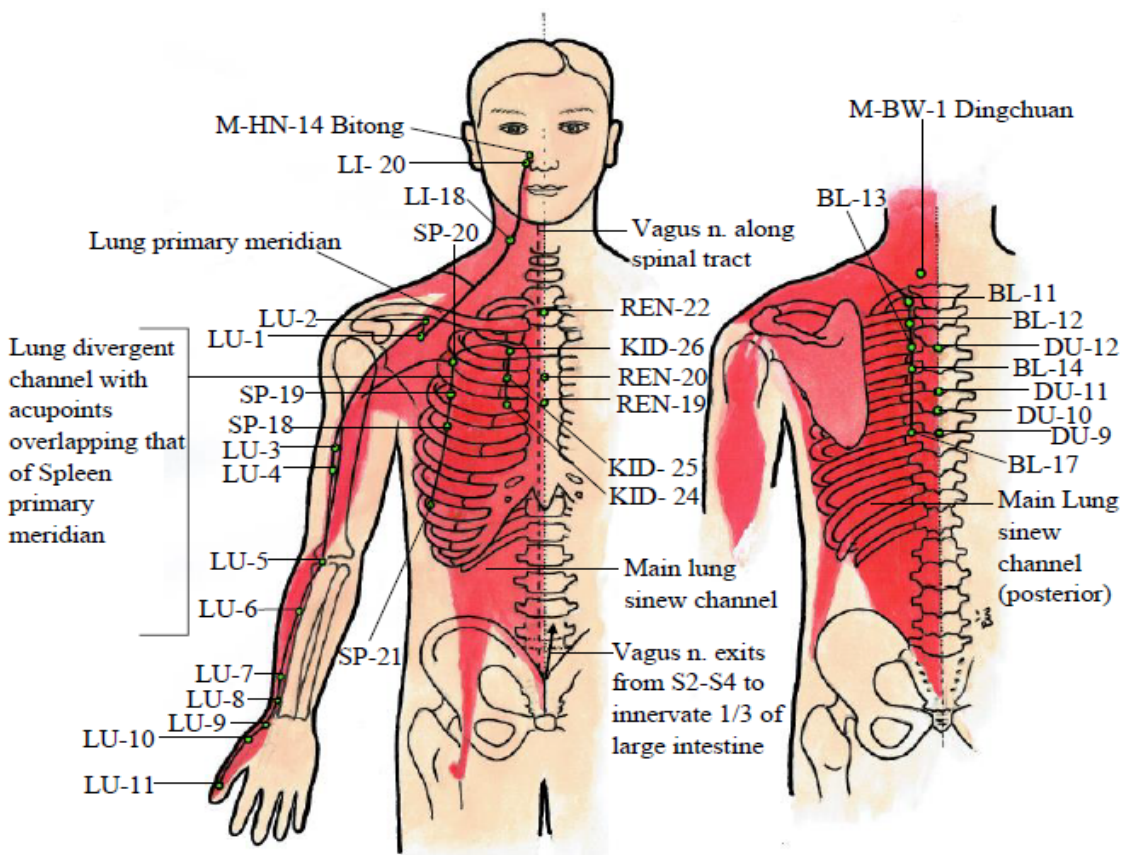

Figure 29. The proposed updated Lung meridian has acupoints from LU-11 to Bitong (M-HN14). The Lung Sinew channel covers a large number of muscles represented in the red domains, with details already described in previous sections, plus some features listed in the tables of the Appendix. The antomical boundary of one or more Sinew Channels is layers of stiff connective tissues to enable various types of locomotion of the pulleys which are built of muscles, bones, tendons and ligaments. Interstitial fluid flow must be potent within each Sinew channel, the failing of which would lead to disease such as the exertional compartment syndrome [15]. The Lung Divegent Channel has five branches, passing through the following acupoints so far known: (i) SP-20 to SP-18; (ii) KID-26 to KID-24; (iii) REN-22, REN-20, REN-19; (iv) BL-11 to BL-14, BL-17; (v) M-BW-1, DU-12 to DU-9. Since members of the Divergent Channel are proposed to be acupoints that can activate the respiration muscles, the above list is not exclusive because there are some other muscles involed in breathing to lessor degrees. The lines joing branches (iii), (iv) and (v) are not drawn in order not to mask the other important lines pertianing to the other channels. The thin dotted line where RN-22 is marked, represents the longtitudinal central line. The thicker dotted line of the left side of the central line represents schematically the route of the right parasympathetic vagus nerve (on one side) that passes through the grey/white matter of the spinal cord from the brain stem (nucleus ambiguus) to the sacrum; this nerve exits from S2 to S4 segments to innervate the last two-third of the large intestine and retum (shcematically represented by the arrow which joins Figure 13 of [17]). We apprehend that this length of the vagus nerve forms the Luo-connecting Channel not being specified in TCM classics. There are 34 acupoints marked. There are no new acupoints, but 22 of them are overlapping with other meridians, and two are extraordinary acupoints. The figure was hand-painted by author PCWF.

method is important. In case the inspiration muscles (e.g. the scalene muscles) are weak, a natural response of a human is to use the sternocleidomastoid muscle to raise the rib cage. The classical Futu (LI-18), influencing the C2-C4 roots is often used to enhance such voluntary inspiration; examples are found in [57] [58] [59]. Note that branches of the C2-C4 nerves also innervate the troublesome genioglossus muscle in senior or obese subjects. We propose that LI-18 is also a 
Lung acupoint (called LUPS-3, duplicating LI-18) and painted in Figure 29; experimental work is called for to investigate whether this acupoint may activate the normal firing action of the genioglossus muscle during the sleep state.

\subsection{The Main Function of the Lung Divergent Channel (LUDC)}

The route of the Lung Divergent Channel has not been well defined in TCM literature. All we learn from the TCM classics is that there is a side branch of LUM emerging from a site in the upper arm, near the shoulder, going to the ventral side of the body trunk. There was no acupoint identified and the function of this route is not defined either. Based on the understanding that the Lung Meridian and other Channels bearing the name Lung is to be related to the function of respiration, we propose that the LUDC has several branches, containing all points that would activate the members of the Sinew Channel (respiratory muscles). We put in the sites of the classical Tianxi (SP-18), Xiongxiang (SP-19), Zhourong (SP-20), Dabao (SP-21) (see Figure 4 of [92]). The first three pertains to intercostal nerves of the external intercostal muscles of the $4^{\text {th }}, 3^{\text {rd }}, 2^{\text {nd }}$ inter-rib spaces respectively, and SP- 21 is related to the $7^{\text {th }}$ inter-rib space and the phrenic nerve that innervates the diaphragm. Note that the right phrenic nerve, after passing laterally to the right atrium and right ventricle, descends through the vena cava hiatus in the diaphragmatic opening at the level of T8 [93]. In view of the discussion in Sections (9) and (10), stimulating SP-18, SP-19, SP-20 amounts to mobilizing several sets of intercostal nerves to enhance respiration. We consider that stimulating SP-21 activates the right phrenic nerve at the T8 level just stated. The left phrenic nerve does not descend in the same way, and SP-21 is not bilateral.

Another branch of the LUDC is a route through Lingxu (KID-24), Shengcang (KID-25), Yuzhong (KID-26). Stimulating these three points would activate the $3^{\text {rd }}, 2^{\text {nd }}, 1^{\text {st }}$ inter-rib spaces (and the pectoralis major muscle) respectively of the inspiratory parasternal muscles with relatively high advantage (green regions in Figure 16 and sites marked in Figure 17 from the top view). These acupoints have been used also to treat lung diseases (see Figure 3 of [92]).

In the third branch, we have Tiantu (REN-22) which activates the C8-T1 nerve, sending message to the root of the lungs (see Figure 13), and has been reported to be one of the principle points in treating COPD [94]. An earlier study using REN-22 indicated efficacy in treating bronchial asthma [95]. The acupoints Zigong (REN-19) and Yutang (REN-18) are in the $2^{\text {nd }}$ and $3^{\text {rd }}$ inter-rib spaces respectively, and their stimulation leads to the contraction of the parasternal inspiration muscles with high mechanical advantage, as explained before. These two points were considered to be among the principal ones to treat chronic bronchial asthma in subjects [96].

In the fourth branch (on the dorsal side, right side of Figure 29), we have the acupoints Dazhu (BL-11), Fengmen (BL-12), Feishu (BL-13), Jueyinshu (BL-14) and Geshu (BL-17); these points are 1.5 cun on both sides of the central line at 
the back. The first four acupoints mentioned above are at the $1^{\text {st }}, 2^{\text {nd }}, 3^{\text {rd }}$, and $4^{\text {th }}$ inter-rib spaces respectively; whereas BL-17 is at the $7^{\text {th }}$ inter-rib space. Since the MA of the EIM is high at the dorsal region, stimulating the first four points initiate the contraction of the external (inspiratory) intercostal muscles (see Figure 15). In clinical practice, there are many examples of application of these points to treat respiratory disorders including asthma, bronchial inflammation, COPD in patients; see e.g. [59] [97] [98]. Applying acupuncture on some of the stated four $\mathrm{BL}$ acupoints in the investigation of the efficacy on smoke-induced COPD in the rat model was reported in [99]. Stimulating BL-17 amounts to activating the right phrenic nerve, and thus the diaphragm at the T8 level as explained above relating to the point SP-21. BL-17 is called a "polar point" in TCM; it was even used with efficacy to treat persistent hiccup in lung and heart transplant patients [100].

It is interesting to note that in a very recent investigation [101], a comparison on the distribution of mechanical or pressing sensitive acupoints on the body surface between bronchial asthma (BA) patients (70) and healthy normal (70). The pressing sensitive acupoints were examined with the finger and the representative index numbers were marked on the nerve distribution graph, keeping track also of the routes of the TCM meridians [101]. It was found that the occurrence of pressing sensitive points was much higher (64/70) in the BA group as compared to the healthy normal group (11/70) with statistical significance < 0.01 . The pressing sensitive points were correlated in sites mainly with the Lung, Urinary Bladder and Large Intestine Meridians. The most frequently occurring pressing sensitive acupoints for the BA patients were BL-13, BL-14, BL-15. These points were distributed in the neighbourhood of the $\mathrm{C} 4$, C6 and T1-T6 roots. We consider that sensitization of an acupoint is correlated with the pathological state of the organ innervated by the nerve that is associated with the sensitized acupoint. The phenomenon is a natural call for treatment like the sore feeling felt at a trigger point when certain muscle is overused.

The results of [101] are consistent with that based on analysis of Sections (8), (10), this section and our previous works [17] and [18], based on neurophysiology and kinesiology.

The fifth branch of the divergent Channel can be considered to begin with the acupoint Dingchuan (M-BW-1), which is in the neighbourhood of the C7, C8 nerves, the branches of which innervate the posterior scalene muscle (see Figure 11); this muscle pulls the second rib up, and enhances inspiration quickly. That is the reason why M-BW-1 is often used, together with BL-13, to treat asthma. Stimulation applied to Zhiyang (DU-9), Lingtai (DU-10), Shendao (DU-11), Shenzhu (DU-12) amounts to stimulating the external intercostal muscles in the $7^{\text {th }}, 6^{\text {th }}, 5^{\text {th }}$ and $3^{\text {rd }}$ inter-rib spaces. The effect is similar to activating the corresponding BL acupoints in enhancing inspiration (see Figure 17). Note that reviewing the content of over 200 publications in the years 1981-1998, the authors in [102] reported that to treat bronchial asthma, acupoints of a mixture of meri- 
dians have been chosen: LU, REN, DU, BL, ST, LI. The acupoints were mainly in the upper abdominal and dorsal abdominal domains, consistent to the acupoints of the Divergent Channels just proposed.

In view of the analysis in this section, we propose a definition for the Lung Divergent Channel (LUDC) for the first time: it is a collection of sub-channels that include acupoints that would lead to the activation of respiratory muscles, or members of the Lung Sinew Channel. Here we have listed five branches, and the action can be obtained by stimulating the sympathetic nerves at local points directly. These acupoints can be overlapping with those of other meridians, as sympathetic nerves have sub-branches that participate in other physiological functions other than activating the respiration muscles.

We would also remark that stimulating many of the acupoints associated with the thoracic nerves T1-T4/T5 (hence the intercostal muscles) also mobilize the trachea and air tracts inside the lungs (see Section 8 and Figure 13).

\subsection{One Major Function of the Lung Sinew Channel (LUSC)}

Within the context of respiratory function, the Lung Sinew Channel consists of all the respiratory muscles (together with their tendons joining the associated bones). A large part of this paper has been devoted to specifications of these members, with 13 tables in the Appendix, giving the origin, insertion, nerves innervation and the respiratory function. The general locomotion functions are not included. Note that the sternocleidomastoid and trapezius muscles are established to be innervated by the sympathetic nerves as well as the CN XI nerve (Figure 12), while some of the other muscles could be innervated by the parasympathetic nerve with significant influence. Classically, it has been considered that the skeletal muscles are in general not much affected by the parasympathetic nerves. We need to wait for new results to ascertain whether the classical concept is true, as this topic is still on the line of frontier research. If there is new result, we will certainly fill in the gaps for other papers to follow in this series. We refer the readers to the figures and 13 tables in the Appendix for other details, in addition to the discussions presented in previous sections.

\subsection{Why Does the Lung Luo-Connecting Channel (LULCC) Exist?}

TCM classics do not leave us with much information of the LULCC. The only relevant statement is "the lung organ is connected to the large intestine", or that the lung organ is the "external organ" and the large intestine is the "internal organ". Such a statement made around 2000 years ago represents great wisdom at that time. Intuitively, we understand that when a person is in the fight or flight state, more blood must flow to the heart and lungs, so that the heart beats and respiration rates are both increased, in order to get more oxygen for the relevant muscles for action. Naturally, the digestive system must be shut down. In our previous work [17], we pointed out that the vagus nerve runs through the (extra-spinal) body trunk to innervate the stomach, the small intestine, and a por- 
tion of the large intestine (see Figure 13 of [17]). Normally the inferior mesenteric ganglion, on reception of inputs from the T10 and T11 roots (which innervate the small intestine and the upper one-third of the large intestine) "sends out" sympathetic nerve fibers to innervate the last two-third of the large intestine, causing it to execute rhythmic contractions when excretory material is in position.

The parasympathetic nerve from S2-S4 (through the pelvic plexus) must stop the action of the sympathetic nerve on the last two-third of the large intestine plus the rectum, during the state of fight or flight. Note that sympathetic and parasympathetic nerves also innervate the genital organ which needs both types of nerves during a sex act. Moreover, the L2 root is a relevant part of the locomotion-respiration coupling center/system, meaning that motion of the lower limbs is also sent back to the breathing centers at the brain stem, as explained in [18]. Locomotion, breathing, heart pumping action, and the large intestine must work in an intriguing, harmonious way for the survival of the host, and the vagus nerve plays an important role. In view of the above analysis, we define the LULCC to be a route for the parasympathetic nerve (the vagus) from the brain stem through the spinal cord to regulate the function of the large intestine.

\section{The Lung Meridian, Sinew, Divergent, Luo-Connecting Channels Work as One Single unit System to Serve Respiration}

The philosophy of TCM is funtional-based; in this case the Lung Meridian and Channels all serve one major purpose of keeping homeostasis of respiration, without prejudice in serving other physiological functions. The proposed updated Lung Meridian with acupoints from LU-11 to M-HN-14 is indicated in Figure 29. Three already known acupoints (LI-18, LI-20, M-HN-14) are added because we cannot find any reason to reject acupoints that can influence the initiation of respiration-inflow of air through the nose. LI-20 is included because the stimulation of this point activates the sternocleidomastoid muscle which is an important muscle in voluntary inspiration.

Stimulation of acupoints can cause somatosensory reflexes at the brain cortex and the relevant spinal segments as summarised in Section (15), with the consequence of enhancing breathing. The Lung Sinew Channel is a collection of large number of muscles represented in the red domains in Figure 29, with details already described in previous sections. The muscles of the hand-arm region "embrace" the main nerves that are closely related in sites to the Lung Meridian. Healthy conditions of these muslces ensure good communication of the reflexes mentioned.

Other muscles of the Lung Sinew Channels are directly responsible for inspiration and expiration for the three types of breathing described in Section (2), and these muscles are described in Sections (3), (4), (5), (7), (8), (9), (12) and (13), with some more information presented in the Appendix. Moreover, the 
Lung Sinew Channel is composed of a number of pulley systems built of muscles (with associated tendons and ligaments) to provide body motions as another major function [15]. The antomical boundary of one or more Sinew Channels is stiff connective tissues, forming compartments (in anatomical terms), enabling the mobility of various types of motion of these pulleys. Note that the compartment petaining to the LUM is always adjacent to/or overlapping with that of the Large Intestine. Interstitial fluid flow must be fluent within each Sinew Channel, the failing of which would lead to disease such as the exertional compartment syndrome (see [5] and [15]). Interstitial fluid flows have been demonstrated to be correlated to several Meridians [6] [7] [8] [9].

The Lung Divegent Channel has five branches, which pass through the following acupoints so far known: (i) SP-20 to SP-18; (ii) KID-27 to KID-25; (iii) RN-22, RN-20, RN-19; (iv) BL-11 to BL-14, and BL-17; (v) M-BW-1, DU-12, DU-10, DU-9. Since members of the Lung Divergent Channel are acupoints that can activate the respiration muscles, the above list is not exclusive because there are many muscles involed in breathing; it suffices to discuss those in Figure 29 as crucial members. Since many acupoints in the Lung Divergent Channel are associated with the upper thoracic nerves, stimulating these acupoints also send signals to the trachea and the root of the lungs (Section 8 and Figure 13).

The Lung Luo-connecting Channel is the "internal route" of the vagus nerve which passes through the spinal cord from its origin (nucleus ambiguus) to the sacrum region. The vagus nerve exit from S2 to S4 segments to inhibit the mobility of the large intestine and rectum as a necessary physiological process in the state of fight or flight, for the survival of the host. The exit of this nerve is schematically represented by the arrow pointing slightly towards the right side (because the descending colon descends from the left side of a person) that joins Figure 13 of [17].

We thus observe that all the four Channels pertianing to the term "Lung" serves respiration as one major function.

\section{Limitations of this Investigation and Future Research}

We have included the influence of the parasympathetic nerves on the function of smooth muscles and other special muscles proper (such as that in the tongue) and in the internal organs (such as lungs and trachea). Skeletal muscles are taken to be influenced only by sympathetic muscles in classical neurophysiology. Recent results indicate that the cranial nerves could also innervate some skeletal muscles as reviewed briefly in Section (7) on the sternocleidomastoid and the trapezius muscles. The progress in research globally on similar innervation has been rather slow. We have to wait for more results from different groups before we can make concrete statements in this issue. The lung system in TCM includes, in addition to the main breathing function, also the function of the sweat gland. Whereas the sympatholysis is used to treat hyperhidrosis in the West [103], the direct relationship between sweating and lung function is not a simple 
issue, and is left for another paper.

Apart from inducing somatosensory reflexes, TCM nociceptive modalities also induce neurogenic inflammation at the site of application, leading to analgesic effects and secretion of peptides, hormones that can be useful in treating an organ disorder in general [2]. This aspect is very lengthy, including interaction of the sympathetic and parasympathetic nerves in the autonomic system just mentioned [104], and has not been considered in this study. There are numerous types of interneurons in the gey and white matters of the spinal cords. The classification of interneurons according to their functions is of prime importance in future medical research.

\section{Conclusions}

1) From the physiological point of view, we observe that the Lung Meridian, Sinew Channel, Divergent Channel and the Luo-connecting Channel serve the repsiration function as one single, closely related unit system. Failure of members of these channels would lead to pathological states. With such novel understanding, different combination therapies can be developed to treat respiration disorders, in particular, COPD. For example, a COPD patient can be weak in inspiration [74] [105] or expiration (which is well established), the acupoints related to inspiratory/expiration muscles are recommended to be chosen for TCM treatments.

2) We also wish to emphasize the importance of relaxing the connective tissues which form "interguments" of muscle units. If the muscles are not in the lowest energy state at rest due to improper distribution of mechanical tension of the fascia, the muscles cannot function well during respiration. A similar example has already been described in [5] on cardiac function. Some of the connective tisses are situated deep between muscles; massage may not be effective in these cases, and warm Bian stone therapy may be applicale.

3) Moreover, understanding the cross-talks between the sympathetic and parasympathetic nerves at the peripheral domains implies that there is communication between internal organs without going through tracts to the brain-this aspect is of great interests to both Western and Chinese Medicines, since in TCM, the several important internl organs are represented by symbols (metal, wood, water, fire, earth) and one organ is supposed to be "governed" by another one. We put forth the notion that understanding the stated cross-talks in the autonomic system would certainly provide evidence-based explanations of the relations between the prime internal organs without the influence of the brain. In the West, the new term "autonomic medicine" emerges recently [106]; in TCM, the corresponding updated concept is the interaction of the sympathetic and parasympathetic nerves involved in the four types of Channels discussed in this paper, and such analysis is an important future project.

4) We have not discovered new acupoints and we do not need to upset the labelling of the acupoints in TCM in general; we just add three known acupoints 
to be included in the Lung Meridian because breathing as the main function of the Lung System must include the nasal region and the neck. We have, for the first time, given a concrete apprehension of the Lung Divergent Channel (with branches covering overlapping acupoints of other Merdians) and Luo-connecting Channel, plus adding many new members of Lung Sinew Channel. This is the $8^{\text {th }}$ paper of the series [2] [3] [5] [14] [15] [17] [18].

\section{Acknowledgements}

We wish to thank Mr. Benjamin Fung, brother of author PCWF, for his unfailing support and assistance during the preparation of the manuscript. Depending on the settings of various journals, the author's name of Peter Chin Wan Fung could appear as P. Fung, or P.C. Fung, or P.C.W. Fung, or Peter C.W. Fung in other international papers. For journals in Chinese language, the author's name appears as 冯戬云. In journals written in English, the author's name of Regina Kit Chee Kong could appear as Kong Kit Chee. For journals in Chinese language, the author's name appears as 江洁慈. All the 29 figures were hand-painted by author PCWF.

\section{Conflicts of Interest}

The authors declare no conflicts of interest regarding the publication of this paper.

\section{References}

[1] Vining, K.H. and Mooney, D.J. (2017) Mechanical Forces Direct Stem Cell Behaviour in Development and Regeneration. Nature Reviews. Molecular Cell Biology, 18, 728-742. https://doi.org/10.1038/nrm.2017.108

[2] Fung, P.C.W. (2009) Probing the Mystery of Chinese Medicine Meridian Channels with Special Emphasis on the Connective Tissue Interstitial Fluid System, Mechanotransduction, Cells Durotaxis and Mast Cell Degranulation. Chinese Medicine, 4, 10. https://doi.org/10.1186/1749-8546-4-10

[3] Fung, P.C.W. (2013) Chapter 5. Plausible Biomedical Consequences of Acupuncture Applied at Sites Characteristic of Acupoints in the Connective-Tissue-Interstitial-Fluid System. In: Chen, L.L. and Cheng, T.O., Eds., Acupuncture in Modern Medicine, InTech Open, Rijeka, 95-131.

[4] Rutkowski, J.M. and Swartz, M.A. (2006) A Driving Force for Change: Interstitial Flow as a Morphoregulator. Trends in Cell Biology, 17, 44-50. https://doi.org/10.1016/j.tcb.2006.11.007

[5] Fung, P.C.W. and Kong, R.K.C. (2016) The Integrative Five-Fluid Circulation System in the Human Body. Open Journal of Molecular and Integrative Physiology, 6, 45-97. https://doi.org/10.4236/ojmip.2016.64005

[6] Tiberiu, R., Gheorghe, G. and Popescu, I. (1981) Do Meridians of Acupuncture Exist. A Radioactive Tracer Study of the Bladder Meridian. American Journal of Acupuncture, 9, 251-256.

[7] Meng, J.B., Gao, H.H., Wang, P., Tian, J.H. and Liu, Y.L. (1987) Primary Approach to Visualize the Courses of Channels by Use of Isotope. Zhenci Yanjiu, 2, 77-81. 
[8] Li, R.W., Wen, S., Meng, J.B., Gao, H.H., Chang, B.Q., Tian, J.X. and Zhang, S.W. (1992) Analysis of the Linear Migration of the Radionuclide along Meridians in Perfused Extremities of Monkey. Zhenci Yanjiu, 1, 67-70.

[9] Zhang, W.B. (2009) Meridians and Collaterals Are the Water Passages. 2nd Edition, Military Medical Science Press, Beijing.

[10] Fei, L., Cheng, H.S., Cai, D.H., Yang, S.X., Xu, J.R., Chen, E.Y., Dang, R.S., Ding, G.H., Shen, X.Y. and Tang, Y. (1998) Experimental Investigation and Scientific Demonstration of the Materialistic Foundation of Meridians and Their Functional Specialties. Chinese Science Bulletin, 43, 658-672. https://doi.org/10.1007/BF02884134

[11] Song, X.J. and Zhang, D. (2010) Study on the Manifestation of Facial Infrared Thermography Induced by Acupuncture Guangming (GB-37) and Hegu (LI-4). Chinese Acupuncture \& Moxibustion, 30, 51-54.

[12] Liu, L.U. (1999) Transmission Routes through the Skin and Chinese Meridian Channels. The Journal of Basic Chinese Medicine, 5, 47-51. (In Chinese, translated by the present authors)

[13] Liu, L.U., Peng, A., Pan J., Zhang, H., Ying, J.Y., Zhang, H. and Xing, X.Y. (2001) Sympathetic Nervous Sensitive Lines and Meridian Essence. China Academy of Chinese Medical Sciences, 21, 285-289.

[14] Fung, P.C.W. and Kong, R.K.C. (2019) Manifestation of Pathological States of Numerous Diseases in the Largest Organ of the Human Body: (I) Basics and the Diseases of Tendon. International Journal of Clinical Medicine, 10, 183-249. https://doi.org/10.4236/ijcm.2019.103018

[15] Fung, P.C.W. and Kong, R.K.C. (2018) Relationship among the Meridians, Sinew Channels and Integrative Five Fluid Circulation System. Traditional Chinese Medicine, 7, 74-92. https://doi.org/10.12677/TCM.2018.71013

[16] Sato, A. (1997) Neural Mechanisms of Autonomic Responses Elicited by Somatic Sensory Stimulation. Neuroscience and Behavioral Physiology, 27, 610-621. https://doi.org/10.1007/BF02463910

[17] Fung, P.C.W. and Kong, R.K.C. (2018) New Insights on Stimulating the Lung Meridian Based on Modern Neurophysiology. Chinese Medicine, 9, 75-117. https://doi.org/10.4236/cm.2018.93006

[18] Fung, P.C.W. and Kong, R.K.C. (2020) Bridging Medicine East and West-Pursuit on the Relation between Biomedical Consequence of Stimulating the Acupoints of the Lung Meridian and Somatosensory Reflexes, Aiming to Treat Chronic Obstruction Pulmonary Diseases. Traditional Chinese Medicine, 9, 145-176.

http://www.hanspub.org/journal/tcm https://doi.org/10.12677/TCM.2020.92022

[19] Shinozaki, Y., Yokota, S., Miwakeichi, F., Pokorski, M., Aoyama, R., Fukuda, K., Yoshida, H., Toyama, Y., Nakamura, M. and Okada, Y. (2019) Structural and Functional Identification of Two Distinct Inspiratory Neuronal Populations at the Level of the Phrenic Nucleus in the Rat Cervical Spinal Cord. Brain Structure and Function, 224, 57-72. https://doi.org/10.1007/s00429-018-1757-3

[20] Lindsey, B.G., Nuding, S.C., Segers, L.S. and Morris, K.F. (2018) Carotid Bodies and the Integrated Cardiorespiratory Response to Hypoxia. Physiology, 33, 281-297 https://doi.org/10.1152/physiol.00014.2018

[21] Ip, M.S.M., Lam, B., Chan, L.Y., Zheng, L., Tsang, K.W.T., Fung, P.C.W. and Lam, W.K. (2000) Circulating Nitric Oxide Is Suppressed in Obstructive Sleep Apnea and Is Reversed by Nasal Continuous Positive Airway Pressure. American Journal of 
Respiratory and Critical Care Medicine, 162, 2166-2171. https://doi.org/10.1164/ajrccm.162.6.2002126

[22] Corfield, D.R., Morrell, M.J. and Guz, A. (1995) The Nature of Breathing during Hypocapnia in Awake Man. Respiration Physiology, 101, 145-159. https://doi.org/10.1016/0034-5687(95)00026-A

[23] Tremoureux, L., Raux, M., Ranohavimparany, A., More’lot-Panzini, C., Pouget, P., Similowski, T. (2014) Electroencephalographic Evidence for a Respiratory-Related Cortical Activity Specific of the Preparation of Prephonatory Breaths. Respiratory Physiology \& Neurobiology, 204, 64-70. https://doi.org/10.1016/j.resp.2014.06.018

[24] Raux, M., Straus, C., Redolfi, S., Morelot-Panzini, C., Couturier, A., Hug, F. and Similowski, T. (2007) Electroencephalographic Evidence for Pre-Motor Cortex Activation during Inspiratory Loading in Humans. The Journal of Physiology, 578, 569-578. https://doi.org/10.1113/jphysiol.2006.120246

[25] Raux, M., Xie, H., Similowski, T. and Koski, L. (2010) Facilitatory Conditioning of the Supplementary Motor Area in Humans Enhances the Corticophrenic Responsiveness to Transcranial Magnetic Stimulation. Journal of Applied Physiology, 108, 39-46. https://doi.org/10.1152/japplphysiol.91454.2008

[26] Dubois, M., Chenivesse, C., Raux, M., Morales-Robles, A., Nierat, M.C., Garcia, G., Navarro-Sune, X., Chavez, M., Martinerie, J. and Similowski, T. (2016) Neurophysiological Evidence for a Cortical Contribution to the Wakefulness-Related Drive to Breathe Explaining Hypocapnia-Resistant Ventilation in Humans. The Journal of Neuroscience, 36, 10673-10682 https://doi.org/10.1523/JNEUROSCI.2376-16.2016

[27] Laviolette, L., Nierat, M.C., Hudson, A.L., Raux, M., Allard, E. and Similowski, T. (2013) The Supplementary Motor Area Exerts a Tonic Excitatory Influence on Corticospinal Projections to Phrenic Motoneurons in Awake Humans. PLoS One, 8, e62258. https://doi.org/10.1371/journal.pone.0062258

[28] Homma, I. and Masaoka, Y. (2008) Breathing Rhythms and Emotions. Experimental Physiology, 93, 1011-1021. https://doi.org/10.1113/expphysiol.2008.042424

[29] Wong, T.K.W., Fung, P.C.W., Chua, S.E. and McAlonan, G.M. (2008) Abnormal Spatiotemporal Processing of Emotional Facial Expressions in Childhood Autism: Dipole Source Analysis of Event-Related Potentials. European Journal of Neuroscience, 28, 407-416. https://doi.org/10.1111/j.1460-9568.2008.06328.x

[30] Klaassen, A.B.M., van Megan, Y.J.B., Kuijpers, W. and van den Brock, P. (1988) Autonomic Innervation of the Nasal Mucosa. ORL, 50, 32-41. https://doi.org/10.1159/000275967

[31] Young, J., Finn, L. and Kim, H. (1997) Nasal Obstruction as a Risk Factor for Sleep-Disordered Breathing. The Journal of Allergy and Clinical Immunology, 99, 757-762. https://doi.org/10.1016/S0091-6749(97)70124-6

[32] Malm, L. (1973) Stimulation of Sympathetic Nerve Fibres to the Nose in Cats. Acta Oto-Laryngologica, 75, 519-526. https://doi.org/10.3109/00016487309139783

[33] Liu, J., Liu, L.G. and Huang, Q.F. (1999) Exploration of Clinical Regularities in Acupuncture and Moxibustion Treatment for Allergic Rhinitis. Yonago Acta Medica, 42, 167-170.

[34] Yang, X. (2004) Treatment of 38 Cases of Allergic Rhinitis by Ventilating and Dredging the Nasal Passage. Journal of Acupuncture and Tuina Science, 2, 49-50. https://doi.org/10.1007/BF02861414

[35] Liu, L.L. and Ma, H.F. (2017) Effect of Acupuncture at Phenomaxillary Ganglia and Local Points for Allergic Rhinitis. Acupuncture Research, 3, 259-262. 
[36] Alvarez, M.J., Olaguibel, J.M., GarcõÂa, B.E., Rodrõ Âguez, A. and Tabar, A.I. (2000) Airway Inflammation in Asthma and Perennial Allergic Rhinitis. Relationship with Nonspecifc Bronchial Responsiveness and Maximal Airway Narrowing. Allergy, 55, 355-362. https://doi.org/10.1034/j.1398-9995.2000.00312.x

[37] Baraniuk, J.N., Castellino, S., Lundgren, J.D., Goff, J., Mullol, J., Merida, M., Shelhamer, J.H. and Kaliner, M.A. (1990) Neuropeptide Y (NPY) in Human Nasal Mucosa. American Journal of Respiratory Cell and Molecular Biology, 3, 165-173. https://doi.org/10.1165/ajrcmb/3.2.165

[38] Potter, E.K. (1988) Neuropeptide Y as an Autonomic Neurotransmitter. Pharmacology \& Therapeutics, 37, 251-273. https://doi.org/10.1016/0163-7258(88)90028-9

[39] Richerson, H.B. and Seebohm, P.M. (1968) Nasal Airway Response to Exercise. Journal of Allergy, 41, 269-284. https://doi.org/10.1016/0021-8707(68)90032-4

[40] Neuwirth, C. and Burkhardt, C. (2016) Markus Weber Motor Unit Number Index in the Nasalis Muscle in Healthy Subjects and Patients with Amyotrophic Lateral Sclerosis. Muscle \& Nerve, 54, 733-737. https://doi.org/10.1002/mus.25100

[41] Sanders, I. and Mu, L. (2013) A Three-Dimensional Atlas of Human Tongue Muscles. The Anatomical Record, 296, 1102-1114. https://doi.org/10.1002/ar.22711

[42] Tseng, C.Y., Lue, J.H., Lee, S.H., Wen, C.Y. and Shieh, J.Y. (2001) Evidence of Neuroanatomical Connection between the Superior Cervical Ganglion and Hypoglossal Nerve in the Hamster as Revealed by Tract-Tracing and Degeneration Methods. Journal of Anatomy, 198, 407-421. https://doi.org/10.1046/j.1469-7580.2001.19840407.x

[43] Standring, S. (2008) Section 4-Head and Neck. In: Wigley, C., Ed., Gray's Anatomy: The Anatomical Basis of Clinical Practice, 40th Edition, Churchill Livingstone, London, 395-699.

[44] Edge, D., McDonald, F.B., Jones, J.F.X., Bradford, A. and O'Halloran, K.D. (2014) Effect of Chronic Intermittent Hypoxia on the Reflex Recruitment of the Genioglossus during Airway Obstruction in the Anesthetized Rat. Progress in Brain Research, 209, 147-168. https://doi.org/10.1016/B978-0-444-63274-6.00008-4

[45] Saboisky, J.P., Butler, J.E., McKenzie, D.K., Gorman, R.B., Trinder, J.A., White, D.P. and Gandevia, S.C. (2007) Neural Drive to Human Genioglossus in Obstructive Sleep Apnoea. The Journal of Physiology, 582, 135-146. https://doi.org/10.1113/jphysiol.2007.139584

[46] Marcus, C.L., Lutz, J., Carroll, J.L. and Bamford, O. (1998) Arousal and Ventilatory Responses during Sleep in Children with Obstructive Sleep Apnea. Journal of Applied Physiology, 84, 1926-1936. https://doi.org/10.1152/jappl.1998.84.6.1926

[47] Yadollahi, A., Montazeri, A., Azarbarzin, A. and Moussavi, Z. (2013) Respiratory Flow-Sound Relationship during Both Wakefulness and Sleep and Its Variation in Relation to Sleep Apnea. Annals of Biomedical Engineering, 41, 537-546. https://doi.org/10.1007/s10439-012-0692-3

[48] Mezzanotte, W.S., Tangel, D.J. and Whit, D.P. (1992) Waking Genioglossal Electromyogram in Sleep Apnea Patients versus Normal Controls (a Neuromuscular Compensatory Mechanism). The Journal of Clinical Investigation, 89, 1571-1579. https://doi.org/10.1172/JCI115751

[49] Clement, Clemente, C.D. (2007) Anatomy-A Regional Atlas of the Human Body. 5th Edition, Plate 19, Lippincott Williams \& Wilkins, Los Angeles.

[50] Amis, T.C., Neill, N.O., Somma, E.D. and Wheatley, J.R. (1998) Epiglottic Movements during Breathing in Humans. Journal of Physiology, 512, 307-314. https://doi.org/10.1111/j.1469-7793.1998.307bf.x 
[51] Netter, F.H. (2019) Chapter 2-Head and Neck. In: Atlas of Human Anatomy, 7th Edition, Elsevier Inc., 11-174.

[52] Ghannouchi, I., Marie, J.P., Duclos1, C. and Verin, E. (2019) Alteration of Swallowing and Ventilation Coordination in Respiratory Diseases in Small Mammals. Dysphagia, 35, 308-313. https://doi.org/10.1007/s00455-019-10024-x

[53] Hodgson, M., Linforth, R.S.T. and Taylor, A.J. (2003) Simultaneous Real-Time Measurements of Mastication, Swallowing, Nasal Airflow and Aroma Release. Journal of Agricultural and Food Chemistry, 51, 5052-5057. https://doi.org/10.1021/jf030118+

[54] Morton, D.A., Foreman, K.B., Albertine, K.H., Weyrich, A.S. and Moyle, K. (2011). Chapter 25: Overview of the Neck, Muscles of the Neck. Gross Anatomy: The Big Picture. McGraw-Hill, New York.

[55] Vassilakopoulos, T. (2012) Control of Ventilation and Respiratory Muscles (Chapter 6). In: Spiro, S.G., Silvestri, G.A. and Agusti, A., Eds., Clinical Respiratory Medicine, 4th Edition, Saunders, Elsevier Inc., 50-62. https://doi.org/10.1016/B978-1-4557-0792-8.00006-4

[56] Costa, D., Vitti, M., de Oliveira, T.D. and Costa, R.P. (1994) Participation of the Sternocleidomastoid Muscle on Deep Inspiration in Man. An Electromyographic Study. Electromyography and Clinical Neurophysiology, 34, 315-320.

[57] Suzuki, M., Namura, K., Ohno, Y., Tanaka, H., Egawa, M., Yokoyama, Y., Akao, S., Fujiwara, H. and Yano, T. (2008) The Effect of Acupuncture in the Treatment of Chronic Obstructive Pulmonary Disease. The Journal of Alternative and Complementary Medicine, 14, 1097-1105. https://doi.org/10.1089/acm.2007.0786

[58] Suzuki, M., Muro, S., Ando, Y., Omori, Y., Shiota, T., Endo, K., Sato, S., Aihara, K., Matsumoto, M., Suzuki, S., Itotani, R., Ishitoko, M., Hara, Y., Takemura, M., Ueda, T., Kagioka, H., Hirabayashi, M., Fukui, M. and Mishima, M. (2012) A Randomized, Placebo-Controlled Trial of Acupuncture in Patients with Chronic Obstructive Pulmonary Disease (COPD). The COPD-Acupuncture Trial (CAT). Archives of Internal Medicine, 172, 878-886. https://doi.org/10.1001/archinternmed.2012.1233

[59] Feng, J., Wang, X., Li, X., Zhao, D. and Xu, J. (2016) Acupuncture for Chronic Obstructive Pulmonary Disease (COPD): A Multicenter, Randomized, Sham-Controlled Trial. Medicine (United States), 95, e4879. https://doi.org/10.1097/MD.0000000000004879

[60] Lloyd, S. (2007) Accessory Nerve: Anatomy and Surgical Identification. The Journal of Laryngology \& Otology, 121, 1118-1125. https://doi.org/10.1017/S0022215107000461

[61] Benninger, B. (2015) Chapter 28-The Accessory Nerve (CN XI). In: Tubbs, R.S., Rozk, E., Shoja, M.M., Loukas, M., Barbaro, N.P. and Spiner, R.S., Eds., Nerves and Nerve Injuries, Volume 1, Science Direct, Elsevier, 399-415. https://doi.org/10.1016/B978-0-12-410390-0.00029-9

[62] Ribeiro, E.C., Marchiori, S.C. and Silva, A.M.T. (2002) Electromyographic Analysis of Trapezius and Sternocleidomastoideus Muscles during Nasal and Oral Inspiration in Nasal and Mouthbreathing Children. Journal of Electromyography and Kinesiology, 12, 305-316. https://doi.org/10.1016/S1050-6411(02)00025-1

[63] McGovern, A.E. and Mazzone, S.B. (2010) Characterization of the Vagal Motor Neurons Projecting to the Guinea Pig Airways and Esophagus. Frontires in Neurology, 1, 153. https://doi.org/10.3389/fneur.2010.00153

[64] Springall, D.R., Cadieux, A., Oliveira, H., Su, H., Royston, D. and Polak, J.M. (1987) 
Retrograde Tracing Shows that CGRP-Immunoreactive Nerves of Rat Trachea and Lung Originate from Vagal and Dorsal Root Ganglia. Journal of the Autonomic Nervous System, 20, 155-166. https://doi.org/10.1016/0165-1838(87)90113-5

[65] Kummer, W., Fischer, A., Kurkowski, R. and Heym, C. (1992) The Sensory and Sympathetic Innervation of Guinea-Pig Lung and Trachea as Studied by Retrograde Neuronal Tracing and Double-Labelling Immunohistochemistry. Neuroscience, 49, 715-737. https://doi.org/10.1016/0306-4522(92)90239-X

[66] Plato, M., Kummer, W. and Haberberger, R.V. (2006) Structural and Neurochemical Comparison of Vagal and Spinal Afferent Neurons Projecting to the Rat Lung. Neuroscience Letters, 395, 215-219. https://doi.org/10.1016/j.neulet.2005.10.078

[67] Wilfrid, J. (2006) Part II-Functional Organization of the Peripheral Autonomic Nervous System. In: Integrative Action of the Autonomic Nervous System: Neurobiology of Homeostasis, Cambridge University Press, Cambridge, 85-207.

[68] Taylor, A. (1960) The Contribution of the Intercostal Muscles to the Effort of Respiration in Man. The Journal of Physiology, 151, 390-402. https://doi.org/10.1113/jphysiol.1960.sp006446

[69] De Troyer, A., Legrand, A. and Wilson, T.A. (1999) Respiratory Mechanical Advantage of the Canine External and Internal Intercostal Muscles. Journal of Physiology, 518, 283-289.

[70] Gandevia, S.C., Hudson, A.L., Gorman, R.B., Butler, J.E. and De Troyer, A. (2006) Spatial Distribution of Inspiratory Drive to the Parasternal Intercostal Muscles in Humans. Journal of Physiology, 573, 263-275. https://doi.org/10.1113/jphysiol.2005.101915

[71] Wilson, T.A., Legrand, A., Gevenois, P.A. and De Troyer, A. (2001) Respiratory Effects of the External and Internal Intercostal Muscles in Humans. Journal of Physiology, 530, 319-330. https://doi.org/10.1111/j.1469-7793.2001.03191.x

[72] Saboisky, J.P., Butler, J.E., Fogel, R.B., Taylor, J.L., Trinder, J.A., White, D.P. and Gandevia, S.C. (2006) Tonic and Phasic Respiratory Drives to Human Genioglossus Motoneurons during Breathing. Journal of Neurophysiology, 95, 2213-2221. https://doi.org/10.1152/jn.00940.2005

[73] Saboisky, J.P., Gorman, R.B., De Troyer, A., Gandevia, S.C. and Butler, J.E. (2007) Differential Activation among Five Humans Inspiratory Motoneuron Pools during Tidal Breathing. Journal of Applied Physiology, 102, 772-780. https://doi.org/10.1152/japplphysiol.00683.2006

[74] Butler, J.E., Hudson, A.L. and Gandevia, S.C. (2014) Chapter 15-The Neural Control of Human Inspiratory Muscles. Progress in Brain Research, 209, 295-308. https://doi.org/10.1016/B978-0-444-63274-6.00015-1

[75] Butler, J.E. and Gandevia, S.C. (2008) The Output from Human Inspiratory Motoneurone Pools. Symposium Report. Journal of Physiology, 586, 1257-1264. https://doi.org/10.1113/jphysiol.2007.145789

[76] Tubbs, R.S., Tyler-Kabara, E.C., Aikens, A.C., Martin, J.P., Weed, L.L., Salter, E.G. and Oakes, W.J. (2005) Surgical Anatomy of the Dorsal Scapular Nerve. Journal of Neurosurgery, 102, 910-911. https://doi.org/10.3171/jns.2005.102.5.0910

[77] Brown, J.M.M., Wickham, J.B., McAndrew, D.J. and Huang, X.F. (2007) Muscles within Muscles: Coordination of 19 Muscle Segments within Three Shoulder Muscles during Isometric Motor Tasks. Journal of Electromyography and Kinesiology, 17, 57-73. https://doi.org/10.1016/j.jelekin.2005.10.007

[78] Nasu, H., Yamaguchi, K., Nimura, A. and Akita, K. (2012) An Anatomic Study of Structure and Innervation of the Serratus Anterior Muscle. Surgical and Radiologic 
Anatomy, 34, 921-928. https://doi.org/10.1007/s00276-012-0984-1

[79] Dawood, M., Bekker, P.J., van Rooijen, A.J. and Korkie, E. (2018) Inter- and Intra-Rater Reliability of a Technique Assessing the Length of the Latissimus Dorsi Muscle. South African Journal of Physiotherapy, 74, 388. https://doi.org/10.4102/sajp.v74i1.388

[80] Tang, L. and Dai, J.X. (2006) Color Atlas of Chinese Digital Human (Male) and (Female). People's Military Medical Press, Beijing.

[81] Yuan, L., Yao, D.W., Tang, L., Huang, W.H., Jiao, P.F., Lu, Y.T., Dai, J.X., Zhang, H., He, Z.Q. and Zhong, S.Z. (2004) A Study on Morphological Basis of Chinese Acupuncture and Moxibustion from Digital Human Body. Jiepou Xuebao (Acta Anatomica Sinica), 35, 337-343.

[82] Langevin, H.M. and Yandow, J.A. (2002) Relationship of Acupuncture Points and meridians to Connective Tissue Planes. The Anatomical Record, 269, 257-265. https://doi.org/10.1002/ar.10185

[83] Sing, N.K. (Chief Editor) (2010) Yellow Emperor's Canon of Medicine. Volume 2, Spiritual Pivot, Wisdom of Chinese Culture Series. Chiao Liu (Canada) Publishing Trading Co. Ltd., Hong Kong.

[84] Harrison, J.W.K., Thomas, P., Aster, A., Wilkes, G. and Hayton, M.J. (2013) Chronic Exertional Compartment Syndrome of the Forearm in Elite Rowers. A Technique for Mini-Open Fasciotomy and a Report of Six Cases. Hand (NY), 8, 450-453. https://doi.org/10.1007/s11552-013-9543-4

[85] Mahakkanukrauh, P. and Somsarp, V. (2002) Dual Innervation of the Brachialis Muscle. Clinical Anatomy, 15, 206-209. https://doi.org/10.1002/ca.10014

[86] Verburgh, C.A. and Kuypers, H.G.J.M. (1987) Branching Neurons in the Cervical Spinal Cord: A Retrograde Fluorescent Double-Labeling Study in the Rat. Experimental Brain Research, 68, 565-578. https://doi.org/10.1007/BF00249799

[87] Verburgh, C.A., Voogd, J., Kuypers, H.G.J.M. and Stevens, H.P.J.D. (1990) Propriospinal Neurons with Ascending Collaterals to the Dorsal Medulla, the Thalamus and the Tectum: A Retrograde Fluorescent Double-Labeling Study of the Cervical Cord of the Rat. Experimental Brain Research, 80, 577-590.

https://doi.org/10.1007/BF00227997

[88] Rustioni, A. and Hayes, N.L. (1979) Dorsal Column Nuclei and Ascending Spinal Afferents in Macaques. Brain: A Journal of Neurology, 102, 95-125. https://doi.org/10.1093/brain/102.1.95

[89] Hoskin, R.W., Fedorko, L.M. and Duffin, J (1988) Projections from Upper Cervical Inspiratory Neurons to Thoracic and Lumbar Expiratory Motor Nuclei in the Cat. Experimental Neurology, 99, 544-555. https://doi.org/10.1016/0014-4886(88)90171-9

[90] Jian, H. (2012) Observation on Effect of Acupuncture at Yuji (LU 10) on the Pulmonary Function of Patients with Bronchial Asthma and Immediate Efficacy of Relieving Asthma. Chinese Acupuncture \& Moxibustion, 32, 891-894.

[91] Liang, F.H., Hou, X.R., Li, L.H., Liang, X., Lu, Y.W., Yang, H. and Zhang, Y. (2018) Acupoint Injection at "Yingxiang" (LI 20) and "Yintang" (GV 29) May Relieve Nasal Allergic Symptoms Possibly by Down-regulating Expression of Histamine Receptor H1 and H4 in Nasal Mucosa of Allergic Rhinitis Rats. Acupuncture Research, 4, 231-235.

[92] Dharmananda, Subhuti (Online Still at the Time of Submission) Acupuncture Treatment of Asthma. https://www.itmonline.org $>$ arts $>$ acuasth 
[93] Oliver, K.A. and Ashurst, J.V. (2020) Anatomy, Thorax, Phrenic Nerves. [Updated 2018 Dec 9]. In: StatPearls [Internet]. StatPearls Publishing, Treasure Island (FL). https://www.ncbi.nlm.nih.gov/books/NBK513325/

[94] Wu, Q., Yu, X. and Li, J.S. (2012) Literature Analysis on the Effect-related Factors of Acupoint Application for Chronic Obstructive Pulmonary Disease. Journal of Traditional Chinese Medicine, 4, 331-334.

[95] Ngai, S.P.C., Hui-Chan, C.W.Y. and Jones, A.Y.M. (2006) A Short Review of Acupuncture and Bronchial Asthma-Western and Traditional Chinese Medicine Concepts. Hong Kong Physiotherapy Journal, 24, 28-38. https://doi.org/10.1016/S1013-7025(07)70006-4

[96] Zhang, B.Z., Wang, D.L., Li, F.C., Wang, Z.F., Xu, H.X., Wang, Q. and Wang, Q. (1990) Comprehensive Treatment of Chronic Bronchitis and Bronchial Asthma. Chinese Clinical Doctors, 2, 28-29. (In Chinese, translated by the present authors)

[97] Liu, J., Liu, L. and Huang, Q. (2010) Exploration of Clinical Regularities in Acupuncture and Moxibustion Treatment for Allergic Rhinitis. Journal of Acupuncture and Tuina Science, 8, 80-84. https://doi.org/10.1007/s11726-010-0080-1

[98] Tian, W., Yang, N. and Yang, T. (2015) Study on the Law of Acupoints Selection in Treating Asthma by Acupuncture. Henan Traditional Chinese Medicine, 35, 158-159.

[99] Li, J., Wu, S., Tang, H., Huang, W., Wang, L., Zhou, H., Zhou, M., Wang, H. and Li, J. (2016) Long-Term Effects of Acupuncture Treatment on Airway Smooth Muscle in a Rat Model of Smoke-Induced Chronic Obstructive Pulmonary Disease. Acupuncture in Medicine, 34, 107-113. https://doi.org/10.1136/acupmed-2014-010674

[100] Lin, C.Y. (2006) Acupuncture for Persistent Hiccups in a Heart and Lung Transplant Recipient. The Journal of Heart and Lung Transplantation, 25, 126-127. https://doi.org/10.1016/j.healun.2005.06.011

[101] Cao, Q.A., Zhang, H.F., Li, L.H., Gong, H.B., Dong, Z.W., Zeng, L.M., Chen, W.G., Xiong, J. and Fu, Y. (2020) Clinical Observation on the Distribution Characteristics and Rules of Pressing Sensitive Acupoints in Bronchial Asthma Patients. Chinese Acupuncture and Moxibustion, 2, 169-172.

[102] Li, J., Wei, J. and Liu, S. (2001) The Rule of Selecting and Using Acupoints of Acupuncture Therapy for Asthma. Acupuncture Research, 25, 78-80.

[103] Noppen, M. and Vincken, W. (1996) Thoracoscopic Sympathicolysis for Essential Hyperhidrosis: Effects on Pulmonary Function. European Respiratory Journal, 9, 1660-1664. https://doi.org/10.1183/09031936.96.09081660

[104] Furness, J.B. (2006) The Organization of the Autonomic Nervous System: Peripheral Connections. Autonomic Neuroscience, 130, 1-5. https://doi.org/10.1016/j.autneu.2006.05.003

[105] White, E.S., Drinnan, M.J., Smithson, A.J., Griffiths, C.J. and Gibson, G.J. (1995) Respiratory Muscle Activity during Rapid Eye Movement (REM) Sleep in Patients with Chronic Obstructive Pulmonary Disease. Thorax, 50, 376-382. https://doi.org/10.1136/thx.50.4.376

[106] Laranjo, S., Geraldes, V., Oliveira, M. and Rocha, I. (2017) Insights into the Background of Autonomic Medicine. Revista Portuguesa de Cardiologia, 36, 757-771. https://doi.org/10.1016/j.repc.2017.01.007 


\section{Appendix}

Table A1. Muscles of the Nasal region and mouth, chin related to acupoints Bitong and Yingxiang (Section (3)).

\begin{tabular}{|c|c|c|c|}
\hline Muscle: & Nasalis & Muscle: & Levator labii superioris alaeque nasi \\
\hline Origin: & Maxilla & Origin: & Nasal bone \\
\hline Insertion: & Alar cartilage of nose & Insertion: & Alar cartilage and upper lip \\
\hline $\begin{array}{c}\text { Nerve in } \\
\text { innervation: }\end{array}$ & $\begin{array}{l}\text { Parasym: Buccal branch of CN VII } \\
\text { Sym: Internal carotid } n .\end{array}$ & $\begin{array}{c}\text { Nerve in } \\
\text { innervation: }\end{array}$ & $\begin{array}{l}\text { Parasym: Buccal branch of CN VII } \\
\text { SYM: Internal carotid n. }\end{array}$ \\
\hline Function: & $\begin{array}{l}\text { Depresses tip of nose, elevates corners of nostrils, } \\
\text { relieving tension of the connective tissues of nasalis }\end{array}$ & Function: & $\begin{array}{l}\text { Dilates nostril, elevates wing } \\
\text { of nose and upper lip }\end{array}$ \\
\hline Muscle: & Procerus & Muscle: & Depressor septi nasi \\
\hline Origin: & Lower nasal bone & Origin: & Nasal bone \\
\hline Insertion: & Skin between eyebrows & Insertion: & Maxilla \\
\hline $\begin{array}{c}\text { Nerve in } \\
\text { innervation: }\end{array}$ & Prasym: Buccal branch of CN VII & $\begin{array}{c}\text { Nerve in } \\
\text { innervation: }\end{array}$ & Parasym: Buccal branch of CN VII \\
\hline Function: & Draw medial angle of eyebrow & Function: & Widening nostrils (see caption of Figure 2) \\
\hline Muscle: & Depressor anguli oris & Muscle: & Orbicularis oris \\
\hline Origin: & Tubercle of mandible & Origin: & Maxilla and mandible \\
\hline Insertion: & Point lateral to the angle of the mouth, called modiolus & Insertion: & Around the lips \\
\hline $\begin{array}{l}\text { Nerve in } \\
\text { innervation: }\end{array}$ & Parasym: Mandibular branch of CNVII & $\begin{array}{l}\text { Nerve in } \\
\text { innervation: }\end{array}$ & Buccal branch of CN VII \\
\hline Function: & Change angle of mouth during speech & Function: & Move the mouth/lips during speech \\
\hline
\end{tabular}

Table A2. The intrinsic muscles of the tongue (Section (4.1)).

\begin{tabular}{|c|c|c|c|}
\hline Muscle: & Superior longitudinal $\mathrm{m}$. & Muscle: & Inferior longitudinal $\mathrm{m}$. \\
\hline Origin: & Proximally to the fibrous median septum, close to epiglottis & Origin: & Root of the tongue \\
\hline $\begin{array}{c}\text { Nerve in } \\
\text { innervation: }\end{array}$ & $\begin{array}{l}\text { Parasym.: hypoglossal nerve (CN XII) } \\
\text { Sym.: branch of ansa cervicalis }\end{array}$ & $\begin{array}{l}\text { Nerve in } \\
\text { innervation: }\end{array}$ & $\begin{array}{c}\text { Parasym.: hypoglossal nerve (CN XII), Sym.: branch } \\
\text { of ansa cervicalis }\end{array}$ \\
\hline Muscle: & Vertical m. & Muscle: & Transverse $\mathrm{m}$. \\
\hline Origin: & Dorsal fascia of tongue & Origin: & Median fibrous septum \\
\hline Insertion: & Sides and base of tongue & Insertion: & Edges of tongue \\
\hline Function: & Changes shape of tongue in mastication and deglutition & Function: & $\begin{array}{l}\text { Changes shape of tongue in mastication } \\
\text { and deglutition }\end{array}$ \\
\hline
\end{tabular}

Table A3. Extrinsic muscles of the tongue (Section (4.2)).

\begin{tabular}{|c|c|c|c|}
\hline Muscle: & Styloglossus & Muscle: & $\begin{array}{l}\text { Genioglossus } \\
\text { It is a fan-shaped muscle forming most of the tongue mass. }\end{array}$ \\
\hline Origin: & Styloid process of the temporal bone & Origin: & Superior of mental spine of mandible \\
\hline
\end{tabular}




\section{Continued}

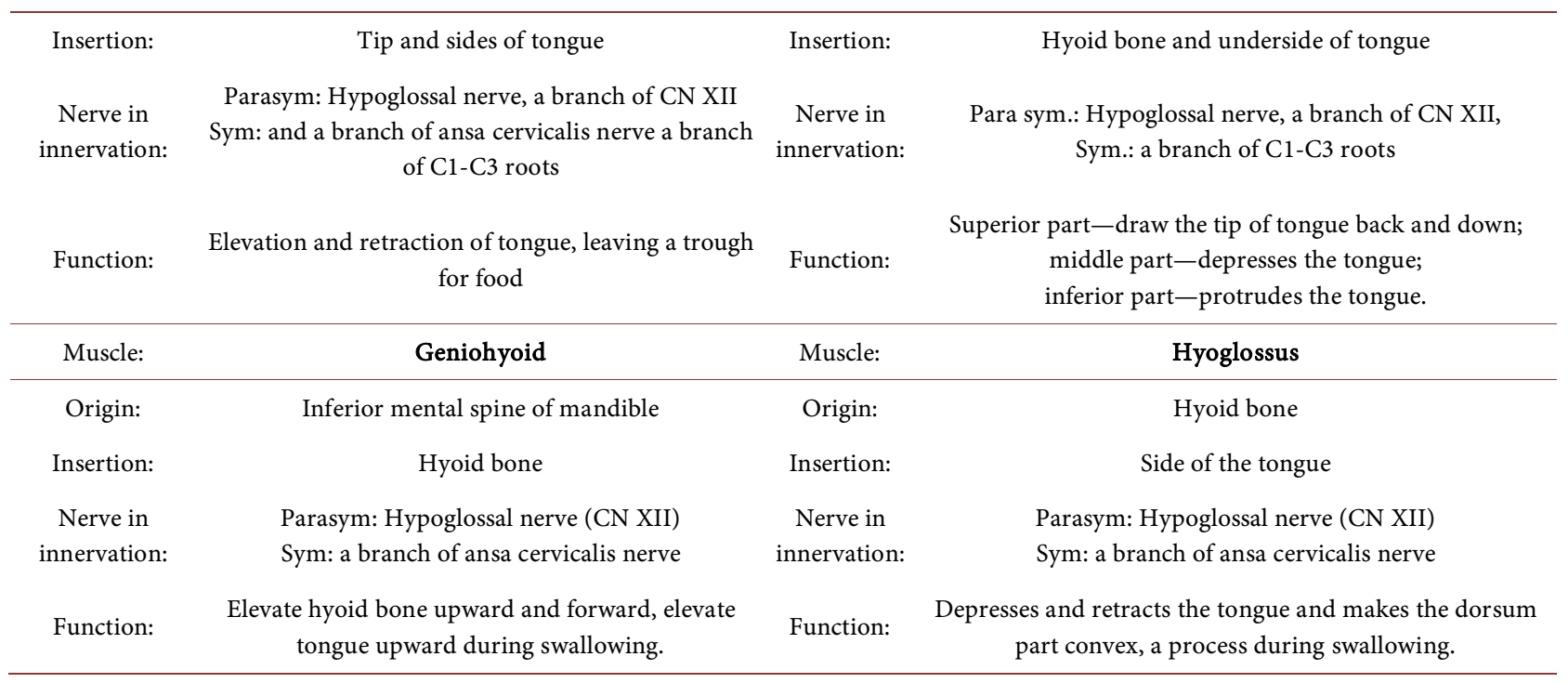

Table A4. The intrinsic muscles of the larynx (Section (5.1)).

\begin{tabular}{|c|c|c|c|c|}
\hline Muscle: & Aryepiglottic (close the glottis for swallowing) & Muscle: & Poste & $\begin{array}{l}\text { or cricoarytenoid (opening glottis to resume } \\
\text { respiration) }\end{array}$ \\
\hline Origin: & Apex of arytenoid & Origin: & in: & Posterior of cricoid \\
\hline Insertion: & Lateral boarder of epiglottis & \multicolumn{2}{|c|}{ Insertion: } & Process of the arytenoid cartilage \\
\hline $\begin{array}{l}\text { Nerve in } \\
\text { innervation: }\end{array}$ & $\begin{array}{l}\text { Parasym.: recurrent laryngeal nerve, a branch of } \mathrm{CN} \\
\text { X (vagus) nerve }\end{array}$ & \multicolumn{2}{|c|}{$\begin{array}{l}\text { Nerve in } \\
\text { innervation: }\end{array}$} & $\begin{array}{l}\text { n.: recurrent laryngeal nerve, a branch of } \mathrm{CN} \mathrm{X} \\
\text { (vagus) nerve }\end{array}$ \\
\hline Function: & Close the epiglottis for swallowing & Function: & $\begin{array}{r}\text { Abdu } \\
\text { vocal li }\end{array}$ & $\begin{array}{l}\text { and rotates the arytenoid cartilage, pulling the } \\
\text { ments from the midline, thus opening the glottis } \\
\text { for respiration. }\end{array}$ \\
\hline Muscle: & Transverse arytenoid (inhibition of respiration) & Muscle: & cle: & que arytenoid (inhibition of respiration) \\
\hline Origin: & $\begin{array}{l}\text { Posterior surface and muscular process of arytenoid } \\
\text { cartilage }\end{array}$ & Origin: & & $\begin{array}{l}\text { rior surface of muscular process of arytenoid } \\
\text { cartilage }\end{array}$ \\
\hline Insertion: & $\begin{array}{l}\text { Corresponding surfaces on the opposite side of the } \\
\text { cartilage }\end{array}$ & Insertion: & Poster & $\begin{array}{l}\text { r surface of apex of adjacent arytenoid cartilage, } \\
\text { extending to aryepiglottic folds }\end{array}$ \\
\hline $\begin{array}{l}\text { Nerve in } \\
\text { innervation: }\end{array}$ & \multicolumn{3}{|c|}{$\begin{array}{l}\text { Parasym.: recurrent laryngeal nerve, branch of CN X Nerve in inner- } \\
\qquad \text { (vagus) nerve }\end{array}$} & $\begin{array}{l}\text { t laryngeal branch of the parasympathetic nerve } \\
\qquad \mathrm{CNX}\end{array}$ \\
\hline Function: & $\begin{array}{l}\text { Abducts the arytenoid cartilage, hence closing the } \\
\text { rima glottidis, and respiration is inhibited. }\end{array}$ & Function: & Add & $\begin{array}{l}\text { gt the arytenoid cartilages towards each other, } \\
\text { to closure of the inlet to the larynx. In other } \\
\text { words, respiration is inhibited. }\end{array}$ \\
\hline Muscle: & \multicolumn{2}{|l|}{ Digastric } & Muscle: & Stylohyoid \\
\hline Insertion: & \multicolumn{2}{|l|}{ Hyoid bone, with intermediate tendon } & Insertion: & Near greater horn of hyoid bone \\
\hline $\begin{array}{l}\text { Nerve in } \\
\text { innervation: }\end{array}$ & \multicolumn{2}{|c|}{$\begin{array}{l}\text { Parasym.: anterior belly: mylohyoid nerve, branch of CN V3. } \\
\text { Posterior belly: digastric branch of CN VII. }\end{array}$} & $\begin{array}{l}\text { Nerve in } \\
\text { innervation: }\end{array}$ & Parasym: Branch of CN VII \\
\hline
\end{tabular}




\section{Continued}

\begin{tabular}{|c|c|c|c|}
\hline Function: & $\begin{array}{l}\text { Elevate hyoid bone during speaking, eating, swallowing and } \\
\text { (mouth) breathing. }\end{array}$ & Function: & $\begin{array}{l}\text { Elevate and retract hyoid bone and tongue } \\
\text { during the first process of swallowing }\end{array}$ \\
\hline Muscle: & Geniohyoid & Muscle: & Mylohyoid \\
\hline Origin: & Inferior mental spine of mandible & Origin: & $\begin{array}{l}\text { Whole length of mylohyoid line of mandible, } \\
\text { forming the floor of oral cavity }\end{array}$ \\
\hline Insertion: & Anterior surface of hyoid bone & Insertion: & Hyoid bone \\
\hline $\begin{array}{l}\text { Nerve in } \\
\text { innervation: }\end{array}$ & $\begin{array}{l}\text { Parasym.: hypoglossal nerve, a branch of CN XII nerve } \\
\text { Sym.: branch of C1 nerve }\end{array}$ & $\begin{array}{l}\text { Nerve in } \\
\text { innervation: }\end{array}$ & Mylohyoid nerve, ranch of CN V \\
\hline Function: & $\begin{array}{l}\text { Elevate the hyoid bone and forward and tongue during the } \\
\text { first process of swallowing; when hyoid is fixed, it depresses } \\
\text { mandible }\end{array}$ & Function: & $\begin{array}{l}\text { Raises oral cavity floor, elevates hyoid bone, } \\
\text { tongue in general; depresses mandible. Such } \\
\text { action proceeds during speaking and swallowing }\end{array}$ \\
\hline
\end{tabular}

Table A6. Extrinsic muscles of the larynx-infrahyoid muscles are below the hyoid bone (Section (5.2)).

\begin{tabular}{|c|c|c|c|}
\hline Muscle: & Omohyoid (for resumption of respiration) & Muscle: & Sternohyoid (for resumption of respiration) \\
\hline Origin: & Upper border of scapula & Origin: & Manubrium of sternum \\
\hline Insertion: & $\begin{array}{l}\text { Hyoid bone, with the intermediate tendon separated the } \\
\text { superior and inferior bellies in terminology. }\end{array}$ & Insertion: & Hyoid bone \\
\hline $\begin{array}{l}\text { Nerve in } \\
\text { innervation: }\end{array}$ & $\begin{array}{l}\text { Sym.: ansa cervicalis, branch originated from spinal } \\
\text { nerves } \mathrm{C} 1-\mathrm{C} 3 .\end{array}$ & $\begin{array}{l}\text { Nerve in inner- } \\
\text { vation: }\end{array}$ & $\begin{array}{l}\text { Sym.: ansa cervicalis, branch originated from spinal } \\
\text { nerves } \mathrm{C} 1-\mathrm{C} 3 .\end{array}$ \\
\hline Function: & $\begin{array}{l}\text { Depress the hyoid bone; it participates in resuming } \\
\text { breathing during the complete swallow action. }\end{array}$ & Function: & $\begin{array}{l}\text { Depress the hyoid bone; it participates in resuming } \\
\text { breathing during the complete swallow action }\end{array}$ \\
\hline Muscle: & Thyrohyoid & Muscle: & Sternothyroid (for resumption of respiration) \\
\hline Origin: & Thyroid cartilage of larynx & Origin: & Manubrium \\
\hline Insertion: & Hyoid bone & Insertion: & Thyroid cartilage \\
\hline $\begin{array}{l}\text { Nerve in } \\
\text { innervation: }\end{array}$ & $\begin{array}{c}\text { Parasym.: hypoglossal nerve, a branch of CN XII nerve } \\
\text { Sym.: anterior rami of } \mathrm{C} 1\end{array}$ & $\begin{array}{l}\text { Nerve in } \\
\text { innervation: }\end{array}$ & $\begin{array}{l}\text { Sym.: ansa cervicalis, branch originated from spinal } \\
\text { nerves C1-C3 }\end{array}$ \\
\hline Function: & Elevates thyroid and depresses the hyoid bone & Function: & $\begin{array}{l}\text { Depress thyroid cartilage; it participates in resuming } \\
\text { breathing during the complete swallow action }\end{array}$ \\
\hline
\end{tabular}

Table A7. Four important inspiration muscles in the neck—three scalene muscles and the Sternocleidomastoid (Section (7)).

\begin{tabular}{|c|c|c|c|}
\hline Muscle: & Anterior scalene muscle (intrinsic inspiration) & Muscle: & Middle scalene muscle (intrinsic inspiration) \\
\hline Origin: & $\begin{array}{l}\text { Anterior tubercles of the transverse processes of } \\
\text { cervical vertebrae bodies C2(3)-C7(6). It is behind } \\
\text { the sternocleidomastoid muscle }\end{array}$ & Origin: & $\begin{array}{c}\text { Anterior tubercles of the transverse processes of the } 2 \text { nd } \\
\text { to } 7 \text { th cervical vertebrae bodies }(\mathrm{C} 2-\mathrm{C} 7) \text {. }\end{array}$ \\
\hline Insertion: & First and second ribs & Insertion: & $\begin{array}{l}\text { Upper surface of the first rib between the subclavian } \\
\text { groove and scalene tubercle. }\end{array}$ \\
\hline $\begin{array}{l}\text { Nerve in } \\
\text { innervation: }\end{array}$ & $\begin{array}{l}\text { Sym.: anterior rami of the cervical } \\
\text { spinal nerves } \mathrm{C} 4-\mathrm{C} 6\end{array}$ & $\begin{array}{c}\text { Nerve in } \\
\text { innervation: }\end{array}$ & Sym.: anterior rami of the cervical spinal nerves C5-C8. \\
\hline Function: & $\begin{array}{c}\text { Elevating } 1^{\text {st }} \text { and } 2^{\text {nd }} \text { ribs and hence rib cage during } \\
\text { inspiration }\end{array}$ & Function: & $\begin{array}{l}\text { Bends the neck (contracting one side) or flexes the neck } \\
\text { (contacting both middle scalene muscles) }\end{array}$ \\
\hline Muscle: & $\begin{array}{l}\text { Posterior scalene } \\
\text { (intrinsic and forced inspiration) }\end{array}$ & Muscle: & Sternocleidomastoid (inspiration) \\
\hline
\end{tabular}




\section{Continued}

\begin{tabular}{|c|c|c|c|}
\hline Insertion: & Outer surface of the second rib & Insertion: & $\begin{array}{l}\text { Mastoid process of temporal bone and the superior } \\
\text { nuchal line }\end{array}$ \\
\hline $\begin{array}{c}\text { Nerve in } \\
\text { innervation: }\end{array}$ & $\begin{array}{l}\text { Sym.: anterior rami of the cervical } \\
\text { spinal nerves } \mathrm{C} 5-\mathrm{C} 8\end{array}$ & $\begin{array}{l}\text { Nerve in } \\
\text { innervation: }\end{array}$ & $\begin{array}{l}\text { Parasym.: CN XI (accessory nerve) } \\
\text { Sym.: ventral rami of spinal nerves C2, C3, C4 }\end{array}$ \\
\hline Function: & Lifts the second rib and tilts the neck to the same side & Function: & Forced inspiration by raising the sternum \\
\hline
\end{tabular}

Table A8. Diaphragm, external intercostal, internal intercostal and parasternal muscles (Section (9)).

\begin{tabular}{|c|c|c|c|}
\hline Muscle: & Diaphragm & Muscle: & $\begin{array}{l}\text { External intercostal muscles } \\
\text { (attached to bony parts of ribs only) }\end{array}$ \\
\hline Origin: & Septum transversum, pleuroperitoneal folds & Origin: & Infero-posterior border of each rib (above) \\
\hline Insertion: & $\begin{array}{l}\text { Left medial crus and right medial lateral crus joined } \\
\text { to vertebral bones L2/L3 }\end{array}$ & Insertion: & Supero-posterior border of the rib (below) \\
\hline Function: & Change the chest cavity volume during respiration & Function: & $\begin{array}{c}\text { Up lifting the rib cage, leading to increase in transverse } \\
\text { area of thoracic cavity-inspiration }\end{array}$ \\
\hline Muscle: & Internal intercostal muscles & Muscle: & Innermost internal intercostal muscle \\
\hline Origin: & Infero-posterior border of each rib (above) & Origin: & Infero-posterior border of each rib (above) \\
\hline $\begin{array}{l}\text { Nerve in innerva- } \\
\text { tion: }\end{array}$ & $\begin{array}{c}\text { Sym.: intercostal nerves, ventral rami of thoracic } \\
\text { nerves }\end{array}$ & $\begin{array}{l}\text { Nerve in inner- } \\
\text { vation: }\end{array}$ & Sym.: intercostal nerves \\
\hline Function: & Weak expiration action & Function: & Weak expiration \\
\hline $\begin{array}{l}\text { Remark: } \\
\text { Parasternal } \\
\text { intercostal m. }\end{array}$ & $\begin{array}{l}\text { Part of the internal intercostal } \mathrm{m} \text {. that is attached to } \\
\text { the cartilaginous portions of the ribs. This part of the } \\
\text { internal } \mathrm{m} \text {. is an inspiratory } \mathrm{m} \text {. Uplifting force } \\
\text { maximizes in upper inter rib spaces }\end{array}$ & & \\
\hline
\end{tabular}

Table A9. Four inspiratory muscles attached to the ribs and scapula (Section (12)).

\begin{tabular}{|c|c|c|c|}
\hline Muscle: & Pectoralis major (inspiration) & Muscle: & Pectoralis minor (inspiration) \\
\hline Origin: & $\begin{array}{l}\text { Clavicular head: anterior surface of the medial half of the clavicle } \\
\text { Sternocostal head: anterior/lateral surface of sternum, } 6^{\text {th }} \text { costal } \\
\text { cartilages }\end{array}$ & Origin: & 3 rd to 5 th ribs \\
\hline Insertion: & Lateral lip of the bicipital groove of humerus bone & Insertion: & Coracoid process of the scapula \\
\hline Function: & Muscle expands the rib cage in different postures of the upper body & Function: & $\begin{array}{c}\text { Drawing the scapula inferiorly and anteriorly } \\
\text { against the thoracic wall, leading to elevation } \\
\text { of ribs during inspiration }\end{array}$ \\
\hline Muscle: & Serratus anterior (Inspiration) & Muscle: & Levator scapulae (inspiration) \\
\hline Origin: & On surface of 1 st to 8 th ribs at side of the chest & Origin: & $\begin{array}{l}\text { Posterior tubercles of transverse processes of } \\
\text { C1-C4 vertebrae }\end{array}$ \\
\hline
\end{tabular}




\section{Continued}

\begin{tabular}{|c|c|c|c|}
\hline Insertion: & Along entire anterior length of the medial border of the scapula & Insertion: & Superior of the medial border of scapula \\
\hline $\begin{array}{l}\text { Nerve in } \\
\text { innervation: }\end{array}$ & Sym.: long thoracic nerves, as branches of roots C5, C6, C7 & $\begin{array}{l}\text { Nerve in inner- } \\
\text { vation: }\end{array}$ & $\begin{array}{c}\text { Sym.: C3, C4 and dorsal scapular nerve, } \\
\text { branch of C5. }\end{array}$ \\
\hline Function: & $\begin{array}{l}\text { Lift the ribs when shoulder girdle is fixed, } \\
\text { and thus assist in respiration }\end{array}$ & Function: & $\begin{array}{l}\text { Moving scapula, } \\
\text { with one result of expanding the rib cage. }\end{array}$ \\
\hline
\end{tabular}

Table A10. Four strong muscles of expiration, and the superior nerve fibers of trapezius as inspiration muscle (Section (13)).

\begin{tabular}{|c|c|c|c|}
\hline Muscle: & Rectus abdominal muscle & Muscle: & Abdominal external oblique muscle (expiration) \\
\hline Origin: & $\begin{array}{l}\text { Crest of pubis (broadens upper border of the } \\
\text { body of pubis) }\end{array}$ & Origin: & Ribs 5 - 12 ; note that 11 th 12 th ribs do not connect the sternum \\
\hline Insertion: & $\begin{array}{c}\text { Costal cartilages of ribs } 5 \text { - } 7 \text { Xiphoid process } \\
\text { of sternum }\end{array}$ & Insertion: & $\begin{array}{l}\text { Xiphoid process (lower end of sternum); outer lip of iliac crest } \\
\text { (curved superior border of ilium), pubic crest (broadens upper } \\
\text { border of body of pubis, which is one of bones that make up } \\
\text { pelvis), pubic tubercle (a prominent forward-projecting tubercle } \\
\text { on upper border of medial portion of superior ramus of pubis), } \\
\text { linea alba, inguinal ligament, anterior superior iliac spine (a } \\
\text { bony projection of iliac bone) }\end{array}$ \\
\hline $\begin{array}{c}\text { Nerve in } \\
\text { innervation: }\end{array}$ & $\begin{array}{l}\text { Sym.: anterior branches } \\
\text { of spinal roots } \mathrm{T} 7-12 .\end{array}$ & $\begin{array}{l}\text { Nerve in } \\
\text { innervation: }\end{array}$ & Sym.: anterior branches of spinal roots T7 - 12 . \\
\hline Muscle: & $\begin{array}{l}\text { Serratus posterior inferior muscles } \\
\text { (forced expiration) }\end{array}$ & Muscle: & $\begin{array}{l}\text { Trapezius } \\
\text { (superior fibers for inspiration and inferior fibers for expiration) }\end{array}$ \\
\hline Origin: & $\begin{array}{l}\text { From spinal processes (points of the vertebrae } \\
\text { closest to skin) of vertebrae T11, T12, L1, and } \\
\text { L2 }\end{array}$ & Origin: & $\begin{array}{c}\text { External occipital protuberance, spinous processes of vertebrae } \\
\text { C7-T12, Nuchal ligament, and occipital bone. Also, the } \\
\text { corresponding supraspinous ligaments }\end{array}$ \\
\hline Insertion: & lower borders of ribs $9-12$. & Insertion: & $\begin{array}{l}\text { Nuchal ligament, medal superior nuchal line, posterior border of } \\
\text { lateral part of clavicle, acromion, spine of scapula. }\end{array}$ \\
\hline $\begin{array}{l}\text { Nerve in } \\
\text { innervation: }\end{array}$ & $\begin{array}{l}\text { Sym.: ventral primary rami of the thoracic } \\
\text { spinal nerves T9-T12 }\end{array}$ & $\begin{array}{l}\text { Nerve in } \\
\text { innervation: }\end{array}$ & $\begin{array}{c}\text { Parasym.: CN XI for motion } \\
\text { Sym.: branches of C2, C3 and C4 for sensory transmission and } \\
\text { motor action. }\end{array}$ \\
\hline
\end{tabular}

Table A11. The largest muscle at the back-the superior portion for deep inspiration and the large inferior portion forced expiration (Section (13)).

\begin{tabular}{cl}
\hline Muscle: & Latissimus muscle (inspiration and expiration) \\
\hline Origin: & $\begin{array}{l}\text { 1) Spinous processes of the } 7^{\text {th }} \text { thoracic to the } 5^{\text {th }} \text { lumbar vertebrae } \\
\text { 3) Thoracolumbar fascia } \\
\text { 4) Inferior angel of scapula }\end{array}$ \\
Insertion: & Bicipital groove of humerus \\
Nerve in innervation: & Sym.: Branches of the C6-C8 roots from posterior cord of brachial plexus at deeper regions of the muscles; \\
sunction: & Posterior muscle fibers are responsible for deep inspiration and anterior fibers function to help forced expiration
\end{tabular}


Table A12. From deltoid to three anterior arm muscles (Section (14)).

\begin{tabular}{|c|c|c|c|}
\hline Muscle: & Deltoid & Muscle: & Bicep brachii (anterior) \\
\hline Origin: & $\begin{array}{c}\text { Anterior border and upper surface of lateral third of } \\
\text { clavicle, acromion, spine of scapula }\end{array}$ & Origin: & $\begin{array}{l}\text { Long head-supraglenoid tubercle } \\
\text { Short head-coracoid process of scapula }\end{array}$ \\
\hline Insertion: & $\begin{array}{c}\text { Deltoid tuberosity, triangular area on anterolateral } \\
\text { surface of middle of the humerus }\end{array}$ & Insertion: & $\begin{array}{l}\text { Radial tuberosity, and bicipital aponeurosis, mainly } \\
\text { attached to ulna bone, and partly attached to the deep } \\
\text { fascia of medial side of the forearm. }\end{array}$ \\
\hline $\begin{array}{l}\text { Nerve in } \\
\text { innervation: }\end{array}$ & Sym.: axillary nerves, a branch of radial nerve & $\begin{array}{l}\text { Nerve in } \\
\text { innervation: }\end{array}$ & Sym.: musculocutanesous nerve (C5-C7) \\
\hline Function: & $\begin{array}{l}\text { Participates in expiration by antagonising the pecto- } \\
\text { ralis major and minor muscles }\end{array}$ & Function: & $\begin{array}{c}\text { Participates in stretching/relaxing the deltoid muscle, } \\
\text { which plays role in expiration. }\end{array}$ \\
\hline Muscle: & Brachialis (anterior) & Muscle: & Brachioradialis (anterior) \\
\hline Origin: & Anterior surface of the humerus, near the distal half & Origin: & Lateral supracondylar ridge of humerus \\
\hline Insertion: & Coronoid process and tuberosity of ulna bone & Insertion: & Radial styloid process \\
\hline $\begin{array}{l}\text { Nerve in } \\
\text { innervation: }\end{array}$ & $\begin{array}{c}\text { Sym.: dual innervation from Musculocutaneous } \\
\text { nerve (derived from C5, C6, C7) and radial nerve } \\
\text { (derived from C7, C8) }\end{array}$ & $\begin{array}{l}\text { Nerve in } \\
\text { innervation: }\end{array}$ & $\begin{array}{l}\text { Sym.: radial nerve of posterior chord (derived from } \\
\text { spinal roots } \mathrm{C} 5, \mathrm{C} 6, \mathrm{C} 7, \mathrm{C} 8, \mathrm{~T} 1)\end{array}$ \\
\hline Function: & $\begin{array}{l}\text { Part of pulley system to stretch/relax deltoid and } \\
\text { pectoralis major and minor muscles }\end{array}$ & Function: & Flexion of elbow \\
\hline
\end{tabular}

Table A13. Muscles of the forearm and thumb (Section (14)).

\begin{tabular}{|c|c|c|c|}
\hline Muscle: & Flexor pollicis longus (anterior) & Muscle: & Extensor pollicis longus (posterior) \\
\hline Origin: & $\begin{array}{l}\text { Middle of anterior surface of radius } \\
\text { bone and interosseous membrane }\end{array}$ & Origin: & $\begin{array}{l}\text { Middle third of posterior surface of ulna, interosseous } \\
\text { membrane }\end{array}$ \\
\hline Insertion: & base of distal phalanx of thumb & Insertion: & Distal phalanx of thumb \\
\hline $\begin{array}{c}\text { Nerve in } \\
\text { innervation: }\end{array}$ & $\begin{array}{l}\text { Sym.: anterior interosseous nerve, lateral branch of } \\
\text { median nerve (derived from spinal roots C6, C7) }\end{array}$ & $\begin{array}{l}\text { Nerve in } \\
\text { innervation: }\end{array}$ & $\begin{array}{l}\text { Sym.: posterior interosseous nerve, a branch of radial } \\
\text { nerve }\end{array}$ \\
\hline Function: & Flexion of thumb & Function: & $\begin{array}{l}\text { Thumb extension (metacarpophalangeal and } \\
\text { interphalangeal). It stretches the CTIF around thumb }\end{array}$ \\
\hline Muscle: & Flexor pollicis brevis (anterior) & Muscle: & $\begin{array}{l}\text { Extensor pollicis brevis (posterior, connected with } \\
\text { abductor pollicis longus) }\end{array}$ \\
\hline Origin: & Flexor retinaculum trapezium bone & Origin: & Posterior surfaces of radius and interosseous membrane \\
\hline $\begin{array}{c}\text { Nerve in } \\
\text { innervation: }\end{array}$ & $\begin{array}{l}\text { Sym.: recurrent branch of median nerve and deep } \\
\text { branch of ulna nerve. }\end{array}$ & $\begin{array}{l}\text { Nerve in } \\
\text { innervation: }\end{array}$ & $\begin{array}{l}\text { Sym.: posterior interosseous nerve, a branch of radial } \\
\text { nerve. }\end{array}$ \\
\hline Function: & $\begin{array}{c}\text { Flexion of thumb at the first metacarpophanlangeal } \\
\text { joint }\end{array}$ & Function: & $\begin{array}{c}\text { Extends proximal phalanx of thumb at } \\
\text { metacarpophalangeal joint. It stretches CTIF around } \\
\text { phalanx of thumb }\end{array}$ \\
\hline Muscle: & Pronator quatratus (ventral) & Muscle: & Opponens pollicis (anterior) \\
\hline Origin: & Medial, anterior surface of the ulna bone & Origin: & $\begin{array}{c}\text { Transvers carpal ligament/flexor reticulum and } \\
\text { trapezium bone }\end{array}$ \\
\hline Insertion: & Lateral, anterior surface of radius bone & Insertion: & Base of the first metacarpal bone (radial side) \\
\hline $\begin{array}{c}\text { Nerve in } \\
\text { innervation: }\end{array}$ & $\begin{array}{c}\text { Sym.: anterior interosseous nerve, branch of lateral } \\
\text { median nerve (derived from C6, C7) }\end{array}$ & $\begin{array}{l}\text { Nerve in } \\
\text { innervation: }\end{array}$ & $\begin{array}{l}\text { Sym.: recurrent branch of median nerve } \\
\text { (derived from C6, C7) }\end{array}$ \\
\hline
\end{tabular}




\section{Abbreviations}

Lung Primary Meridian $=$ Lung Meridian $=$ LUM

Lung Sinew Channel $=$ LUSC

Lung Divergent Channel $=$ LUDC

Luo-connecting Channels = LULCC

Governing Meridian = DU Meridian

Conception Meridian $=$ REN Meridian

Urinary Bladder Meridian $=$ BL Meridian

Kidney Meridian $=$ KID Meridian

Large Intestine Meridian = LI Meridian

Spleen Meridian $=$ SP Meridian

Cranial nerve $=\mathrm{CN}$

Lung Special Acupoint = LUSP

External intercostal muscle $=\mathrm{EIM}$

Internal intercostal muscle $=$ IIM

Parasternal intercostal muscles $=$ PIM

Mechanical advantage $=\mathrm{MA}$

Nerve $=\mathrm{n}$.

Muscle $=\mathrm{m}$.

Eencephalogram/Eencephalography $=$ EEG

Electronyography $=$ EMG

Chronic obstructive pulmonary disease $=$ COPD 